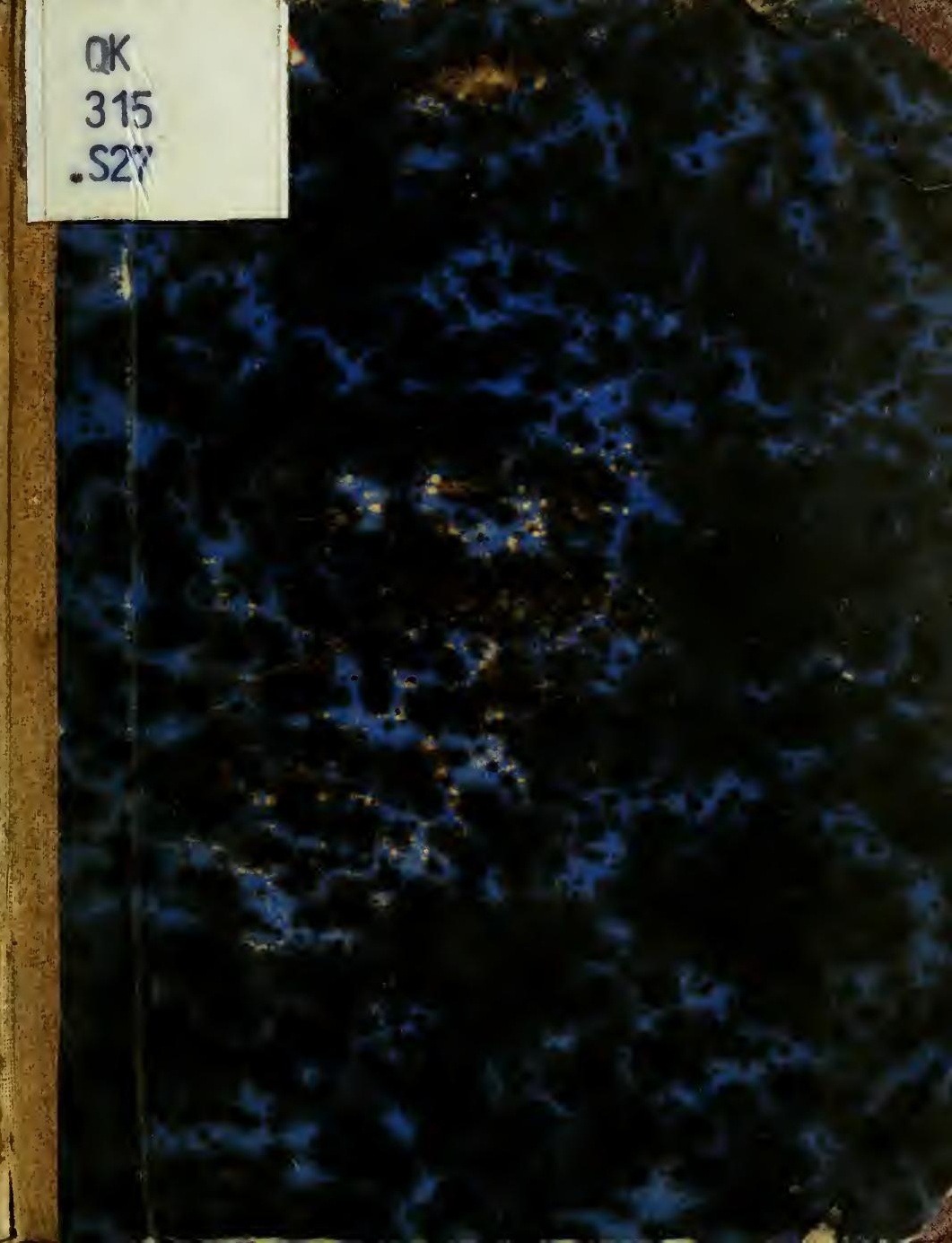




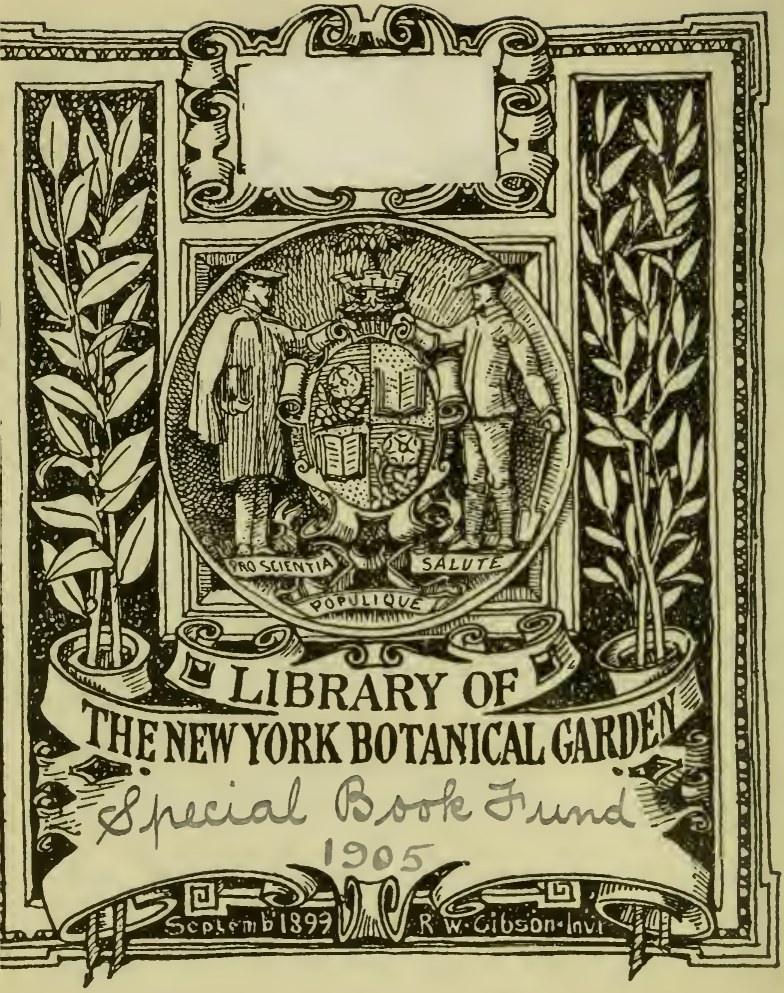


<smiles>[C]1=CC=[C+]1</smiles> 



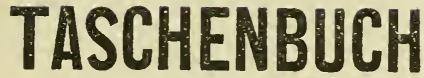

für

\section{reisende Botaniker}

im

Kanton Luzeru. 
LUZERN. A. BOLZERN'sche BUCHDRUCKERET 


\title{
TASCHENBUCH
}

\section{reisende Botaniker}

im

\author{
Kanton tuzerin,

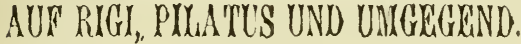

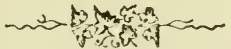 \\ Nach \\ Dro 』。 Go Kraugr's \\ Prodromus Flora Lucernensis. LiERARY \\ NEW YORK \\ BOTANICAL \\ Vermehrt \\ GATDEN.
}

mit mehr als 500 Pflanzenarten und eigenen

Beobachtungen, nebst einem alphabetischen

Gattungsregister,

herausgegebeu

von

-. Sebobinger-Pinter,

IIandelsgärtner und Privatlehrer der Botanfk, sowie Mitglied der Naturforschenden Gesellschaft

in Luzern.

1866. 
EK315

.527 


\section{LIBRARY \\ NEW YORK \\ DGTANICAL \\ GARDEN.}

VORREDE.

Der von Herrn Dr. J. Georg Kraner sel., zur Zeit Professor der Naturgeschichte an der hiesigen höhern Lehranstalt und Griinder der naturhistorischen Sammlung im Museum, im Jahr 1824 in lateinischer Sprache herausgegebene PRODROMUS FLORA LUCERNENSIS war ein beliebter Begleiter aller im Kanton Luzern exkursirender Botaniker.

Seit jener Zeit haben sich aber viele neue Pfianzen in unserm Kanton eingebiirgert, und Hr. Dr. Steiger sel., der unermuidliche Forscher is) in der Naturgeschichte iiberhaupt, wie speziell in der Pflanzenkunde, hat bekanntlich unter dem Titel: „Die Flora des Kantons Luzern, der Rigi und der Pilatus" ein botanisches 
Handbuch herausgegeben, das jedem Dilettanten dieser Wissenschaft als hilfreicher Rathgeber zur Seite steht.

Allein seiner Grösse wegen ist dieses Handbuch nicht zu einem Reisebegleiter geeignet, desswegen habe ich - ungeachtet zu erwartender Kritik - es unternommen, ein „Verzeichniss der Luzerner Pflanzen" nach der Eintheilung von Hrn. Dr. J. R. Steiger sel., und nach der Form des Taschenbiichleins von Dr. J. G. Kraner sel. herauszugeben; aber anstatt wie dieser in latcinischer, in d e u t s cher Sprache.

Man findet darin keine Beschreibung der Pflanzen, sondern einzig den botanischen Namen, die Bliithezeit und den Standort. Im Gattungsregister, das alphabetisch gehalten ist, bedentet die vordcre Zahl, die Seitenzahl, wo diese Pflanze in Dr. Steiger's LuzernerFlora nachgeschlagen und mithin die Beschreibung derselben gefunden werden kann.

Seit vielen Jahren habe ich mich dieser ebenso unterhaltender, wie belehrenden Wissenschaft mit besonderer Vorliebe gewidmet, und in dieser Zeit in meiner Umgebung nicht 
nur manches Vorurtheil gegen die Erleruung derselben beseitiget, sondern selbst durch mein eigenes Beispiel mehrere, besonders jüngere Leute ermuthiget, ihre Mussestunden darauf zu verwenden, was nicht Wenige mit ziemlichem Erfolg gethan haben.

Ich glaube der Hoffnung leben zu dürfen ohne unbescheiden zu sein, mein Reisehandbüchlein werde von Exkursirenden Botanikeın - seien sie nun Priester oder Laien in dieser Wissenschaft - ebenso gerne zum Reisebegleiter gewählt, als zur Zeit Dr. Kraner's "Prodromus".

Zum Schlusse noch folgende Bemerkungen:

1) Die Zahlen nach den Pflanzennamen bedeuten die Bliithezeit, z. B. 3-6 heisst März, bis Juni u.s. f.

2) Diejenigen Pflanzen, welchen nebst der $\mathrm{N}_{\mathrm{t}}$. noch Buchstaben beigefuigt sind, sind F o rmen, nicht selbststïndige Arten.

LUZERN, im Dezbr. 1864. 



\section{II 0 n a n d r i a.}

\section{Monogynia.}

1. Hippuris vulgaris. 6-8. Im Schiltwald, in Giessen an der Reuss, an der Sure bei Triengen, im Niuhlebach, besonders häufig am Schnitzthurm bei Stansstad.

\section{Digynia.}

2. Callitriche stagnalis. 4-9. Im stehenden und fliessenden Wasser. Am Luzernersee, im Rotherthal, Suren- und Hitzkircherthal.

3. - platicarpa. Neben dev vorigen Art.

4. - vernalis. Neben den vorigen.

5. - hamulata. Ebenso.

6). - a utumualis. Herbst. In Gräben im Schiltwalde neben der Reuss. 


\section{I) i a n it ri a.}

\section{Monogynia.}

7. Circaea lutetiana. 6-7. Fast überall an schattigen feuchten Hecken, dunkeln Wäldern der Ebenen und Berge. An der Ringmauer auf der Musegg, im Giitschwald, Rifig, Biregg, bei Sursee und Geuensee. Am Kiemen bei Immensee.

8. Cir c a e a a $\mathrm{l}$ p in a. 7-8. Alpen u. Voralpen. Am Pilatus nicht selten. Zwischen Neualp und Eigenthal, im Aufsteig nach Bründlenalp, auf Mïhlemääs, in den Buchwäldern ob Alpnacht, bei Briidern u. 'Twannegg am Schimberg und im Aufsteigen nach Giirmschalp.

9. - intermedia. In der Bergregion. Im Rifig- und Chiifirain-Wald, zwischen Winikon und Reiden, im Boowald bei St. Urban, bei Fliihli und Kurenhiitten im Entlebuch.

10. Veronica eham a edris. 4-6. Ueberall an Hecken und Gebuischen bis zur Tannengrenze.

11. - "r tic a e fol ia.4-7. In der Bergregion hïufis bis 6000' 110̈ho. Am Rigi bis 
Kulm, von Kriens und Horw bis Klimsenhorn, vom Menzberg bis Napf, von Fluihli bis Emmenthalfuh, an der Schratten bis Nesselstock, am Sonnenberg gegen Littau, oberhalb der Herrgottswalderbriicke, im Moos bei Luzern gegen dem Weinbergli.

12. Veronica officinalis. 5-7. An Waldrändern, auf trockenen Weiden und Triften bis zur Tannengrenze. Im Walde bei Ebikon und Buchenrain, zwischen Weggis und Vitznau, am Guitsch und Sonnenberg bei Luzern. 13. - montana. 5-6. In feuchten Wäldern hin und wieder. Am Giitsch bei Luzern, Biregg, Rothenburg und St. Urban.

14. - tencrium. 5-6. An Strassenrändern hin und wieder, zwischen Schenkon und Komlenbach, bei Sursee, im Hitzkircherthal, zwischen Baldegg und Gelfingen, bei Schongau.

15. - beccabunga. An Quellwassern, in Gräben und langsam fliessenden Bächen häufig.

16. - anagallis. 5-8. In stehenden Wassern und Gräben der Ebene häufig. Um Luzern an der Halden, zwischen 
Rothsee und Rathhausen, in Surenthal.

17. Veronica scutellata. 6-9. In Suinipfen der Ebene. Am Luzernersee, bei Wauwyl, am Mauen-, Baldegger- und Hallwilersee, in Sumpfgräben bei Büron, Triengen und Geuensee, bei Ebikon, Dierikon und St. Urban.

18. - hedera efolia. 4-9. Auf Getreideäckern häufig. Um Eschenbach, Hochdorf und Sursee, im Suren-, Wigger- und Winathal, bei Weggis und Ettiswil.

19. - agrestis. 4-8. Auf Wiesen und Aeckern nicht selten. Im Hitzkircherund Surenthal.

20. - о раса. 4-5. Häufig auf Aeckern u. trockenen Stellen im HitzkircherthaI.

21. - b uxba $u$ mi i.5-9. In Hitzkircherthal anf Aeckern.

22. - arvensis. 3-9. In Aeckern u. Wiesen häufig.

23. - serpillifolia. 5-9. Auf Triften und Aeckern von der Ebene bis in die. Alpen, nicht selten.

24. - triphyllos. 4-5. Bei Dagmersellen in der Nähe des Waisenhauses.

25. - $10 \mathrm{ng}$ ifo łia. 7-8. In Gärten. 
26. Veronica a phylla. 7-8. Auf den Alpen bis $7000^{\prime}$ Höhe. Von Rigikulm bis Scheilegg, am Pilatus auf Klimsenhorn, Kastelnalp, Briindlen, Trokenmatt, Widderfeld, am Schimbrig, auf Schratten, Haglern u. Rothhorn.

27. - alpina. $7-8$.

"a) - $\quad$ rotundifolia. Auf unsern Al-

"b) - " acutifolia. pen härfig. Am Rigi, Pilatus, auf Briindlen, Schafmatt, Haglern, Fenerstein, Nesselstock bis Rothhorn.

28. - saxatilis. 7-8. Am Rigi, Pilatus, Schratten, Rothhorn, Schimbrig. Auf Felsen und Gesteinen häufg.

29. - fruticulosa. 7-8. An rothen Totzen auf Pilatus, am Rigi, doch seltener als Voriges, am Nesselstock im Geröll des nördlichen Abhangs.

30. - syriaca. 5-7. In Anlagen. 31. Syringa vulgaris. 5-6. In Gürten und Lustgebüschen.

32. - persica. 5-6. In Gärten, doch seltener als der Vorige.

33. Ligustrum vulgare. 6. An Hecken,

Gesträuchen und Waldrändern der

Ebene bis zur Buchengrenze.

3t. J a s minum off $\mathrm{ic}$ in a le.6-9. In Gärten. 
35. J a sminum fruticans. 6-8. In Gärten hin und wieder.

36. - grandiflorum. 7-8. In Gärten. 37. Forstitia viridissima. 5-7. In Anlagen.

38. Fraxinus excelsior. Häufig auf fenchten Stellen, aber auch auf trockenem Boden in der Ebene bis 3000' Höhe. 39. - pendula. In Gärten. 40. Lemna trisulca. 5. In stehenden Wassern hin und wieder.

41. - minor. In stehenden Wassern u. Gräben nicht selten. An der Halden bei Luzern häufig.

42. - gibba. In stehenden Wasserm.

43. - arrhiza. In stehenden Wassern. Bei Sursec.

44. - polirhiza. In stehenden Wasseri. Zivischen Rothsee und Dierikon,

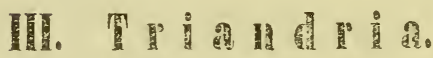

\section{Monogynis.}

5. Centranthus ruber. 6-9. In Giirten. 96. Valeriana officinalis. 6-8. An Gräben und Hecken, auf feuchtem und trockenem Boden der Ehene häufig: 
und bis $4000^{\prime}$ Höhe, z. B. auf Emmenthal an der Schratten und am Pilatus.

47. Valeriana a $\mathrm{gust}$ ifolia. 6-8. Wie der Vorige.

48. - montana. 7-8. In der Berg- u. Alpenregion, nicht eben gar häufig. Beim Renggloch, am Pilatus auf Klimsenhorn, am Rigi, bei Maisee am Rothhorn, am Nesselstock, an der Schrattenfluh, bei Emmenthal und an der Schafmatt.

49. - tripteris.5-8. AnAblängen d.Bergregion bis $4000^{\prime}$ Höhe. Am Rigi 11. Pilatus, auch in der Ebene. Auf Tribschen bei Luzern, an der Renggbriicke bei Littal, im Rothenburger Bachtobel, v. Ennethorw bis Kriens.

"a) - - Form mit einfachen Blättern. Gleiche Blüthezeit und Standorte.

50. - dioica. 4-5. Auf Sumpfwiesen iiberall.

51. Fedia olitoria. 4-5. In Aeckern hin und wieder, um Luzern häufig, bei Weggis, Sursee und Büron.

52. - dendota. In Getreideäckern nicht 
selten. Im Rain, Suren-, Hitzkircherund Wiggerthal, bei Hochdorf.

53. Fe di a a uri c ula. 6-7. In Getreideäckern nebst der vorigen Art, und mit derselben häufig verwechselt. In Wiggerthal nicht selten.

54. Montia fontana. 4-5. Auf fouchten Aeckern bei Dierikon.

55. Iris germanica. 5-6. In Gärten. 56. - florentina. 6-7. In Gärten. 57. - odoratissima. 6-7. In Gärten.

58. - s ambucina. 6-7. In Gärten hin und wieder. Häufig auf dem Friedhof in Luzern. Verwildert an den Mauern bei Altdorf.

59. - pseudacorus. 6-7. Au stehenden Wassern, Seen, Flüssen und Gräben häufig. An all' unsern Seen. Im Suren- und Hitzkircherthal.

60. - gramiuea. 6-7. In Gärten, auf dem Kirchhef zu Luzern.

61. Crocus ver nus. $4-5$. Häufig auf Rigi, Pilatus und den Entlebucherbergen, gleich nach dem Schmelzen des Schnees bis 5000 Höhe. Bei Wergis findet man schon Exemplare im Yäız am Sec.

62. - longiflorus. 7. Beim Schneeschmel- 
zen in grosser Hitze anf gutem Boden.

63. Crocus lutens. 3-4. In Gärten.

64. Gla dialu s comm un is. 6-7. In Gärten. 65. Poliknemum arvense. 8-9. Auf Getreideäckern. Nicht selten nm Luzern; auf Sonnenberg, bei Neggen, im Ititzkireher-, Wigger- und Surenthal, bei Hochdorf.

\section{Tetrandria.}

\section{Monogynia.}

66. Trapa natans. 6-S. Im Weiher bei St.

Urban gegen Roggwil hin.

- 67. Cornus Mascula. 3-4. In Gärten.

68. - sanguinea. 5-6. In Hecken und Gebiisclien.

69. - alba. 6. In Anlagen.

70. Ptelea trifoliata. 6. In Anlagen.

71. Galium crutiata. 4-6. Gemein in Wiesen, Hecken und Gebüschen bis zur Tannengrenze.

72. - rotundifolinm. 5-6. In Bergwäldern nicht selten. Am Gütsch u. Sonnenberg, Gschweich, Schwarzenberg, Nenzberg, Rigi tiber Vitznan, am Pilatus \&uf Miihlemääs und selhst 
in der Nähe des Mondmilchloches.

Im Haltiwald.

73. Galium mollugo. 5-9. Gemein auf Wiesen, an Hecken, Weg- u. Waldrändern und Gebiischen.

74. - l u ci du m. 5-6. An Hügeln u. trockenen Stellen hin und wieder. An der Halden und Hofgasse bei Luzern, auf Schwarzenberg, am Lopper, auf Rigi hin u. wieder, häufig bei Kindlismord, zwischen Rain und Eschenbach, bei Wikon und Dagmarsellen.

75. - sylvestre.5-6. An Hügeln u.trockenen Stellen bis zur Buchengrenze.

76. - boccone. An denselben, jedoch mehr beschatteten Stellen.

77. - umbellatum 7-8. In der Alpenregion. Am Pilatus an der Ringfluh. 78. - pumilum. 7-8. Am Pilatus an der Ringfluh und am Mittaggipfi.

79. - su p in u m. 5-6. An trockenen Hïgeln nicht selten. Auf Schwarzenberg und beim Holzhof.

80. - saxatile. An feuchten steinigen Orten. Am nördlichen Abhang des Nesselstockes, des Pilatus u. Feuerstein, Emmenthalfluh an der Schratten.

81. - helveticum. 6-7. Im Geröll der Pi- 
latuskette nicht selten, im Nauen, an Esels- u. Ringfluh, zwischen Trockenmatt und Nittaggipti.

82. Galium sylvaticum. 6-7. In Wäldern der Hiigelregion hin und wieder. Im Hitzkircherthal zwischen Mosen und Reinach, zwischen Dagmarsellen und Reiden, an der Hochfluh, bei Weggis am Rigi.

83. - verum. 6-9. Auf trockenen steinigen Hiigeln. Am Fusse des Rigi und des Pilatus, auf der Halbinsel bei Winkel, häufig am Lopper bis auf die Rengg, zwischen Hochdorf und Hitzkirch, am Lindenberg bei Hohenrain bis Schongau.

84. - aparine. 6-8. Ueberall in Getreide-, Flachs- md Lrdäpfeläckern, an Heken und Gebiischen.

\$ร. - spurium. 7-9. Standort d. Vorigen. 86. - palustre. 6-9. An sumpfigen Stellen, in Gräben häufig, an all' unseru Seen und Mö̈sern.

87. - uliginosum. 6-9. Aehnliche Standorte. Am Luzernersee, bei Aesch und Mosen, im Miiswanger-Moos, bei Weggis und Meierskappel.

88. A sperula odorata. 5-6. In Wäldern 
und Gebüsrhen der Ebene bis in dic Berge häufig.

89. Asperula taurina. 6-7. Bei Luzern, am Wege nach Horw u. beim Hünenberg, am Bürgen bis Stans häufig, am Fusse des Rigi bei Kiissnacht, Vitznau, Seewen, Lowerz, am Fusse des Pilatus hin und wieder, bei Stans in Masse an Hecken und Grebüschen.

90. - cynanchica. 7-8. An trockenen Hügeln hin und wieder. Zwischen Aesch und Schongau, häufig am Pilatus, am Lopper, auf Rossegg, Mattalpgrat, auf dem Leib, am Oberhaupt und Ringfluh, zwischen Mondmilchloch und Widderfeld, auf Emmenthal an der Schratten, am Rigi bei Kindlismord.

91. Sherardia arventis. 7-9. Auf Aeckern häufig. In Suren- und Hitzkircherthal, bei Münster, Ettiswil, Kiussnacht, zwischen Vitznau und Gersau.

92. Scabiosa arvensis. 6-8. Auf Aeckern u. trockenen Wiesen und Hügeln bis Bramegg.

43. - collina. 6-8. Gleiche Standorte. 
94. Seabiosa rigidiuscula. Auf der Höhe bei Seeburg.

95. - sylvatiea. 6-9. Häufig an Waldrändern, Hecken und Gebiischen der Ebene bis iber die 'Tannengrenze.

96. - long if olia. 6-9. Gleiche Standorte. 97. - succisa. 6-10. Auf feuchten Wiesen und an schattigen Orten häufig.

98. - columbaria. 7-9. An trockeneu Orten und Hügeln der Ebene, Berge und Alpen häufig. Zwisehen Weggis und Vitznau.

99. - I u eida. 7-9. Am Pilatus auf Tomlisalp u. Frackmiindalp, am Rothhorn, Feuerstein und Schafmatt.

100. - involuerata. 7-9. Am Geissonrain bei Schongau.

101. - atropurpurea. 7-9. In Gärten. 102. Dipsacus sylvestris. 7-8. Nicht selten auf Feldern, an Wegränderu und Gräben der Ebene. Bei Kriens, im Surenthal, am Rigi bei Goldan bis Seewen.

103. - fullonum. 7-8. Hin und wieder angebaut.

101 - pilosus. Am Fusse des Rigi vou Küssnacht bis Weggis, bei Emmeu, Uffikon, zwischen Sursee und St. 


\section{$-22-$}

Erhardt, an Waldrändern und Bachufern.

105. Globularia cordifolia. 5-8. An felsigen Stellen der Alpenregion häufig. Auf Rigi, Schimberg, Feuerstein, Nesselstock, Rothhorn, Schrattenhöhe bis Stricktossen, Pilatus am Klimsenhorn, Esel und Regenflihli, Schafmatt bis Kragenberg, bei Lützelau und am Lopper bis an den Vierwaldstättersee hinunter.

106. - nudicaulis. 6-8. Gleiche Standörter. Auf Rigi und Pilatus, Klimsenhorn bis Kriesiloch und Esel.

107. Plantago lanceolata. 5-9. Gemein auf allen Wiesen und Aeckern bis in die Alpen.

" a. - lanc. pumila. ) Gleiche Standorte.

108. - montana. 6-8. Auf allen unseru Alpen und Voralpen. Auf Rigi, Pilatus, am Nauen, am Fusse des Esels, Trockenmatt, Stricktossen, an der Schratten, Nesselstock und Rothhoru.

109. - alpinum. 5-8. Auf Alpen und Voralpen häufig. Auf Rigikulm, Nauen am Pilatus, Stricktossen an 
der Schratten, auf Silwängen, Hag• lern, Nesselstock, Tagweid und Rothhorn.

110. Plantago media. 5-9. Häufig in Wiesen, an Wegen und grasigen Plätzen der Ebene bis an den Fuss des Nesselstockes.

111. Plantago major. 6-9. In der Ebene iberall an Wegen und Strassen.

na. - m. phylostachia. )

"b. - " minima.

Ebenso.

112. Centunculus minimus. 8-9. Auf Aeckern hin und wieder. Bei Buchenrain, Rothenburg, zwischen Holzhof und Hellbühl, bei Hilperingen und Aesch.

113. Alc hemilla vulgaris. 6-8. Ueberall in Wiesen und an feuchten Stellen der Ebene und Berge.

114. - alpina. 7-8. Auf allen unsern Alpen und Voralpen.

115. - pentaphyllea. 7. Auf feuchten Stellen des Pilatus, gegen Gerasmätteli und am Fusse des Esels.

116. - arvensis. 5-9. In Aeckern häufig. Bei Sursee, Ruswil, Adligenschwil, Emmen and Hellbühl.

117. Majanthemum bifolium. 5-7. Fast 
in allen, besonders Tannenwäldera der Ebene und Berge bis über die Buchengrenze.

118. Sanguisorba offic inalis. 7-9. Auf Wiesen der Ebene und Berge, besonders im Hinterland, um St. Urban, zwischen Ettiswil und Zell, am Pilatus am Fusse des Klimsenhorns, auf Oberalp und Trockenmatt. Im Entlebuch auf Nesselbrunnenboden und in Möösern bei Hasle, häufig zwischen Alpnacht und Sarnen und auf dem Stansstadermoos.

119. Isnardia palustris. 7-9. In Sumpfgräben hin und wieder, doch selten. Beim Würzenbach am Luzernersee, bei der Fildern in Torfgräben, im Fischweiher von St. Urban, Langenthal $z u$.

\section{Digynia.}

120. Cusenta epilin um. Häufig im Flachs. Bei Hildisrieden und Kriens.

121. - epithymum. 7-8. An trockenen Stellen. Auf wildem Thymian, Schafgarben und Klee.

122. - europa a. 7-8. Auf Nesseln, 
Hopfen und Weiden, in Heeken and Gebuischen hin und wieder. Bei Sursee, Ebikon und Flübli and in der Nähe des Nidlenpalastes bei Luzern.

\section{Tetragynia.}

123. Ilex a quifolium. 5. Häufig in Wäldern.

124. Sagina procumbeus. 5-10. Um die Häuser herum, in Gärten, aut Aeckern und Triften, an feuchten Orten der Ebene and Berge.

125. - a petala. 6-7. In Kornfeldern zwischen Sursee nnd Kaltbach, auf mehr trockenen Stellen.

126. Potamogeton natans. 7-8. In stchenden Wassern, Weihern und stagnirenden Seen. Im Weiher bei Keggen, ob Haltiried.

, a. - nat. vul garis.) Gleiche Blüthezeit

, b. - „ellipticus.) u. gl. Standorte.

127. - fluitans. 7-8. An der Sure, im Egelmoos bei Triengen, im Hit\%kircherthal bei Aesch und Mosen in Gräben und Bächen. Im ZeIl- 
moos an See bei Sursee, in der Rolıne bei Dierikon.

128. Potamogeton densus. 7-8. In stehend- $u$. fliessendem Wasser. An der Reuss, am Vierwaldstättersee bci Küssnacht, Weggis, Brunnen, Meierskappel, an d. Sure, im Hitzkircherthal.

129. - s erratus. 7-8. Im Moos bei Luzern und an der Emme.

130. - lucens. 6-8. Am Luzernersee, häufig. Gegen Fröschenburg und an der Halden, bei Küssnacht.

131. - crispus. In See bei Küssnacht und Weggis. In Teichen und Bächen hin und wieder. In den Weihern im Obergrund bei Luzern.

132. - perfoliatus. 7-8. In Flüssen und stehenden Wassern. In der Reuss bei Luzern, im Suren- und Hitzkircherthale, im Rothsee, bei Weggis und Küssnacht.

133. - pusillus. 6-8. Häufig in Bächen, stehenden Wassern, Gräben und Teichen. Im Moos am Luzernersee, an Hallwilersee, in Surenthal, im Weiher ob Haltiried bei Heggen, im Dorfbach und in der Rhone bei Ebikon u. in Gräben bei Meierskappel. 
134. Potamogeton peclinatus.6-7. Am Mauensee und Luzernersee selten.

\section{Pentandria. \\ 1. Monogynia.}

135. Cerinthe auriculata. In Gärten.

136. E c hium vulgare. 6-9. Auf trockenem Kiesboden häufig, überall. Bei Littau, Kriens, im Surenthal, am Schwendeleberg bei Willisau massenhaft.

137. Lithospermum arvense. 5-6. Häufig in Getreideäc-ern um Sursec, Buiron, Sempach, Eich, Hildisrieden, Hochdorf, Münster, Neudorf und Ettiswil.

138. - officinale. 5-7. An steinigen 0rten hin und wieder. An der Emme. von Emmenbrücke bis Thorenberg, am obern Krienbach, bei Ennethorw, am Fusse des Rigi, bei Immensee, zwischen Weggis und Vitznau, Kindlismord und Urmiberg.

, a. - off. latifolia. 5-7. Mit dem Vorigen.

139. Pulmonaria angustifolia. 4-5. Iu 
Gebüschen und Hainen, an Waldrändern hin und wieder. Im Galgenwäldli bei der Emmenbrücke, im Schiltwald an der Reuss, an der Emme zwischen Schachen und Malters, am Fusse des Pilatus, im Stösswald.

140. Pulmonaria of ficinalis.4-5. In Gebüschen hin und wieder. Bei Niederschongau u. Aesch, zwischen Mosen und Beinwil, im Wäldchen zwischen Sursee u. St. Erhardt, im Stösswald, gegen den Pilatus aufwärts.

141. Heliotropium peruvianum. In Gärten.

142. - europacum. In Gärten.

143. Myosotis palnstris. 5-8. Ueberall an Gräben und sumpfigen Stellen, auf feuchten, lehmigen Aeckern u. Wiesen.

144. Myosotis sylvatica. 5-8. In Gebüschen und Bergwäldern, nicht selten. Auf Dietschiberg, bei Adligenschwil, Dagmarsellen, von Hochflah bei Reiden bis Letten, bei Wikon, auch bei Ennethorw.

145. - alpestris. 5-8. Auf Alpen nnd Voralpen nicht selten. Am Rigi, 
Pilatus, Mittaggipfi, Risetenfuh, Rothhorn, Nesselstock, :Schratten und Schafmatt.

145. a. Myosotia alp. minima. Gleiche Blüthezeit u. Standorte.

146. - arvensis. 5-7. Auf trokenen Stellen, in Getreideäckern nicht selten. An Mauern bei Gersau.

147. $0 \mathrm{mphal}$ odes verna. 4-5. In Gärten. 148. Borrago officinalis. 6-7. In und um Gärten.

149. Symphytum officinalis. 5-6. An Gräben, in Gärten und auf feuchten Wiesen häufig. Im Suren- u. Wiggerthal, bei Dierikon, Grosswangen und Gettnau, zwischen Schlund bei Kriens und Ennethorw, zwischen Blatten und Malters.

„a. - off. latifolia. 5-6. Gleiche Standorte.

150. Cynoglossum officinale. 6-7. Nicht häufig. Im Galgenwäldli bei der Emmenbrücke, zwischen Emmen und Rathhausen, bei Acheregg am östlichen Ausläufer des Pilatus.

151. Anchusa officinalis. 6-8. Auf sandigen Anhöhen bei Wikon, hin und wieder in Gärten. 
152. Anchusa italica. In Gärten.

153. Ly copsis arvensis. Bei St. Urban, Grossdietwil, zwischen Reiden und, Dagmarsellen an der Hochfluh, zwischen Rothsee und Rathhausen.

154. Asperugo procumbcus. 5-6. Hin und wieder, doch selten, an Schutthaufen.

155. Anagallis arvensis. 6-7. Häufig in Getreideäckern und gebauten Orten. 156. - c a erulea. 6-7. Nicht selten in Getreideäckern. Bei Sursee, Büron, Geuensee, Neudorf, Münster und im Hitzkircherthal.

157. - carnea. In Gärten.

158. - fruticosus. In Gärten.

159. L y s ima chia vulgaris. 6-7. An Gräben und feuchten Orten häufig. An all' unsern See'n. Im Surenthal und an der Halden bei Luzern.

160. - thyrsiflora. 6-7. Am Weiher bei Egolzwil, am Wauwilersumpf, nordöstlich vom Mauensee massenhaft, am Sempachersee, zwischen Zell " Schenkon, am Rothsee, bei Sursee am Henkergraben, auch an der Wigger.

161. - punctata. 6-7. In Gärten.

162. - nummularia. 6-7. An Gräben, 
feuchten Stellen, Wiesen und Wäldern häufig.

163. Lysimachia nemorum. An Hecken, in Gebüschen u. feuchten Wäldern häufig. Am Guitsch bei Luzern, zwischen Weggis und Vitznau, an den Hergottswalderpriigeln.

164. Sollya heterophylla. In Gärten. 165. Nalana paradoxa. In Cärten. 166. N e mophyll a dis c o idalis. In Gärten. 167. - insignis. In Gärten.

168. Primula elatior. 2-8. An Hecken, auf Wiesen, in Wäldern, überall häufig, selbst bis hoch in die Berge.* 169. - officinalis. 5-6. Auf trokenen offenen Wiesen. Im Hitzkircherthal, bei Gelfingen, Herlisberg, Hitzkirch, Aesch u. Schongau, im Heutschenmoos bei Geuensee, zwischen Horw und Winkel, am Dottenberg zu Adligenschwil, bei Weggis bis in die Voralpen des Rigi, am Pilatus in

* Diejenige, welche schon im Januar und Februar blühet, dürfte füglich als besondere Art unter dem Namen Prim. p a e c ox aufgestellt werden, da sie so viele besondere Kennzeichen hat, dass auch Jedermann, der nur weuige Pflanzenkenntnisse besitzt, sie von der später blühenden eigentichen Prim. clatior zu unterscheiden พei:s. 


\section{$-32$}

der Fräckmïndalp und am Regeufliuhli, an der Halden bei Luzern.

169 a. Primula of fic. Hochstenglige Form. Auf den Rigialpen.

170. - a c a u 1. 4. In Gärten häufig. Am Bürgen u. Rotzberg, vom Alpnachterstaad, am Fusse des Pilatus bis Sarnen an Hecken und Gebüschen.

a. - a c a u l. Hochstenglige Form mit Doldenblithen. 4. Im Rotzloch.

171. - chixensis. In Gärten.

172. - viscosa. 6-7. Am Pilatus an Felsen über Bründlenalp, am Feuerstein.

173. - integrifolia. 5-6. Selten. An Pilatus? Auf Rigischeidegg hin u. wieder, häufig auf Niederbauen, ganze Rasen bildend.

174. - farinosa. 5-7. Wo P. offic. u. mit diesen vermengt.

175. - auricula. 5-6. An Felsen der Alpen und Voralpen. Am Rigi, Pilatus. Rothhorn, Schratten, Napf und Enzifluh. Auch in Gärten.

176. A adrosacea chamaejasme. 6-8. Häufig in allen unsern höhern Gebirgen. Vom Rigi, Pilatus u. Napt bis Rothhorn, von 4-7000' Höhe.

17i. - villosa. Ohne Wurzelausläu- 
fer. Gleiche Blithezeit und gleiche Standorte, mit der Vorigen vermengt. 178. Androsacea helvetica. 6-7. Zwischen Felsritzen der höchsten Punkte am Pilatus: am Esel u. dem kahlen Felsgrate bis zum Oberhaupt, unter dem Kriesiloch gegen den Hergiswiler-Abgrund, auf Tomlishorn und auf der Schafmatt.

180. Sold anella alpina. 5-6. Auf allen unsern Alpen und Voralpen.

181. - elusii. 7. Dr. Steiger fand diese Art einzig auf dem Pilatus am Esel, da wo selten der Schnee shmolz u. jetzt der Obwaldner Gasthof steht. 182. Hottonia palustris. 5. In Sumptgrïben bei Wauwil. Selten.

183. Cyelamen europa eum. 4-9. In unteralpigen Laubholzwäldern. Am Rigi zwischen Kuissnacht $u$. Seeboden, am Fusse des Vitznauerstockes, unter Wil bei Gersau, am Grütli unter Seelisberg, am Gütsch bei Brunnen, auch in Gärten.

184. Menyanthes trifoliata. 4-6. In Sümpfen der Ebene und Berge bis $5000^{\prime}$ Höhe. An allen unsern See'n. An der Halde bei Luzern, in Wig- 
gern-, Suren- u. Hitzkircherthal, suf der Horwerallmend, auf dem Seeboden am Rigi, gegen Maisee au Fusse des Rothhorns, anf Gürmseb-。 alp.

185. Swertia perennis. 7-8. An Sumpfstellen der Berge und Voralpen. Am Schattenberg bei Kriens bis Miihlemääs, am Rigi-Dossen, am Pilatus u. Feuerstein, auf Schönenboden im Sörenberg, auf der Tagweid, bei Maisee u. gegen das Stäfeli am Rothhorn.

186. Erythraea centaurum. 7-8. Häufig auf trockenen Hügeln mit lehmigem Boden. Bei Luzern am Sonnenberg, bei Adligenschwil u. Udligenschwil, Meggen, auf Bramegg, Lindenberg und Gschweich.

187. - pulehella. 7-8. Auf feuchtem etwas sumpiigem Boden. Von Emmeu bis Inwil an der Reuss, im Surenund Hitzkireherthal, am Fusse des Pilatus, am Sehattenberg u. an der Bramegg.

188. - nana. 7-8. In Bergsümpfen gegen das Eigenthal, auf der Neualp.

189. Gentiana verna. 3-7. Auf feuchten 
Wiesen der Berge und Alpen, auch in der Ebene. Bei Schongau, am Gschweich, Napf, Rigi, Pilatus, Schratten, Schimberg, Nesselstock und Rothhorn, bei Ennethorw.

190. Gentiana bavarica. 7-8. Auf allen unsern höhern Bergen. Auf Rigi, Napf, Pilatus, Lanzenfluh, Schratten, Nesselstock, Tagweid, Rothhorn, Haglern, Feuerstein, an bewässerten Stellen.

191. - utriculos a. 7-8. In der Voralpenregion bis in die Ebene herabsteigend. Am Gschweich sclten, am Fenerstein und Nesselstock. Am Pilatus?

192. - nivalis. 7-9. Auf den höchsten Gräten unserer Berge. Auf Rigikulm nicht häufig. Am Pilatus anf Oberhaupt, Tomlishorn, Gemsmättli und. Widderfeld. Auf Schafmatt, Schrattenhöhe, Heftiboden, Rothhorn und Feuerstein.

193. - purpurea. 7-8. Häufig auf Rigi, Schratten, Schafmatt, Nesselstock und Pilatus.

194. - punctata. 7. Selten in unserm Gebiete, östlich vom Dossen am Rigi. 
195. Gentiaua asclepiadea. 8-9. Hälfig in der Bergregion, jedoch selten uiber die Buchengrenze. Am Fusse des Rigi, des Pilatus und Napf. In den Wäldern ob Hitzkirch, bei Heidegg, im Geuensee'r Bachtobel, im Wiholz bei Neudorf, auf Langwasen bei Kriens, auf Schwarzenberg und auf allen Entlebucherbergen.

n a. - a selep. alba. Bisweilen auf Neualp.

196. - pneumonanthe. 9. In Sumpfwiesen der Ebene und Berge häufig. Auf der Horwer-Almend, bei Richensee u. Aesch, auf dem SchonganerMoos, am Baldeggersee häufig. Vou der Hummelsriti bis zur Rothfluh bei Ennethorw, gegen das Mühlemääs am Pilatus.

196. a. - - Grossstenglige Form. Auf dem Goldauerschutt.

197. - a c a u lis. 5-7. In der Berg- u. Alpenregion an grasreichen Stellen häufig. Auf Rigikulm, Napf, Bäucheln, auf allen Entlebucherbergen, Nesselstock, 'Tagweid, Rothhorn, auf der ganzen Pilatuskette, am Esel u. Kriesiloch bis in die Ebene bei Ennethorw. 
198. Gentiana cruticata. 7-9. Hin und wieder in der Ebene bis in die Vor: alpen. Häufig an der Reuss bei Inwil und im Schiltwald. In Geuensee in den sogen. Leimlöchern, am Röthler bei Winikon, auf der Bramegg, im Eigenthal, am Rigi, auf dem Schneeälpli, zwischen Weggis und Vitznau.

199 - ciliata. 8-10. Auf feuchten u. trockenen Stellen der Ebene u. Berge bis zur Buchengrenze, nicht selten., Am Berge zwischen Triengen und Geuensee, am Gschweich, am Stenıpfelberge bei Dagmarsellen, bei Münster, im Hitzkircherthal, am Lindenberg bei Heidegg, bei der Looren, auf Bramegg bei Fahrnbuhl, am Sonnenberg, beim Waldbruder auf dem Rigi, u. über der Buchengrenze am Feuerstein, im Schiltwalde an der Reuss.

200. - campestris. 8-9. Auf Bergen bis in die Ebene hinunter. Am Lindenberg, in der Ehrlosen, Stempfelberg, im Krienserhochwald, bei Flühli, auf dem Rigi, Blasen am Schratten, Esel, Tomlishorn u. Widderfeld am Pila- 


\section{- $38-$}

tus, auf dem schroffen Grate des Schimbergs.

200. a. Gentiana camp. Grosstenglig e Form. Zwischen Weggis und Vitznau.

„b. - camp. alba. Auf Felsenblöcken der Laubalp am Pilatus.

201. - a marella. 8-9. Auf feuchten Wiesen der Ebene u. Berge häufig. Längs der Reuss bei Inwil, von Genensee bis Marchstein am Berge, bei Littau, an der Bramegg, bei Gormund und auf dem Rigi.

202. - lutea. 7-8. Häufig auf dem Rigi beim Waldbruder, Kaltbad, am Dossen u. Vitzinauerstock, seltener \&m Pilatus, siidlich rom Widderfeld, auf Birchboden, im Kigenthal zwischen Rothstock und Rümling, am Nesselstock, anf Tagweid.

203. Azalea procumbems. 5-7. Gleich nach dem Schmelzen des Schnee's. Am Pilatus, von der Sehneeschmelze bis zum Mittaggipfi, an der Schrattenfluh und Fenerstein massenhaft, auf Haglern.

204. - pontica. In Gärten.

205. - indica. In Gärten. 
206. Verbascum thapsus. 7-8. An trockenen, steinigen Orten, an Wegen und Waldrändern, in Gärten hin u. wieder, von der Ebene bis in die Voralpen. Häufig im Grund am Schimberg.

207. - th a p s if or m e. 7-8. Hin u. wieder an Wegen. Im Hitzkircherthal, bei Wikon, an der Hochfluh bei Reiden, in Gärten häufig.

208. - dy chnites. 7-8. Nicht gar häufig. Bei Sursee und Schenkon, auf dem Bürgen.

209. - pyramidatum. 9-7. Auf dem Bürgen.

210. - nigrum. 7-9. Häufig an Wegen und Hecken. Am Sempachersee, im Suren- und Hitzkircherthal, bei Inwil, Sursee, Reiden, Kriens und Meggen.

211. - b lattaria. 7-8. Hin $u$. wieder in Gärten, z. B. auf Krämerstein.

212. Polemonium coerule um. 6-7. In Gärten.

213. Phlox paniculata. 7-9. In Gärten.

214. - ma culat a. 7-9. In Gärten.

215. Convolvulus sepium. 7-9. In 
Hecken und Fruchtäckern hänfig bis zur Tannengrenze.

216. Convolvulus arvensis. 7-9. In Aeckern und Kornfeldern häufig.

217. - purpurcus. 6-9. In Gärten. 218 - tric o 1 or. In Gärten. 219. I p o ma e a tric ol or. In Gärten. 220. - $1 \mathrm{i} \mathrm{mb}$ a ta. In Gärten. 221. Nicotian a tabacum. 7-8. In Gärten. 222. - rustic a. 6-9. In Landgärten. 223. P etunia hybrida. In Gärten. 224. H y o s c a m u s n igr. In Gärten. 225. Datura stramonium. Auf Schutthaufen um Häuser und Gärten.

226. - a r b o rea. In Gärten. 227. - s $2 \mathrm{ngu}$ in ea. In Gärten. 228. - wirkitii. In Gärten. 229. A tropa bella donna. 7-9. In abgeholzten Waldungen. Im Galgenwäldli, Schiltwald, zwischen Inwil u. Emmen, Eschenbach, in den Wäldern von Geuensee, Büron, Sursee, Hafendeckel, Gründel, Chüsirain n. Ehrlosen, in Hrn. Mahler's Wäldli bei Luzern.

230. Nicandra physalodes. 8-9. In Gärten.

231. Physalis alkekengi. 6-7. Häu- 
fig am Fusse des Rigi, zwischen Lützelau n. Vitznau, bei Kindlismord, beim Hochstein, über der Brust bei Ennethorw, in Gärten.

232. So lanum tu bcrosum. Angebant. 233. - nigrum. 6-9. An Mauern und Schutthaufen, in Gärten, um Lazern und im Surenthal.

234. - d u l c a mara. 6-7. Hin und wieder an schattigen Hecken, an Gräben u. fenchten Sicllen längs den Ufern der Flüsse, nicht selten. An der Emme u. Reuss, im Schiltwald, bei Inwil, am Luzerner-, Sempacher- $u$. Wauwilersee, längs der Sure, bis in die Voralpen, beim Brüderer - Mättli am Schimberg.

235. - 1 y c o p e r s i c u m. 6-9. In Gärten. 23\%. L y c i u m b a r b a r u m. 6-9. In Gärten.

237. Vin c a m in or. 4-5. Häufig an troekenen steinigen Orten, an Hecken, Weg-, Wald- u. Bachrändern.

"a. - min. Form mit violettrothen Bliithen. Im Surenthal, bei Geuensee am Dorfbach, im Wiggerthal.

238. - m a j o r. 4-5. In Gärten. 239. N e rill m ol eander. In Gärten. 
240. Cynanchum vincetoxicum. 5-6. An steinigen Orten der Berge und Vorberge nicht selten. Am Fusse des Rigi, zwischen Weggis und Vitznau häufig am Fusse des Pilatus, an Biirgen und Lopperberg.

241. Campanula pusilla. 6-8. Massenhaft an felsigen $u$. kiesigen Orten der Alpen und Voralpen, und mit den Bächen u. Waldströmen bis in die Ebene hinuntergeschwemmt. An der ganzen Pilatuskette bis zum Rothhorn, an der Schratten, Napf, Rigi, Emmenbrücke, Obergrund in Luzern. 242. -.. rotundifolia. 6-9. Nicht selten an' trockenen Orten, an Wegen $u$. Hecken der Lbene und Berge bis in die Alpen. An der Strasse nach Münster bei Hildisrieden, Rain, Adligenschwil, Littau, am Rigi, Pilatus und Schimberg.

243. - linifolia. 7-8. Auf allen unsern Alpen und Voralpen. Am Pilatus und der ganzen Bergkette bis zum Rothhorn. Am Rigi und auf den Entlebucherbergen.

244. - valdensis. 7-8. Am Pilatus im Autsteigen nach Brüdlen. 
245. Campanula rapunculus. 5-7. Gemein an Hecken, Rainen, Wiesen und Feldern der Ebene und Hügel.

246. - patula. 5-7. Bei Adligenschwil.

247. - rhomboidalis. 7-8. In der Voralpenregion. Auf Blasen bei Fluhli, Emmenthal, an der Schratten, zwischen Tannhorn u. Nesselstock, hinter Sörenberg, Schönenboden, Staffelalp, Nesselstock und Tagweid.

248. - trachelium. 7-8. Häufig in der Hiigelregion. Am Lindenberg, am Hundsrücken bei Ebikon und $\mathrm{Bu}$ chenrain.

249. - urtica efolia. 7-8. Häufig an Hecken, Gebiischen und in Wäldern bis in die Alpen. So noch im Grund am Fusse des Schimberges.

250. - rapunculoïdis. 7-8. Auf trockenen gebauten u. ungebauten Stellen. Um Luzern, Münster, Rickenbach, Wetzwil, Hildisrieden, Neudorf, . Schongau und im Surenthal.

251. - persicifolia. 6-7. Auf Hügeln zwischen Dagmarsellen und Reiden, von der Hochfluh bis in's Luthernthal.

252. - pyramidalis. 6-8. In Gärten. 
253. C a mp a nu la glom erata. 7-8. Häufig von der Bergregion bis zur Tannengrenze. Auf den Höhen des Wiggerthales, bei Reiden, im Hitzkircherthal, in der Ehrlosen, am Rigi und Napf, im Eigenthal, am Pilatus anf Steiglis- und Tomlisalp, am Schimberg bis zur Höhe des Hengstes, am Nesselstock und der Schrattenfluh, am Ufer der Emme bis gegen die Emmenbrïcke.

, a. - aggregata. 7-8. Auf der Hochfluh bei Reiden.

"b. - hirta. 7-8. Ebendaselbst.

254. - cervicaria. 6-7. Auf trockenen Hügeln hin u. wieder zerstreut. An Waldrändern zwischen Triittlingen n. Gottsmännigen bei Sempach, zwischen Reiden u. Dagmarsellen, bei Inwil, am Lindenberg, zwischen Emmen und Rothenburg.

255. - thyrsoides. 7-8. Ain Pilatus auf Steiglisalp und der Holzfluh, auf der Riiche bei Fliihli, auf Schafmatt $\mathbf{~}$. Schrattenfluh.

256. - b a rbata. 7-8. An grasreichen Stellen der Alpen und Voralpen. Auf fast allen Alpen des Pilatus, auf dem 
Widderfeld, Tomlisalp, am Fusse der Schratten, auf Bäuchlen bei Escholzmatt, im Sörenbergli.

256. a. Campanula barb. nana. Auf Rigi, vom Dächli gegen Klösterli.

257. - media. 6-8. In Gärten. 258. - carpathica. In Gärten.

259. Prismatocarpus speculum. 7. Im Getreide nicht selten. Um Sursee und Ettiswil, Münster und Hochdorf, im Suren- und Wiggerthal.

260. P hy teuma spic a tu m. 5-7. Häufig in Gebüschen, an Hecken und Wegrändern der Ebene und Hügel bis zur Tannengrenze. So noch auf der Tagweid über dem Nesselstock und am Fusse des Rothhorns. Bei Luzern am Guitsch und auf dem Wesemlin.

261. - betonicaefolium. 7-8. Am Pilatus hin und wieder, auf Schneeschmelze am rothen Totzen, auf Fräckmünd und auf Klimsenhorn, Oberalp u. Widderfeld.

262. - orbiculare. 6-9. Auf Wiesen $n$. Hügeln bis hoch in die Berge. "a. - orb. long ifolium. 6-9. An dem Fusse des Pilatus hin und wieder, über Hergiswil. 
263. Phyteuma hemis phaericum. 7-8. Am Pilatus nicht selten, auf Mittaggipfi u. Geissriicken, Tomlis- u Klimsenhorn, auf Feuerstein u. am Nesselweng.

264. Jasione montana. 6-7. Auf trockenen Weiden und Hiigeln hin und wieder. Auf Gschweich bei Büron, Sonnenberg bei Luzern, Sedelhof und Hundsrüeken, bei Emmen, auf der Megger-Allmend, bei Udligenschwil, auf Scharmoos und Schwarzenberg, bei Pfaffnau.

„ a. - mont. nana. Auf den Pilatusalpen, z. B. oberhalb dem Bonerli, gefunden von J. Schobinger-Pfister. *

265. Lonïera periclymenum. 6-8. In Gebiischen und Hecken nicht selten. Um Luzern, im Habsburgeramt, bei Rothenburg, im Surenthal, am Fusse des Rigi.

266. - caprifolium. 7-9. In Gärten.

* Es ist manchmal fast unbegreiflich, wie die gelehrten Herren Botaniker Arten aufstellen können, wo ein Diletant kaum mit der Lupe eine Abweichung in der Bekleidung bemerkt, dass diese Herren dann aber solche Formen übergehen können, als eigene Arten aufzustellen, welche ein Diletant ohne bewaffnetes Auge schnell uaterscheidet. 
267. L on ïecra etrusca. In Gärten.

268. - xylosteum. 5-6. In Hecken, Gebüschen u. Wäldern hänfig.

269. - nigra. 4-5. Auf Bergen und Voralpen. Im Tobel bei Rothenburg, Wiholz bei Neudorf, bei Sehongau ain Geissenrain, im Gütseh- und Haltiwald, am Fusse des Rigi und des Pilatus.

270. Lonîecra alpigena. 5-7. Auf Bergen und Voralpen nicht selten. Im Rothenburgertobel u. Forrenwaldtobel, Käserntobel bei Tann, am Rigi u. am Vitznauerstock, auf dem Pilatus, am Tellenpfad und im Aufsteig nach Brüdlen, im Emmen- thal an der Schratten und am Nesselstock.

271. - tartarica. 5. In Gärten.

272. Symphoria racemasa. 6-7. In Anlagen.

273. Evonymus europaeus. 5-6. Häufig in Heeken.

274. - latifolius. 5-6. Am Luzernersee hin $\mathrm{u}$. wieder, in Heeken und Gebüschen. Bei dem. Meggerhorn, am Rigi bei Küssnacht, Greppen, Vitznau und Gersau, am Zingel bei See- 


\section{$-48-$}

wen, bei Arth, am Bürgen und Lopperberg.

275. Rhamnus frangula. 5-6. Ueberall an Hecken, Bächen und feuchten Stellen der Ebene.

276. - cathartica. In Hecken und Gebiischen hin u. wieder, doch seltener. Gegen Ebikon, bei Oberhocken, Geuensee, Büron, Horw.

277. - alpina. 5-6. Am Bürgen u. Lopperberg.

278. - pumila. 5-6. An Felsen des Pilatus, der Bründlen, Matt- u. Kretzenalp, Mondmilchloch, an der Schratten, auf dem Heftiboden und an der Schafmatt.

279. Ribes grossularia. 3-4. Gemein in Hecken und Gärten.

280. - rubrum. 4-5. In Gärten.

281. - nigrum. 5. In Gärten. So bei Dr. Gehrig in Weggis.

282. - al pinum. 6-7. Auf der Hammerschwand am Bürgen, nahe dem steilen Abhange, auf Kretzenalpfluh am Pilatus, auf dem Rigi hinter Seeboden und im Zingel bei Seewen.

283. - sanguineum. 5. In Gärten. 284. - a u reum. 4-5. In Gärten. 285. Vitis sylvestris. Bei Weggis am Sce. 
286. Vitis vinifer a. Angebaut. 287. - hederacea. In Anlagen. 288. Hedera helix. Ueberall bis zur Buchengrenze.

289. Viola o dorat a. 3. Fast iiberall. 290. - suavis 3-4. Bei Meggen häufig.

291. - hirta. 3-4. An trockenen Stellen häufig. Bei Weggis, Horw u. Littau. „a. - h. alba. Bei Weggis und Meggen.

"b. - hirt sciaphila Bei Weggis.

„c. - hirta collina. Mit den Vorigen.

292. - palustris. 4-8. An sumpfigen Stellen. Am Rothsee, Luzerner- und Mauensee, bei Wauwil, im Surenthal, bei Aesch, Mosen, Müsswangermoos, Dagmarsellen, in Bergsiimpfen des Pilatus und des Rigi, anf Seeboden.

295. - c 4- 4eberall an Hecken u. in Wäldern der Ebene bis in die Alpen.

296. - rupii. 5-6. Auf dem MuiswangerMoos, bei Wauwil.

297. - pumila. 5-6. Auf der Halbinsel bei Horw, auf trocken gelegtem Sumpf- $u$. 'Torfboden, zwischen Leimi u. Berghof, zwisehen Horw und Kastanien- 
baum, bei Udligenschwil, an Graben-Rändern bei Wauwil.

298. Viola tricolor. 5-8. In Gärten Wiesen, Aeckern und auf Schutthaufen. Häufig auf Schwarzenberg, Bramegg, bei Meggen, zwischen Ebikon und Rathhausen.

ra. - altaica. In Gärten gezogen.

299. - arvensis. 5-8. In Getreideäckern häufig.

300. - lutea. 6-7. Am Pilatus häufig, an der Eselsfluh, auf dem Oberhaupt, gerade iiber dem Kriesiloch.

301. - calcarata. 7-8. Auf dem Pilatus, vom Esel gegen dem Laub.

302. - cenisia. 7. Im Geröll zwischen Ringfluh und Esel am Pilatus häufig.

303. - biflora. 5-7. Auf allen unsern höhern Bergen. Am Rigi, Pilatus, Schimberg, Fenerstein, Rothhorn, Schratten, Bäucheln, Napf, 4000' $7000^{\prime}$ Höhe, im Schatten von Felsblöcken und Felswänden, in Wäldern und Gebüschen. Im Eigenthal, am Riimling nach gegen den Rothstock, an feuchten Stcllen.

304. Viola mirabilis. 4-5. Am Fusse des Rigi, im Tobel bei Kindlismord, am 


\section{$-51-$}

Bürgen, häufig im Hitzkircherthal, bei Gelfingen, zwischen Hitzkirch und Heidegg am Bachufer, am Gaissenrain bei Schongau.

305. Impatien nolitangere. 7-8. An schattigen feuchten Orten häıfig, in Wäldern. In Hrn. Mahlers Töbeli, bei Eschenbach, an der Schaubern, im Rifig- und Surseerwald, bei Eggerschwil.

306. - b a l s a mina. 7-8. In Gärten.

307. - insignis. 7-9. In Gärten. In und um Luzern verwildert. Im Schweizerhofgarten.

308. Thesium pratense. 6-7. Im Reussthal, an Zusammenfiss der Reuss und Emme, Zwischenwasser bei Entlebuch, am Rigi auf Urmiberg.

309. - alpinum. 6-7. Häufig von Fliihli bis Sörenberg und Nesselstock, am Rigi und am Napf, Pilatus, Schimberg, auf Emmenthal an der Schratten, am Rothhorn.

310. Celosia cristata. In Gärten.

311. Haberothamu us el egans. In Gärten.

\section{Digynia.}

312. Astrantia minor. 7-8. Auf all un- 
sern hohen Bergen. Auf Rigi und Napf, am Pilatus auf Bonerli, Bründlen und Klimsenhorn, auf Schimberg, Gürmsch bis Feuerstein, Schratten, Staffelweid bis Tagweid, gegen den Nesselstock und das Rothhorn.

313. Astraulia major. 6-8. Auf den Entlebucherbergen nicht selten, am Ursprung der Emme bis Tagweid und Nesselstock. Am Pilatus seltener, auf Trockenmatt gegen den Stäffeligrat und westlich vom Hühnerhubel. In Luzern im Schweizerhofgarten.

314. Sanicula europaea. In feuchten, schattigen Töbeln und Wäldern der Ebene bis zur Buchengrenze. Vom Gütschwald bis auf Bründlen am Pilatus.

315. Hydrocotyle vulgaris. 7-8. Auf sumpfigen Stellen. An den Seen von Luzern, Sempach, Mauensee und Wauwil, bei Aesch, Egelmoos bei Büron.

316. Eryngium a lpinum. 7-8. Am Pilatus selten, auf Entlebucherbergen.

317. Daucus carota, 7-8. Ueberall an 


\section{$-53-$}

Wegrändern, in Wiesen u. Aeckern.

Im Grossen angebaut.

318. Daucus grandifl orus. 6-8. Hänfig anf Feldern im Surenthal, um Sursee und Ettiswil, bei Münster, Neudorf, Hochdorf, Schongau u. Emmen.

319. Caucalis anthriscus. 7-9. Häufig an Hecken, in Wäldern und Gesträuchen, überall. Bei Sursee, Ebikon.

320. - infesta. 7-8. Anf Getreideäckern. Im Hitzkircherthal, bei Richensee, Altwis, Aesch und Schongau.

321. - daucoides. 6-7. Hin und wieder in Aeckern. Zwischen Sempach 11. Schenkon, beim Seehüsli, Schongau, im Surenthal, hänfig bei Triengen im Hofacker und bei Münster.

322. A thamantha libanotis. 7-8. In der Berg- und Alpenregion. Am Lopperberg, am Pilatus anf Mattalp, ain Nesselstock, von Schlachthiutte bis Nesselweng häıfig, am Rigi von Gersau bis Brunnen.

323. - cretensis. 7-8. An felsigen Stellen der Alpen nicht selten. Häufig am Pilatus an Tomlisegg, auf Klimsenhorn, Kastelen bis Kriesiloch und 
Esel, Nesselstock, Rothhorn und auf der Schratten an der Emmenthalfluh, auf Stricktossen und der ganzen Höhe, am Rigi und auf Hochenzi am Napf, am Schimberg und an der Schafmatt.

324. Heracleum sphondylium. 7-8. Ueberall auf Wiesen und Aeckern der Ebene und Berge.

325. Pastinaca sativa. 7-9. Häufig im Surenthal, von Sursee bis Marchstein, von Hochdorf bis Mosen, am Fusse des Rigi vereinzelt, bei Immensee u. von Arth bis zum Dächli. In Gärten gepflanzt.

326. Peucedanum palustre. 7-9. Auf sumpfigem Boden. Am Rothsce, Luzerner-, Mauen- u. Wauwilersee, im Zellmoos bei Sursee, Egelmoos bei Triengen, bei Kiissnacht, im Bürgensumpf und auf Seeboden ain Rigi.

327. - cervaria. 8-9. Auf der Hochfluh bei Reiden, und am Schimberg.

328. Imperatoria ostruthium. 6-8. An felsigen Orten der Alpen und Voralpen. Am Pilatus zwischen Schneeloch und Mittaggipfi, auf Oberalp, 
Hochenzimätteli, im Sörenbergli, auf Haglern, Nesselstock u. Schratten. 329. Angelica sylvestris. 7-8. Häufig. an Gräben und Bächen, in Wäldern der Ebene und Berge.

330. Laserpitium latifolinm. 7-8. An Rigi uiber Vitznau, bei Kindlismord und Seewen, am Pilatus, besonders häutig an der Hochfluh, am Nesselstock.

331. - siler. 6-7. Häufig in der Bergund Voralpenregion. Auf Rigi, bei Kindlismord, am Zingel bei Seewen, am Lopper und Buirgen, oft bis zum Seegestade, am Pilatus bis zur RingAluh, im Kragenberg, an der Schafmatt, ob Kurzenhiittenalp.

332. - simplex. 7-8. Auf Rothhorn häıfig, von der Spitze iiber den ganzen langen Grat, welcher Maisee von Tagweid trennt.

333. Anthriscus sylvestris. 5-6. Häıfig in Wiesen und Baumgärten der Ebene und Berge.

334. - alpestris. 7. Am Pilatus ob Bründlenalp, am Felsenbande und am Tellenpfad. 
335. Anthriscus cerefolium. 7. In Gärten gebaut, verwildert auf Schutthaufen.

ᄁ a. - ceref. psilocarpa. ) Gleiche

n b. - - trichocarpa. ) Standorte.

336. Che rophillum an reum. 6-8. Häufig auf Wiesen ur. an Hecken, von der Ebene bis in die Voralpen. Bei Zell, Sursee, Krumbach, Wetzwil, Sempach, Ruswil, im Entlebuch.

337. - temulum. 5-7. An schattigen, etwas feuchten Stellen der Ebene, an Hecken und Gebïschen häufig. Im Surenthal, um Hochdorf, Wauwil, Reiden, Zell und Ebikon.

338. - hirsutum. 6-7. Häufig auf feuchten Wiesen an Bächen und Hecken, von der Ebene bis in die Alpen.

339. - cicutarium. 7-9. Im Wald unter Briindlenalp, auf Tellenpfad am Pilatus häufig, bei Fellmis am Vitznauerstock.

310. S c andix pecten-veneris. $5-6$.

Häufig in Aeckern des Hitzkircherthals, bei Miinster, im Surenthal, an der Halden bei Büron.

341. Coriandrum sativum. 6-8. In Gärten. 
342. Oenanthe fistulosa.6-7. Auf sumpfigem Boden selten. Bei St. Urban. 343. Bupleurum ranunculoides. 7-8. Am Pilatus nicht selten, auf Rossegg, Oberhaupt, Ring- u. Holzfluh, Tomlisegg, am Nesselstock, auf Tagweid unter Maisee, am Rothhorn u. an der Schrattenfluh.

344. - rotundifolium. 6. Zwischen Weggis und Vitznau, in den Wiesen am See, sehr selten. Gefunden von J. Schobinger-Pfister.

345. Foeniculum officinale. 7-9. In Gärten.

346. Silaus pratensis. 6-8. Auf feuchten Wiesen, besonders im Hitzkircherthale, bei Mosen, Aesch, Schongau, Müswangen und Hämikon.

347. Petroselinum sativum. 6-7. In Gärten.

348. A pin g graveolens. 7-9. In Gärten. 349. Carum carvi. 5-6. Auf Wiesen der Ebene bis in die Voralpen nicht selten. So noch auf Napf, Bramegg, Blasen bei Flühli, Emmenthal an der Schratten, Sörenberg bis Nesselstock, auf Kastelen am Pilatus. 350. Pimpinella magna. 7-8. Häufig auf 


\section{$-58$}

Wiesen und Triften der Ebene bis hoch in die Alpen.

350, a. Pimpinella mag. rubra. Am Pilatus.

„ b. - mag. laciniata. An der Halden bei Luzern.

351. - saxifraga. 7-8. Aut trockenen Stellen, an Rainen, Wegrändern u. steinigen Hügeln fast überall.

352. - anisu m. 7-8. In Gärten.

353. Aegopodium podagraria. 7-8.

Ueberall um die Häuser und an Hecken, in etwas feuchtem Boden.

354. Meum mutellina. 7-8. Auf all' unsern Alpweiden über der Buchengrenze. Auf Rigi, Pilatus, Feuerstein und Rothhorn.

355. - a tham anticum. 6-8. Am Pilatus. 356. A ethusa cynapium. 7-8. Häufig in Fruchtfeldern, auf Schutthanfen und in Gärten.

357. Cicuta virosa. 7-8. An all' unsern Seen. Nicht selten am Luzernersee, häufiger am Rothsee, bei Mauensee, Wauwil, neben Calla palustris im Chüsirainwald, am Sempachersee. 358. Conium maculatum. 7-8. In Apo- 
thekergärten gepflanzt. Hin u. wieder um Luzern verwildert.

359. Berula angustifolia. 7-8. Häufig in Wassergräben, an Teichen und Sümpfen. Um Luzern, Hochdorf, im Suren- und Wiggerthal, vom Rothsee bis Gisikon, an Gräben rings um den Rigi.

360. Heloseia dium repens. 8-9. Selten u. schwer zu finden, weil sehr klein, im Grase verborgen. Hin und wieder am Luzernersee, beim Badeplatz an der Halden, im Stansstaderried. 361. U1mus campestris. 3-4. In Bergwälder eingestreut. Am Sonnenberg, bei Horw, im Hergottswald, Horwerhochwald, in Anlagen.

362. Chenopodium bonus henricus.59. Um Häuser u. Scheunen an Wegen und Hecken nicht selten. Bei Luzern, auf Rigi und Pilatus, in der Nähe der Sennhütten.

363. - album. 7-9. Auf Schutthaufen, bebauten und unbebauten Stellen in der Nähe der Dörfer.

364. - u rbic u m. 8-9. An Schutthanfen 1 . ungebauten Stellen hin und wieder. Bei Luzern, Sursee und Geuensee. 
365. Chenopodium murale. 7-9. Um Muinster.

366. - polyspermum. 8-9. In Aeckern und Kartoffelfeldern nicht selten.

Um Luzern, am Sonnenberg, bei Emmen, Waldibrugg u. Eschenbach. 367. Beta cicla. In Gärten angebaut. 368. - rapacea. Im Grossen angebaut. 369. Atriplex patula. 7-10. Auf Aeckern häufig als Unkraut.

370. - hortensis. 7-8. In Gärten angebaut. 371. Amaranthus blitum. 7-9. Auf Schutthaufen, an Mauern und unkultivirten Orten hin und wieder. Um Luzern, bei Weggis.

372. - c a u d a tus. 7-9. In Gärten. 373. - cruentus. 7-9. In Landgärten. 374. Spinacia olcracea. In Gärten angebaut.

"a. - oler. spinosa. ) Ebenso.

375. Blitum virgatum. Hin und wieder angebaut, auch verwildert.

376. - capitatum. Ebenso.

\section{Trigynia.}

377. Staphylea pinnata. 5. Hin und wieder in Gärten, bisweilen auch ver- 
wildert. Am Nöllithörli bei Luzern, auf Bösegg bei Willisau in der Nähe der Kapelle, zu Buholz bei Than.

378. Staphylea trifolia. In Anlagen.

379. $\mathrm{R}$ hus cotinus. In Anlagen.

380. - typhina. ) 7-8.

381. - coriaria. J Ebenso.

382. Tamarix germanica. 5-7. Zwischen

Eich und Schenkon, auf Sandstellen am See, im Kiesbett der Emme hin und wieder, von der Emmenbrücke bis Flühli, am Ruimlig bei Schachen.

383. - gallica. 7. In Anlagen.

384. Viburnum lantana. 5. In Hecken u. Gebüschen nicht selten.

385. - opulus. 5-6. In Hecken und Gebüschen, an feuchten Stellen, auch in Gärten.

386. Sambucus nigra. 5-6. In Hecken und Gebiischen, auch in Gärten.

387. - ebulus. 7-8. An trockenen Hiigeln und Abhängen, in abgeholzten Waldungen häufig bis zur Buchengrenze. Nördlich vom Rothsee, in der Ehrlosen, bei Münster, zwischen Sursee und St. Erhard, Hafendeckel, am Guitsch, im Rothenburger Bach- 
tobel, bei Inwil, oberhalb Entlebuch

gegen dem hl. Kreuz.

388. Sambucus racemosa. 3-4. In Wäldern der Berge und Voralpen bis $5000^{\prime}$ hoch. Am Sonnenberg bei Luzern, bei Hildisrieden, Rain, Wirtlemwald bei Hochdorf, Surseerwald, im Rifig, bei Meggen, am Rigi.

\section{Tetragynia.}

389. Parnassia palustris. 7-8. Ueberall auf feuchten, sumpfigen Wiesen der Ebene bis hoch in die Alpen.

\section{Pentagynia.}

390. Static e armeria. 6-8. Häufig in Gärt. 391. Armeria formosa. In Gärten.

392. Lin um usitatis sima. 6-8. Angebant. 393. - c a tharticum. 7-8. Häufig auf trockenen und feuchten Wiesen der Ebene bis in die Alpen. Auf Bramegg, am Schimberg und bei Emmenthal an der Schratten.

394. Drosera rotund ifolia. 7-8. Auf Siimpfen und Torfmooren. Am Luzernersee, bei Ennethorw, am Rothund Mauensee, Wauwylersumpf', 
Schonganermoos, im Rothenburgerwald, am Nasssteg bei Meggen, auf Seeboden ain Rigi, im Vollenloch unter Mühlemääs am Pilatus, auf Gürmschalp.

395. Drosera longifolia. 7-8. Gleiche Standorte.

396. $\mathrm{Sibbaldia}$ procumbens. 6-8. Auf unsern Bergen hin und wieder. An feuchten Stellen der Schrattenfuh, am Schneeloch zwischen Oberalp u. Mittaggipfi am Pilatus, uber Maisee am Rothhorn, am Fusse des obersten Gipfels am Fenerstein, Siebenegg gegenüber, auch zwischen Staffel und Kulm am Rigi.

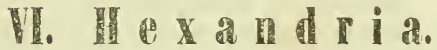

\section{ILonogynia.}

397. Berberis vulgaris. 5-6. In Hecken und Gebiischen der Ebene u. Berge, stellenweise durch den ganzen Kanton. Bei Ennethorw, Gerlischwil, Malters und im Surenthal. 
398. B e r b e ris a $q u$ ifo $l i u m .5-6$. In Gartenanlagen.

399. Tradescantia virginiaca. In Anlagen.

400. P e p lis p or tul a. 7-8. Am Luzerner-, see gegen die Halden, zwischen Ebikon und Root in Sumpfgräben, auf der Reiderallmend.

401. L e u с о u m vernum. 3-4. In Wiesen und Baumgärten häufig. Bei Büron, Hochdorf, Rothenburg, Hitzkirch, Mosen, an der Emmenbrücke, bei Staffeln, Emmen, Pfafiwil, Gisikon, Horw, Kriens, Obernau, Ennethorw, Ebikon, im Lehn bei Schenkon, massenhaft bei Hergiswil am Lnzernersee, bei Winikon, im Egelmoos bei Triengen, am Fusse des Rigi, von Kiissnacht uiber Weggis bis Kindlismord, und noch im hintern Seeboden auf Rigi, auch gegen dem Rotzloch.

402. G a la $\mathrm{n}$ thus $\mathrm{n}$ ivalis. 3-4. Im Gleng zwischen Schötz u. Ebersecken, bei Winikon in Baumgärten, häufig an der Ennergass, in Wiesen gegen Reitnau zu, in Gärten gezogen. 403. Narcissus pseudonarcissus. 
3-5. Häufig in Wiesen und Baumgärten. Bei Luzern, Meggen, Meierskappel, Immensee, Rothenburg, Eschenbach, Horw, Ebikon.

404. Narcissus poëticus. 5-6. Am

Pilatus im Sternenbödeli, zwischen Nawen und Klimsenhorn, und auf der Ilgenblanke, zwisehen Lauelenalp und dem Heidentannli, westlich vom Klimsenhorn, auch auf den Entlebucherbergen. 405. - b if l o r u s. 4-5. In Gärten.

406. - 10 b a tus. 4. Um Luzern bei St. Karli, gegen den Rothsee, auf dem Hundsriicken bei Ebikon.

407. - j on quill a. 3-4. In Gärten. 408. - t a z e t t a. 3-4. In Gärten. 409. Hemerocallis flava. 6-7. In Gärten.

410. - fu lva. 7-8. In Gärten. Verwildert bei Weggis, an den Ufern der Reuss bei Emmen.

411. F u n k i a s u b c o r d a t a. 9. In Gärten. 412. - ov a ta. 7-8. In Gärten. 413. A paganthus umbellatus. In Gärten.

414. Convallaria majalis. 5. Hin und wieder in Bergwäldern. Bei Wer- 


\section{$-66-$}

thenstein, St. Katharina zu Inwil an der Reuss, im Walde bei Pfaffnar, an der Hochfuh bei Reiden bis gegen Dagmarsellen, bei Gersau am Rigi, auch in Gärten.

415. Convallaria multiflora. 5-6. In Hecken u. Gebiischen der Ebene iiberall.

416. - p o ly g o n a tu m. 5-6. Nicht selten in der Voralpenregion. Bei Gersau am Rigi, am Fusse des Pilatus.

417. - verticillata. 5-6. In der Bergund Voralpenregion, in Gebuischen und Wäldern. Am Rigi, zwischen Greppen und Känzeli, am Pilatus im Aufsteigen nach Brïdlen und Tellenpfad, im Horwerhochwald, an der Schratten, am Bürgen, im Wiholz bei Neudorf, auf der Müswangerhöhe, am Lindenberg, im Schiltwald an der Reuss.

418. Staptopus amplexifolius. Selten. Am Pilatus auf der Mattseite der Rössligeralpfluh, beim Mondmilehloch u. gegen das Mittaggipfi.

419. M u scari racemosum. 4-5. Um Luzern an der Halden, bei Seeburg, Weggis, Meggen, Vitznau, im Hitz:- 
kircherthal, bei Hochdorf, Kleinwangen, Ermensee, im Surenthal bei Geuensee, bei Grosswangen und Uffikon.

420. Muscari botryoides. 4. Um Litzern neben dem Friedhof in's Probsten Mätteli, anf Thorenbach, bei Rathhausen, auf Hundsriicken, bei Meggerhorn.

421. Hyacinthus orientalis. 3-5. In Gärten.

423. - Robert Steiger. Topfpflanze im Schobinger'schen Garten.

423. Allium cepa. 6-8. In Gärten angebaut.

424. - fistulosum. 6-8.

425. - a scalonicum. 6-7. $\}$ Ebenso.

426. - schoenoprasum. 6-7.

427. - - a l pinu m. 7-S. Am Rigi zwischen Kulm und Klösterli, auf Tagweid am Rothhorn, am Nesselweng, Schrattenfluh, am nördlichen Fusse des Feuersteins, häufig auf Hunkelen und Bargelenalp, auch in der Angstalp. Zwischen Weggis und Vitznau.

428. - vineale. 7-8. Häufig in Getreideäckern. Im Suren-, Winen-, Hitz- 
kircher- und Wiggerthal, bei Emmen, Eschenbach und Ettiswil.

429. - oleraceum. 7-8. Am Fusse des Rigi, zwischen Vitznau und Gersau. 430. - carinatum. 7-8. Am Fusse des Rigi, bei Weggis und Vitznau, am Gschweich bei Egolzwil.

431. - fallax. 7-8. Am Fusse des Rigi, beim Fallenbach, Kindlismord zu. 432. - sativum. 7-8. Gebant.

432. - porrum. 7-8. In Gärten gebaut.

433. - ursinum. 4-5. An feuchten Stellen in Gebiischen und Wäldern bis zur Buchengrenze. Am Pilatus selbst bis zur 'Tannengrenze. Im Obernau bei Kriens, zwischen Kriens and Ennethorw. In den sog. Hochwäldern am Pilatus.

434. - victoralis. 7-8. An felsigen Stellen des Pilatus, häufig auf Neunhemeleralp, südlich vom Hergiswiler Frakmiint, vereinzelt am rothen Totzen, auf Schafinatt an der Baumgartenfluh und Rischlifluh, am Nesselstock.

435. - moly. 7-8. Zierpflanze in Gärten. 436. Scilla bifolia. 3-4. An steinigen 0rten, in Gebuischen und Wiesen. Bei 
Weggis, Sempach, zwischen Sursee und Schenkon, Geuensee beim Zollhaus, bei Büron, Triengen, Hochdorf, Baldegg, Gelfingen, Hitzkirch, Stäffligen und Uffikon.

437. S c illa a mo en a. 4-5. In Gärten. 438. $0 \mathrm{rn}$ ith og a l u m lute $\mathrm{um}$. 3-4. In Wie- sen der Ebene nicht selten. Bei Geuensee, Büron, Hochdorf, Hitzkirch, Nendorf, Dagmarsellen, Horw, Kriens u. Obernau, bis in die Bergregion.

439. - umbellatum. 5-6. In Getreideäckern häıfig. Bei St. Karli, Kriens, Seeburg, Emmen, Eschenbach, Buchenrain, Hochdorf, Sursee, von Eich bis Triengen.

440. - nutans. 4-6. Im untern Theile des Surenthals von Winikon bis Stafielbach.

441. Lloydia scrotina. 7-8. Am Rothhorn.

442. Tulipa gessneriana. 5. In Gärten. 443. - sylvestris. 5. Verwildert bei Emmen an der Reuss.

444. Lilium candidum. 6-7. In Gärten und auf Kirchhöfen.

445. - bulbiferum. 5-7. An Felsen bei 
Liitzelau, Gersan, Kindlismord bis Seewen am Fusse des Rigi, am Lopperberg bis zum See herab, häufig in Landgärten.

446. Lilium tigrinum. 7-8. In Gärten.

447. - martagon. 7-8. Am Pilatus auf Tellenpfad, Schneeschmelze, Briindlen, Horwerhochwald, auf dem Rigi gegen das Känzeli, am Felsenthor, bei Gersau, Lowerz, auf Schwarzenegg am Napf, Schimberg, Schafmatt, Silwängen, Emmenthal an der Schratten, Nesselstock. Auch in der Hïgelregion, Kraiengïtsch, Biregg bei Luzern, am Gaissenrain bei Schongau.

448. - chalcedonicum. 7-8. In Gïrten. 449. Fritillaria imperialis. 4-5. In Gärten.

450. Anthericum ramosum. Am Fusse des Rigi, von Liitzelau iiber Vitznau und Gersau bis Seewen. Am Pilatus auf Nauen und Klimsenhorn. Anf Kurzenhiitten hinter Fliuhli, auf der Rüche im Kragen.

451. - liliago. Am Pilatus rechts von der Matthütte gegen das Matthorn und an der Holzfluh, am südlichen $\mathrm{Ab}$. 
hange der Schafmatt, auf der Riiche bei der alten Glashütte im Kragen. 452. Anthericum liliastrum. Von Gärtner Hochstrasser kultivirt.

453. Asperagus of $\mathrm{i} \mathrm{c}$ in a lis. Gemiisepflanze in Gärten.

\section{Trigynia.}

454. Colchium antumnale. 9. Auf feuchten Wiesen.

455. V e r a tru m a l b u m. 6-7. Häufig auf Bergen und Voralpen. Auf Rigi und Pilatus, in Sörenberg bis Staffelalp und Tagweid, Emmenthal $u$. Salzboden an der Schratten, sogar in der Ebene, im Surseerwald und anf dem Mïswangermoos.

456. $\mathrm{R} u \mathrm{~m}$ ex a c e to s a, 5-7. Ueberall auf Wiesen und Triften der Ebene und Berge, selbst bis hoch in die Alpen. 457. - a c e to s ellav5-7. An trockenen sandigen Stellen und Hügeln nicht selten.

458. - a rifolius. Auf Voralpen bis 4000' Höhe. Häufig am Nesselstock und auf 'Tagweid, in Staffelwald hinter 
Sörenberg, im Emmenthal bei Stricktossen an der Schratten, am Rigi. 459. $\mathrm{R} \mathrm{u} \mathrm{mex} \mathrm{s}$ c t a t u s. An Schutthalden unserer Berge, zwischen Steingeröll. An der Ringfluh am Pilatus, Rothhorn, Nesselstock, Tagweid bis Staffelwald an der Schrattenfluh, auf Rigi, Schwarzenegg am Napf.

460. - g l a u c u s. In Gärten als Gemüsepflanze. An den Schlossinauern von Hohenrain, um Luzern an Mauern bei der Reuss verwildert.

461. - obtusifolius. 7-8. Häufig in Wiesen und Aeckern, an Wegen und Strassen bis zur Buchengrenze.

462. - pratensis. Bei Nottwil am Sempachersee, Winikon.

463. - c ris p u s. 6-8. An gebauten, etwas feuchten Stellen in Wiesen u. Weiden nicht selten. Um den Luzernersee häufig.

464. - c onglom eratus. 7-8. An Gräben und feuchten Stellen hin und wieder. Bei Emmen, Rothenburg, Rain, Surseerwald.

465. - al pin us. 6-7. Auf Fellmis an Vitznauerstock, auf Schratten, Staffelalp linter Sörenberg. 
466. Rumex hydrolapathum. 7-8. In feuchten Wäldern und an Gräben. Zwischen Rain und Süsstannen, bei Luthern.

467. - diggens. Am Pilatus im Geröll der Ringfluh, auf Kastelenalp, an der Schrattenfluh, doch nicht häufig, bei Maisee am Rothhorn.

408. - pati en tia. Gemüsepflanze in Gärten. 469. Al is m a plantago. 7-8. Ueberall in Sümpfen und Gräben, an Seen und auf Weiden.

\section{II e p $t$ a n $d r i a$.}

\section{Monogynia.}

470. A esculus hip pocastanum. 5-6.

In Anlagen und Alleen.

471. - pavia. 5-6. Ebenso.

472. - macrostachis. 7-8. Ebenso.

473. - flava. Bisweilen, doch selten in Anlagen. Vor dem Schweizerhof in Luzern, gegen den Neuplatz hin. Bei Wartenfluh. 


\section{0 c t a n d r i a.}

\section{Monogynia.}

474. Vaccinium myrtyllus. 5-7. Gemein in Wäldern der Ebene und Berge.

475. - uliginosum. 5-7. In Torfgründen nicht selten, bis hoch in die Alpen. Un unsere kleinen Seen, im Cliüsirainwald, auf Langwasen, Mühlemääs, am südlichen Abhang vom Klimsenhorn, im Eigenthal, auf Oberalp und Mittaggipfi, Gürmsch und Fenerstein, am Bürgen. moosigem Grunde der Ebene, Vorberge und Alpen nicht selten.

477. 0 xycoceos palustris. 6-8. In nassen Torfsümpfen, am Sempacheru. Mauensee, bei Wauwil, am Rothsee, im Chïsirainwald, Nasssteg bei Meggen, Vollenloch gegen dem Miihlemääs, im Eigenthal, Bürgensumpf, auf Seeboden am Rigi, Forrenmoos bei Neierskappel.

478. Erica vulgaris. 6-9. An trockenen Hügeln, Waldrändern, Torfboden, 
Haiden häufig, von der Ebene bis hoch in die Alpen.

478. a. Erica vulg. alba. Auf Scharmis bei Schwarzenberg.

479. - c a rnea. 2-6. Am Pilatus auf Steigli, Matt- u. Klimsenhorn häufig, ebenso: an Rigi, an den Felsen rings um den Luzernersee, vom Stutz bis Kastanienbaum, bei Meggenhorn, Weggis und Vitznau, am Lopper und Biirgen.

na. - carn. alba. Bei Gersau. 480. Chlora perfoliata. 6-7. Auf lehmigem Boden am Fusse des Rigi, oberhalb Weggis, auf dem Goldauerschutt.

481. Koelreutera paniculata. 7-8. In Anlagen um Luzern nicht selten. Auf Felsberg, im Löwengarten. 482. Epilobium angustifolium. 6-8. In abgeholzten Waldungen fast überall, von der Ebene bis $4000^{\prime}$ Höhe. Häufig noch auf Mrühlemääs am $\mathrm{Pi}$ latus.

483. - rosmarinifolium. 7. Hin und wieder zwischen Sempach und Schenkon am See, am Goldauerschutt nicht selten. 
484. Epilobium parbiflorum. 6-7. An Gräben und fcuchten Stellen fast iiberall bis zur Tannengrenze.

485. - hirs u tum. 6-7. An Gräben u. feuchten Stellen. An der Halden bei Luzern, bei Eschenbach, Goldau am Fusse des Rigi.

486. - montanum. 6-7. In Hecken und. Gebiischen der Ebene bis zur Buchengrenze häufig, an schattigen Orten.

487. - palustre. 7-8. Auf Moorboden u. in Sümpfen. Im Hitzkircherthal bei Mosen und Aesch, auf dem Müswangermoos, um Luzern, am Rothsee, bei Mauensee. In der Berg. region auf Langwasen bei Kriens, gegen das Miihlemääs, auf Haglern, Rigi Schneealp und Seeboden.

488. - r o s e u m. 7-8. An Gräben, Bächen und feuchten Stellen nicht selten. Um Luzern häıfig längs den Mauern, an der Halden, in der Hofgasse, am Rothsee.

489. - trig o n u m. 7-8. Auf feuchten, nicht sumpfigen Stelien all' unserer höhern Berge, von der Buchen- bis zur Tannengrenze. Im Eigenthal am Pila- 
tus, beim Rigiklösterli, am Napf, Sörenberg im Staffelwald, auf Nesselstock, Emmenthalfluh an der Schratten.

490. Epilobium tetrag onum. Um Luzern an sumpfigen Stellen, in schattigen Waldungen. Im sog. Einschlag bei Müswangen.

491. - o riganifolium. 7-8. In der Bergregion auf feuchten Stellen. Aut Brïndlenalp am Pilatus, Emmenthalfluh an der Schratten.

492. - a lpinum. 7-8. Auf feuchten felsigen Stellen des Rigi, am Pilatus auf Bründlen und im Nauen, auf Haglern, Emmenthal an der Schratten.

493. Oenothera biennis. 6-7. Hin und wieder an den Ufern der Reuss und Emme, bei Blatten, Emmen, an der Wigger in der Lupfen, um Sursee, bei den alten Burgen von Rothenburg, Heidegg, Baldegg und Wikon, bei St. Urban und Roggliswil, bei Gersau an der Rigi. In Gärten als Zierpflanze.

na. - - rubra.
494 - bistorta. In Gärten.

495. A c er p seudoplatanus. 5. In He- 
ken, Wäldern und Anlagen bis in die Voralpen nicht selten. Auf Schwarzenberg, Bramegg, im Aufsteig nach Brïndlen, am Napf, bei Briidern, im Grund am Schimberg, an der Emmenthalfluh auf Schratten. 496. Acer platanoides. In Anlagen hin und wieder. Am Fusse des Rigi und am Biirgen.

497. - campestris. 5. In Hecken, Gebüschen und Waldrändern häufig, bis in die Voralpen.

498. - striatum. In Lustgebuischen hin und wieder.

499. Tropacol u m maju s. 6-10. In Gärten. 500. Daphne mezereum. 3-4. In Wäldern und Gebüschen der Ebene u. Berge bis in die Alpen. Bei Büron, Genensee, Ehrlosen, Käsern, Schiltwald, Ebikon, auf dem Sonnenberg, im Bachtobel bei Rothenburg, bei Doppleschwand, Hasle, am Rigi, Pilatus bis an die Ringfluh und Tomlisalp, auf Nesselstock, Schrattenfluh, im Scliwandtobel bei Kriens und im Haltiwald.

501. - a l p in a. 5--6. Am Rigi, am Sehwenditossen der Schafmatt. 
502. Daphne laureola. Am Fusse des Rigi, hänfig zwischen Weggis, Vitznau und Gersau, besonders bei Luitzelau, am Felsenthor, beim Waldbruder, am Bürgen.

503. Passerina annua. 7-9. In Halnäckern nicht selten. Bei Eschenbach, Ballwil, Münster, Littau, Sempach am See, am Eicherberg bis Kulmerau, im Surenthal von Geuensee bis Triengen.

504. Godetia vildenovi. 505. Fuchsia fulgens. 506. Hydrangia hortensis.

In Gärten.

\section{Trigynia.}

507. Polygonum bistorta. 6-7. Auf feuchten Wiesen häufig, von der Ebene bis an den Fuss des Esels an Pilatus.

508. - vivip a rum. 7-8. Hänfig auf all' unsern Alpen und Voralpen. Auf Rigi und Napf, an der Pilatuskette bis Nesselstock und Rothhorn, auf Schafmatt und Schratten, im Eigenthal.

509. - a m p h y biu m. 
509a. Polygonum amphybium natans. Am Luzernersee hin und wieder, so am Inseli, bei Greppen und Meggen, an der Sure, in Weihern beim Rifig und bei St. Urban, in Reussgiessen bei Inwil.

n b. - amph. terrestre. Am Luzernerund Sempachersee, iiberhaupt auf trocken gelegtem Boden nicht selten. An der Sure.

510. - hydropipa. 7-9. An feuchten Stellen nicht selten, in lehmigen und feuchten Aeckern häufig. Um Luzern und im Surenthal fast iiberall.

511. - mite. 7-9. Am Luzerner- und Sempachersee, bei Sursee, Mauensee, Ettiswil, iiberhaupt an Gräben und feuchten Stellen.

512. - persicaria. 7-9. Auf Aeckern, an Gräben und feuchten Stellen häufig. 513. - la p a thi foli u m. 6-9. Um die Häuser herum, an Mistlachen und Sümpfen. Am Luzernersee.

514. - minus. 7-9. Um Luzern hin und. wieder. Bei 'Tribschen, auf der Meggerallmend, im Moos bei Müswangen, bei Buchenrain gegen die Reuss. 
515. Polygonum orientale. 9-10. In Gärten.

516. - aviculare. 6-10. Ceberall an Wegen, gebauten und ungebauten Orten bis zur Buchengrenze.

517. - convolvulus. 7-9. Fast iiberall, in Aeckern und angebauten Orten der Ebene und Vorberge.

518. - dumetorum. 7-9. Hie und da in Hecken und Gebüschen. Zu Weggis an der Gartenmauer von Dr.

Gehrig, bei Nottwil.
519. - fagopyrum. 7-8. Hin und wieder gebant, auch verwildert in Getreide und Halmfriichten.

520. - sibaldi i. In Gärten.

\section{Tetragynia.}

521. Paris quadrifolia. 5-6. In schattigen Hecken, Gebüschen und Wäldern der Ebene bis in die Berg. region.

522. Adoxa moschatellina. 3-4. An Hecken und in Gebüschen nicht selten. Häufig zwischen Luzern und Horw, Kriens, Obernau, beim Wirthshaus zu Ebikon, bei Bürgeln im 
Rain, Stäfligen, Buchs, in Zügholz zu Dagmarsellen, beim Weiherhaus in Ettiswil, im Eichwald bei Triengen, bei Sursee und Hildisrieden, aın Rigi zwischen Klösterli u. Dächli.

\section{De c a n d r i a.}

\section{Monogynia.}

523. Monotropa hypopitys. 6-7. In dunkeln Tannen- und Buchenwäldern zerstreut. Um Luzern am Giitsch u. Sonnenberg, bei Ebikon, Rathhausen, beim Rothen, in der Ehrlosen, zwischen Riidikon und Altwis am Gaissenrain, im Wald bei Winikon, bei St. Urban und Pfaffnau, im Sennhäuserwald, bei Dagmarsellen, Obernase bei Vitznau, zwischen Küissnacht $u$. Meierskappel. 524. Rhododendron ferrugineum. 6 -8. Häufig auf Rigi, Napf, Pilatus, Guirmsch, Schafmatt und allen Bergen des Entlebuchs von 4-6000' Höhe, am Bürgen bis zum See herab. 
524.a. R hod od endron ferrug. album. Auf Frakmiunt und am Fusse der höchsten Spitze des Feuersteins.

525. - hirsu tu m. 7-8. Auf Rigi, Napf, Pilatus, an der Enzifluh, auf Emmenthal an der Schratten, am Nesselstock und auf allen Entlebucherbergen, am Lopper und Bïrgen bis zum See hinunter.

526. - intermedium. Hin und wieder neben den Vorigen, so unter RigiScheidegg.

527. Andromeda polifolia.6-7. In Torfsuimpfen der Ebene und Berge bis in die Alpen. Bei Wanwil, am Mauensee, im Müswangermoos, Nasssteg bei Meggen, im Chiisirain- I. Rothenburgerwald, auf Seeboden am Rigi, im Bürgensumpf, Vollenloch, auf Pilatus am Widderfeld, bei Salwidli, auf Gürmsch, Fenerstein, im Eigenthal.

528. Arbatus uvae ursi. Am Pilatus im Steingeröll hin und wieder, an Tomlisfluh, vom Birchboden gegen das Mondmilchloch, in der Völli auf Schratten.

529. - alpina. 6-7. Auf Rigikulm, am Pi- 
latus hin und wieder, so über Bründ. len, im Bonerli, auf dem Engelfeld des Klimseuhorns häufig, in der Völli auf Schratten.

530. Pyrola rotundifolia. 6-8. Hin und wieder in feuchten Wäldern und Gebüschen. Zwischen Kriens und Horw, im Guitschwald, auf Dietschiberg, im Eigenthal, beim Holzhof, am Gaissenrain bei Schongan, auf den Entlebucherbergen, auf Rigi.

531. - chloranta. In schattigen Wäldern, selten, am Fusse des Pilatus, zwischen Eigenthal und Rothstock im Walde.

532. - media. Auf Rigi, im Walde zwischen Küssnacht und Seeboden, im Stösswald am Fusse des Pilatus.

533. - m in or. 6-7. Nicht selten in Wäldern und Gebiischen der Berg- und Voralpenregion. Häufig auf Rigi zwischen Klösterli und Schild, vom Kaltbad nach Scheidegg, am Pilatus zwischen Bründlen und Oberalp, im Eigenthal, auf Gürmsch, Haglern, Emmenthal an der Schratten, bei Schongau, Winikon, im Kraienbuihl bei Kulmerau. 
534. P y rola s e c u nda.6-7. In Bergwäldern häufig. Um Luzern am Gütsch, Dietschiberg, im Biregg- und Schachenwald, am Renggloch, bei Rothenburg, in der Ehrlosen, auf den. Letten bei Winikon, bei Finsterwald auf Bramegg, auf 'Tellenpfad am Pilatus, im Emmential an der Schratten.

535̃. - uniflora. 6-7. In Wäldern der Voralpen. Am Pilatus hin und wieder, so auf Frakmiint, im Walde ob Miihlemääs, im Bonerli, uiber der Staffelhuitte, in den Bergwäldern bei Pfaffnal, am Sonnenberg bei Luzern. 536. Ruta grave olens. 6-8. In Landgärt. 537. Dictamnus albus. 6-7. In Gärten, z. B. im 'Tivoli.

\section{Digynia.}

538. Chrysosplenium alternifolium. 3 -4. Häufig an feuchten Stellen,

Bächen und Gräben bis $4000^{\prime}$ Höhe.
539. - oppositifolium. 5-6. Seltener als die vorige Art. Bei Brunnquellen nicht selten um Luzern. Am Gütsch, in Gigelitobel, bei Rönimoos, im 
Brunnenloch, bei Ebikon, im Rothenburgertobel, Rifig- und Rathhauserwald, Sirtel bei Reiden.

540. Seleranthus annuls. 5-6. In Getreidefeldern und Fruchtäckern zerstreut. Im Surenthal und bei Münster.

541. Saxifrag a mutata. 6-8. Bei uns nicht selten an feuchten Felsen der Bergund Voralpenregion, bis in die Ebene hinab. Am Napf, der Luthern entlang bis Luthern, vom Enziloch bis Stächelegg, der Foutanne nach bis Doppleschwand, an der Emme bei Wolhausen und Werthenstein, auf Rigi bis zum Kaltbad und Staffel, im Tobel unter Hergottswald, über Trockenmatt am Pilatus.

542. - a i z o i d es. 7--10. An feuchten Stellen auf Rigi und Napf, Schimberg, Schratten am Stricktossen, Nesselstock, Tagweid, Kastelen, Bründlen und Trockenmatt am Pilatus, an der Emme von Fliulli bis Werthenstein und Schachen, vom Napf bis Luthern.

543. - a u tumnalis. 7-10. An der Emmenthalfluh und auf Nesselweng, vom 
Klimsenhorn bis Kriesiloch am Pilatus.

544. Saxifraga muscoides. 6-7. Am Pilatus auf Rossegg, Eselsfluh, Tomdishorn, Widderfeld, Gemsmätteli, Klimsenhorn, auf Fenerstein, Rothhorn, Nesselstock, Tagweid, Schafmatt, Stricktossen an der Schratten. 545. - aizoon. Auf felsigen Stellen der Vorberge und Alpen häufig. Auf Rigi, Napf, Bäucheln, Schratten, Nesselstock, Rothhorn, Feuerstein und der ganzen Pilatuskette, zwischen Weggis und Vitznal, Seewen und Lowerz, im Rotzloch.

546. - c a esia. 6-7. Am Pilatus vereinzelt, iiber Stillaub am Schimberg, auf Emmenthalfluh, Stricktossen, Schrattenhöhe und Schafmatt.

517. - andros a cea. 6-7. An feuchten Stellen des Pilatus, am Fusse des Esels, auf Kastelenalp bis Kriesiloch, Gemsmätteli, zwischen Nesselstock und Maisee am Rothlorn.

548. - tritactylites. 4-5. An trockenen Stellen, an Mauern und in Feldern hiu und wieder. Auf Herrengraben bei Sursee, bei Hochdorf, Gelfingen, 
Nunwil, Eschenbach und auf dem Emmenfelde.

549. S a x if a g a o p p ositifolia. 5-7. Häufig auf unsern Gebirgen. Auf Rigi zwischen Kaltbad u. Staffel, auf Kulm und Rothstock, am Napf und Enziloch, am Pilatus in der Tellenpfadlucke, am Esel, auf Kastelenalp, Widderfeld, Mittaggipfi u. Schwarzflühli, Nesselstock, Tagweid und Rothhorn, auf Emmenthalfluh und Stricktossen an der Schratten.

550. - rotundifolia. 6-8. An feuchten, begrasten Stellen der Voralpen bis $6000^{\prime}$ Höhe. Aut all' unsern Bergen.

551. - b ry o i de s. 7-8. Ueber der Tannengrenze, zerstreut an der Pilatuskette bis Rothhorn, nicht häufig. Ueber Bründlen und Trockenmatt, gegen Mittaggipfi, vom Klimsenhorn gegen Kriesiloch.

552. - stellaris. 6-8. An bewässerten Stellen häufig, auf all' unsern Bergen. Auf Rigi und Napf, auf Kastelenalp und Bründlen und der ganzen Pilatuskette bis Rothhorn, auf 
Stricktossen und Emmenthalfluh an der Schratten.

553. Saxifraga cuncifolia. 6-7. An trockenen felsigen Stellen hin und wieder. Im Wald unter Schneealpeli und am Wege zwischen Goldau und Scheidegg am Rigi, am Pilatus zwischen Mittaggipfi und Widderfeld, auf Schafmatt.

554. - umbrosa. 5-6. In Landgärten. 555. - c a espitosa. In Gärten. 556. Gypsophila repens. 6-8. Im Geschiebe der Alpen häufig. Am Pilatus, Nesselstock, Schratten bis $7000^{\prime}$ Höhe. Anf der Spitze des Fenersteins, auf Schrattenhöhe, herabgeschwemmt an der Emme bei Fliihli bis zum Zusammenfluss der Reuss fast überall.

557. Gypsophila muralis. 7-8. In Halmfeldern. Bei Udligenschwil und Immensee, Buchenrain, Hochdorf, Triengen und Dagmarsellen.

558. - paniculata. ) 559. - dichatoma. ) In Gärten. 560. Saponaria officinalis. 7-8. An Hecken, Fluss und Bachufern nicht selten. Im Surenthal bei Genensee, 
Biiron, Triengen, im Wigger- und Hitzkircherthal.

560.a. Sa p onaria off. fl. pleno. In Gärt. 561. - vacaria. Bei Dr. Pfyffer an der Halden bei Luzern und auf Misthaufen.

562. Dianthus caryophyllus. 7-8. In Gärten, verwildert auf Mauern. 563. - sylvestris. 7-8. Am Lopper, Bürgen und Rigi an felsigen Stellen, auf Schafmatt über Grön und auf der Ruichi. Auf Schratten und am Pilatus, im Aufsteigen rom Mondmilchloch gegen das Widderfeld.

"a. - syl. uniflorus. ) Gleiche

"b. - $\quad$ imbricatus.) Standorte. 564. - c a esius.5-7. Häufig auf Kirchliöfen. 565. - deltoides. 6-10. Auf den Anhöhen von Dagmarsellen und Reiden.

566. - chinensis. 7-10. In Gärten.

567. - plum arius. 7-8. Auf Kirchhöfen u. in Gärten.

568. - superbus. 7-8. Auf feuchten Stellen der Ebene und Berge bis in die Voralpen. Bei Śchötz, zwischen Hochdorf und Ballwil, an der Rigi. 569. - armeria. 7-8. In der Hügelregion, an Gebiischen und Waldrändern hin 
und wieder. Am Dietschiberg, Weinberg und Geissenstein bei Luzern, zwischen Ebersol und Hohenrain, bei Schongau, auf den Anhöhen von Knntwil bis Wikon.

570. Dianthus barbatus. 7-8. In Landgärten, auch verwildert.

571. - c arthusianorum. 6-8. An dürren trockenen Stellen, doch selten. An der Schützenmaner bei Münster.

572. - prolifer. 7-8. Im Sande bei Dagmarsellen und ron da auf den Sandhïgeln bis Wikon zerstreut.

573. - sylvaticus. 9. Im Schanzwalde bei Winikon.

\section{Trigynia.}

574. Cherleria sedoides. 7-8. Auf den höchsten Punkten unserer Alpen. Am Pilatus auf Klimsenhorn, Esel, Tomlishorn u. Widderfeld, zwischen Trockenmatt und Mittaggipfi, auf Schafinatt, Schratten, Fenerstein u. Rothhorn.

575. Silene inflata. 6-8. An Wegen und trockenen Stellen, in Aeckern nicht selten. 
576. Silen e alpina.6-8. Am südlichen $A b-$ hange der Schratten und am Nesselstock.

577. - armeria. 6-8. In Gärten.

578. - quadrifida. 7-8. Selten. An feuchten, felsigen Stellen. Am Nesselstock zerstreut, an der Emmenthalfluh auf Schratten häufig.

579. - acaulis. 6-8. Auf allen unsern höhern Gebirgen nicht selten.

580. - exs capa. 6-8. Am Nesselstock, auf Schratten und Feuerstein, am Pilatus, vom Klimsenhorn gegen Kriesiloch.

581. - natans. 5-6. An steinigen, trockenen Orten, an Wegen und Felsen der Ebene, Berge und Alpen.

582. - galli ca. 6-7. In Getreideäckern 1 . Erdïpfelpflanzungen hin und wieder. Zwischen Wolhusen und Entlebuch, auf dem Schongauermoos.

583. Stellaria media. 3-10. Fast überall, auf Aeckern, Schutthaufen und an Wegen.

584. - alsinoides. 3-10. Mehr auf feuchtem und fettem Boden.

585. - n e morum. 6-7. An waldigen Orten der Bergregion. Häufig gegen Mi- 
chelskreuz am Rotherberg, Buchen bei Wolhusen, am Fusse des Rigi bis Kaltbad, am Pilatus und Nesselstock.

586. Stellaria graminea. 5-7. In Hecken und Gebiischen, auf Aeckern und Wiesen häufig.

587. - uliginosa. 6-7. Auf feuchten Wiesen und an torf haltigen Stellen nicht selten. An der Halden bei Luzern und bei Winkel, im Surenthal, am Rothsee, auf dem Müswangermoos, bei Rothenburg.

588. - holos tea.4-5. Längs der Fluh beim Löwendenkmal in Luzern.

589. Mochringia trinervia. 6-8. An Hecken, in Wäldern und schattigen Orten hänfig.

590. - muscosa. 6-7. An feuchten und schattigen Felsen der Voralpen. Am Fusse des Rigi, des Pilatus und der Scliratten, am Bürgen und Lopper, im Rotzloch, bei Briidern, selbst in der Alpenregion, so an der Ringfluh des Pilatus.

591. - polygonoides. 6-7. Im Geröll der ganzen Pilatuskette, im Nauen, auf Klimsenhorn, an der Eselsfluh, auf 


\section{$-94-$}

Brüdlenalp, zwischen Trockenmatt und Mittaggipfi, am Nesselstock, Roth- und Tannhorn, Schrattenfluh. 592. Arenaria verna. 6-8. Am Pilatus auf Klimsenhorn und Oberhaupt, an Rothhorn und den ïbrigen hohen Bergen.

593. - subnivalis. 6-8. Auf Eselsgrat am Pilatus.

594. - villarsii. Auf Rothhorn, Schafmatt, Widderfeld am Pilatus, zwischen Trockenmatt und Mittaggipfi, auf Emmenthalfluh auf Schratten, Nesselstock.

595. - saxatilis. 6-8. Am Pilatus auf den höhern Spitzen der Tomlisalp und des Widderfeldes, am Rigi.

596. - t en nifolia. 6. In Aeckern, Feldern und an Mawern nicht selten. Im Hitzkircherthal, von Hochdorf bis Aesch, um Sursee.

597. - serpyllifolia. 7-8. Häufig in Korn. feldern, an Manern und sandigen Stellen. Lm Luzern, Sursee und Buttisholz.

"a. - serp. glutinosa. Auf fettem Boden.

n b. - - alpina. In der Alpenregion. 
598. Arenaria ciliata. Am Pilatus, Schim-

berg, Schafmatt, Schratten, Rothhorn, Rigi und Napf.

"a. - cil. multicaulis. Mehr auf den höhern Grïten der gleichen Berge.

\section{Tetragynia.}

599. Deutzia scabra. 5-6. In Anlagen. 600. - gracilis. ) In Gärten.

\section{Pentagynia.}

602. Lychnis flos cuculi. 5-10. Auf trokenen und feuchten Wiesen überall häufig.

603. - diurna. 4-6. Häufig um Luzern in Wiesen und an offenen Waldrändern bis in die Voralpen. Auf Rigi und Pilatus.

ra. - diurna. Grïn bliihend. 4-6. Bei Adligenschwil.

604. - vespertina. 6-10. Auf mehr trokenen Standorten, auf Hïgeln, Aeckern und an Wegrändern. Häufig um Luzern, so an der Halden bei Dr. Pfyffer.

605. - chalad o nica. 6-7. In Gärten. 


\section{$-96-$}

606. Agrostemma githago. 6-7. Unter dem Getreide nicht selten.

607. - c orona cia. 6-8. In Gärten.

608. Cerastium a qua ti cu m. 7-8. Gemein an feuchten Stellen und Gräben der Ebene, fast überall.

609. - alpinum. 5-8. Am Rigi, am Pilatus auf Klimsenhorn und am Kriesiloch häufig, auf der ganzen Bergkette bis Rothhorn und Scheibengütsch.

610. - strictum. 7-8. Am Pilatus, häufig auf Mattalp und der ganzen Kette bis zur Klusmatt an der Schratten.;

611. - triviale. 5-10. Fast uiberall in Aeckern und Wiesen der Ebene bis in die Alpen. So noch auf Mittaggipfi und Kastelnalp am Pilatus.

612. - viscosum. 5-8. An Wegen und in Aeckern ziemlich häufig. Um Luzern, auf dem Hundsrïcken und bei Weggis.

613. Spergula arvensis. 6-7. In Saatfeldern häufig. Um Ettiswil, bei Pfaffnau, besonders in der Bergregion, am Gschweich bei Büron, bei Buchenrain, auf Sonnenberg, 
Schwarzenberg, im Entlebuch auf Blasenalp, auf Rigi iiber Lowerz. 314. Spergula nodosa. 7-8. In torfhaltigem Boden. Zwischen Hitzligen 1 . dem Mauensee, am Wauwilersumpf. "a. - nod. pubescens. Gleiche Standorte.

615. - saginoides. 7-8. An felsigen und feuchten Stellen unserer Gebirge zerstreut. Auf Rigikulm u. Scheidegg, am Pilatus, im Sörenberg, Salwidenwald, auf Salzbodenalp an der Schratten, an Nesselstock u. Rothhorn.

616. $0 \times a$ lis a cetosella. 4-5. In Hecken und Wäldern der Ebene bis hoch in die Berge, so noch auf Gürmschalp. 617. - stricta. Bei Luzern im Löwengarten, am Rothsee, auf angebautem Waldboden, hin und wieder in Gartenwegen.

618. - tetraphylla. In Gärten. 619. S e d u m t ele p hi u m. 7-8. An trockenen Hügeln, steinigen und gebauten Orten, Hecken und Bachufern hin und wieder. Um Luzern bei Tribschen, bei Neuenkirch, Sempach, Sursee, Rothenburg, Geuensee; im 
Eichwald bei Triengen, Eschenbach, Tann und Dagmarsellen.

620. S e d u m a c r e. 6-7. An sonnigen, trokenen, steinigen Orten, an Gartenmauern hin und wieder. Bei Luzern, Wartenfluh, Weggis, Vitznau, Hochdorf, Gelfingen, Hohenrain, Rain, im Wiggerthal.

621. - s exang u lare. 7-8. An felsigen, steinigen Orten um Luzern, auf $\mathrm{Mu-}$ segg, Dietschiberg, an der Strasse von Hochdorf bis Hitzkirch und Richensee.

622. - s axatile. 7-8. Am Pilatus hin u. wieder, siidlich vom Widderfeld, dem Mondmilchloch zu.

623. - a tr a tu m. An felsigen, etwas feuchten Orten. Nicht selten am Pilatus an der Holzfluh und südlich vom Widderfeld, auf Kastelnalp, an der ganzen Bergkette bis Rothhorn, am Nesselstock und an der Schratten, beim Kaltbad anf Rigi.

624. - a lbu m. 7-8. Häufig auf Mauern, Felsblöcken, von der Ebene bis in die Alpen. Um Luzern, auf Rigi, Pilatus.

625. - dasyphyllum.6-7. Nicht selten 
in der Berg- u. Alpenregion. Auf Rigi über Weggis und Greppen, am Pilatus und Nesselstock, bei Flühli an den Mauern des Kirchhofs.

626. Sedum villosum. Auf fenchten torfhaltigen Wiesen der Ebene u. Berge. Um St. Urban häufig, am Gütsch bei Luzern, am Wege zwischen Neualp und Eigenthal, am Schilt neben Höchberg, auf Mühlemääs und Bramegg am Fusse des Pilatus, im Moos bei Genggelhausen, in der Blasen bei Flühli.

\section{D o d e ca n d r i a.}

\section{Monogynia.}

627. A sarum europa e am. 4-5. In Wäldern hin und wieder. Im Galgenwäldli bei Emmenbrücke. Massenhaft im Schiltwald an der Reuss, häufig im Surseerwald; zwischen Sursee und Knutwil.

628. Portulaca oleracea. 7-8. Hie und da verwildert auf Schutthaufen. Bei 
Sursee, St. Urban, auch in Gärter gezogen, doch selten.

628.a. Portulaca ol. sativa. In Gärten.

629. Lythrum alicaria. 7-8. An Gräben und feuchten, sumpfigen Stellen der Ebene bis zur Bucliengränze.

\section{Digynia.}

630. Agrimonia eupatoria. 7-8. An trockenen Stellen, Hecken, Wegrändern und Hitgeln bis in die Voral pen. Zwischen Weggis u. Vitznau.

\section{Trigynia.}

631. Reseda odorata. 6-9. In Gärten.

632. - luteola. 6-8. Bei Maria Zell, zwischen Sursee und Schenkon.

\section{Dodeagynia.}

633. Sempervivum tectorum. 7-8. Am Pilatus in der Nähe des Mondmilchloches, am südlichen Abh fnge der Schafmatt, bei Grön und Hurbelen, auf Bodenhüttenalp an der Schratten, auf Rigi iiber Gersau. Häufig 
anf Matern, Brunnenstöcken, Hausdächern und in Landgärten.

634. Sempervivum montanum. 7-8. In Gärten.

\section{I c os a in d r i a.}

\section{Monogynia.}

633. Philadelphus coronarius. 5-6.

In Anlagen.

636. - grandifl or as6-7. In Anlagen.

637. Myrthus communis. 8-9. In Anlag.

638. Punica granatum. 7. In Kübeln.

639. Prunus armeniaca. 3-4. In Gärten.

640. - spinosa. 4. In Hecken u. Gebiischen häufig.

641. - insititia. 4. Gebaut.

642. - d omestica. 4-5. Gebaut.

643. - avium. 4-5. In Wäldern und ange-

(644. - Cerasus. 4-5. Kultivirt.

, a. - - austera)

, b. - - acida. )

Kultivirt.

645. - Padu s. 4-5. An Hecken, in Gebüschen und feuchten Wäldern nicht selten. Im Surenthal, bei Geuensee, Büron, Winikon, Eschenbach, 
Emmen, längs der Reuss im Schiltwald, bei Rathhausen, Buchenrain, Mauensee im Horbachwäldli, bei Dagmarsellen.

\646. Prunus 1 ahaleb. 4-5. In Anlagen. Auf Thorbach bei Luzern.

647. - La uro Cerasus. 5-6. In Anlagen. Im Tivoli bei Luzern.

648. - lusitanica. In Anlagen. Beim Kastanienbaum am Luzernersee.

649. Persica vulgaris. 4. In Gärten an Spalieren.

650. A m y galus com munis. 4-5. In Weggis an geschuitzten Orten, z. B. im Garten bei Hrn. Gerwer Küttel.

\section{Digynia.}

651. Mespilus germanica. 5. Angebaut und verwildert. In der Nähe des Stundensteines bei Littau.

\652. Crataegus oxycanthe. 5. In Hecken und Gebüschen.

\653. - monogyna. 5-6. dito.

654. - pyracantha. 4-6. In Anlagen. 655. Cotoneaster vulgaris. 5. Am Gais. senrain bei Schongau, am Rigi bei Vitznau, auf Pilatus an der Ringfluh. 
656. Cotoneaster tomentosa. 5-6. Am Rigi beim Waldbruder, bei Vitznau, Gersau und auf Urmiberg, am Lopper und Bürgen, auf Napf.

657. Pyrus communis. 4-5.

„a. - - sylvestris. In Hecken, Wäldern, Gebüschen.

"b. - - sativus. 4-5. Angebaut. 658. - malus. 4-5. In Wäldern.

659. Cydonia vulgaris. In Gärten und um die Häuser hin und wieder gebaut.

660. - japonica. 5. In Anlagen.

661. Amelanchier vulgaris. 5-6. Am Luzernersee auf Felsen bis zur Buchengrenze. Bei Seeburg, am Rigi bei Weggis, Vitznau, Gersau bis Seeboden, am Lopper, im Aufsteigen nach Briindlen am Pilatus, an der Schratten.

662. Sorbus a uc uparia. Nicht selten. In Gehölzen der Ebene und Berge bis hoch am Pilatus, auch in Gartenanlagen.

663. - domestica. Hie und da angebaut, doch selten.

664. - hybrida. In Anlagen um Luzern. 665. - torminalis. 5. Am Rigi, bei Luzern 


\section{$-104-$}

anf dem Guitsch und in Anlagen hin und wieder.

666. Sorbus aria. 5-6. In Gebüschen und Laubwaldungen der Hiigel- u. Bergregion bis zur Tannengränze. 667. - edulis. 5-6. In Anlagen.

668. - chama e mespilus. 6-7. Ueber der Tannengränze an begrasten Stellen. Am Pilatus zwischen Mattalp und Laubgrat, zwischen Oberalp u. Mittaggipfi, am Fusse der Schratten häufig gegen die Völli, im Walde und auf Alp Sihlwängen.

669. Spicaea salicifolia. 6- 7 . An Hecken hinter dem Eichwald bei Luzern.

670. - opulifolia. 6-7.

671. - oblongifolia. 5 .

672. - triloba. 6-7.

673. - ulmifolia.

674. - sorbifolia. 6-7.

In Anlagen um Luzern.

675. - aruncus. 6-7. An schattigen Hiigeln und Abhängen, in Gebüschen, an Gräben der Ebene und Berge bis $3000^{\prime}$ Höhe nicht selten. Am Gütsch bei Luzern, im Rothenburgerbachtobel.

676. - ulmaria. 6-9. An Gräben u. teuch- 
ten Stellen der Ebene und Berge

bis zur Buchengränze.

576.a. Spicaea. ulm. denudata. Gleiche:

Standorte.

$\rightarrow$ b. - ulm. glauea. Gleiche Standorte. 677. Kerria japoniea. 5-9. In Anlagen.

\section{Poligynia.}

678. Rosa arvensis. 6-7. An Waldrändern, Hecken und Gebüschen der Ebene bis in die Voralpen.

, a. - arv. stylosa. 6-7. Bei Weggis gegen die Brünni nicht selten.

679. - canina. 6. An Hecken der Ebene bis in die Voralpen häufig.

"a. - can. alba.

\$80. - sempervirens. 7-8. In Gärten.

681. - d a ma s e ena. 6-10. In Gärten.

f52. - pimpinella. In Gärten.

"a. - - spinosissima. In Gärten.

,b. - - poteriefolia. In Gärten.

683. - multiflora. In Gärten.

684. - gallica. 6-7. In Gärten.

, a. - - burgundica. In Gärten.

685. - centifolia. In Gärten.

na. - - muscosa. In Gärten. 
685.b. Rosa centifolia provincialis. In Gärten.

686. - alpina. In der Hügel- und Bergregion bis zur 'Tannengränze, nicht gar selten. Auf Rigi, Pilatus, in Aufsteigen zum Hergottswald, auf Napf, Bürgen, im Rothenburgertobel.

*a. - alp. pyrenaicum. Nicht selten am Pilatus und Napf, bei Fellnau am Vitznauerstock.

687. - rubiginosa. 6. In Gebüschen und Hecken hin und wieder. Zwischen Malters und Schwarzenberg.

688. - tomentosa. 6. In Hecken, Gebüschen und Wäldern hin und wieder. An Fusse des Rigiberges, zwischen Hochdorf und Rain, bei Aesch und Schongau, im Buchenwäldchen bei Rüdikon, bei Luthern.

689. - po mifera. 6-7. In Gärten.

690. - Iu tea. In Gärten.

„a. - - punicea. In Gärten.

, b. - - bicolor. In Gärten.

691. Rubus idaeus. 6-8. In abgehauenen Wäldern, an offenen, trockenen Stellen der Ebene und Berge bis in die Voralpen. Häufig zwischen Bründlen und Oberalp. 
692. Rubus fruticosus. 7-8. In Waldungen und Vorwäldern.

na. - fruticosus corylifolius. dito

nb. - - - glaudulosus. dito

n c. - - polymorphus. dito

693. - caesius. 6-7. An Wegen, Hecken und steinigen, unbebauten Stellen nicht selten.

694. - s a x a tilis. 6-8. Auf felsigen Stellen der Berge und Alpen. Am Biirgen, Lopper, Rigi, Pilatus u. Schrattenfluh. Auch hin und wieder in der Ebene, so auf dem Muiswangermoos.

695. - o doratus. 6-9. In Anlagen.

696. Dryas octopetala. 6-8. Auf all' unsern hohen Gebirgen. Auf Rigi, Napf, Nesselstock, Tagweid, Rothhorn, auf der ganzen Pilatuskette, auf Schafmatt, vom Salzboden bis Stricktossen an der Schratten. Auch in der Ebene, wie am westlichen Felsenbande der Landstrasse beim Holzhof.

697. Tormentilla erecta. 6-9. Häufig an feuchten und trockenen Stellen, Waldungen und Sumpfwiesen der Ebene bis auf den Feuerstein. 
698. P o tentilla verna. 4-5. An sonnigen, trockenen Stellen, Weg- und Waldrändern nicht selten.

699. - s a lisburgensis. 6-7. Am Pilatus auf Brïndlen und Trockenmatt, auf Rigi hin und wieder.

"a. - - alpestris. Gleiche Standorte. 700. - reptans. 7-8. Auf Lettboden an Wegen und Gräben häufig.

701. - a u rea. 7-9. Häufig auf all' unsern Alpen und Voralpen. Auf Rigi, Napf und an der Pilatuskette.

702. - min im a. 7. Auf Schrattenfluh und Bründlenalp.

703. - anserina. 6-9. Gemein an Wegen und Wiesen, besonders auf Lehmboden in der Nähe von Wohnungen.'

704. - fruticosa. In Anlagen.

705. - fragariastrum. 2-5. An trockenen Stellen, Weg- und Waldräindern häufig.

706. - caulescens. 6-8. An Felsen des Pilatus nicht häufig, an Tomlisfluh, Schinfluh, im Aufsteigen vom Mondmilchloch gegen das Widderfeld, am Rigi auf Urmiberg und im Zingel bei Seewen häufig. 707. - formosa. In Gärten. 
708. Fragaria vesca. 5-10. Häufig an Hecken, Weg- und Waldrändern, Gebüschen, sonnigen Abhängen, iberall bis hoch in die Alpen.

709. - collina. An offenen, nicht bebuschten Hügeln.

710. - elatior. 6. Am Gütsch bei Luzern. 711. - grandiflora. In Gärten gezogen. 712. Geu n urbanum. 5-6. Häufig an sonnigen Stellen, an Hecken und Wegrändern der Ebene bis 3000' Höhe. 713. - rivale. 5-6. Häufig an Gräben, Bächen und nassen Stellen bis in die Alpen.

»a. - riv. hybridum. 5-6. Im Hitzkircherthal und an der Schafmatt.

714. - montanum. 5-7. Auf Alpen und Voralpen. Auf Rigi, Napf, Salz. boden an der Schratten, Briindlen, Matt- und Tomlisalp am Pilatus.

715. - reptans. 7-8. Am Pilatus.

716. Comarum palustre. 5-7. In Sumpfund Torfboden. Am Luzernersee, Roth- und Mauensee, bei Wauwil, im Schongauermoos, Egelmoos bei Triengen, Ehrli bei Winikon, Fohrenmoos bei Meierskappel bis Seeboden am Rigi, im Bürgensumpf. 
717. Calycanthus floridus. 5-7. In Anlagen.

\section{P o l y a n d $\mathbf{r}$ i a.}

\section{Monogynia.}

718. Eschscholzia californica. In Anlagen.

719. - croccea. In Anlagen.

720. M a g nolia discolor. In Gärten.

C 721. Chelido ni u m m a us. 5-9. Häufig an schattigen Stellen, Mauern, Heken und Schutthaufen.

722. Papaver rhaeas. 6-7. In Kornfeldern im Wigger-, Suren-, Winenund Hitzkircherthal, selten im Amt Luzern.

723. - d u bi u m. 6-7. An gleichen Orten. Um Ettiswil häufiger als rhaeas. Im Surenthal herrscht dieses vor, im Hitzkircherthal sind beide gemischt.

724. - s o m nif erum. 7. In Gärten.

725. - orientale. dito.

726. - alpinum. Am Pilatus im Geschiebe der Esel- und Ringfluh häufig.

727. Actaea spicata. 5-6. In dunkeln 
Waldungen zerstreut. Bei Luzern am Gütsch, beim Löwendenkmal, an der Renggbrücke, im Rothenburgertobel, Schiltwald an der Reuss, zwischen Sursee und Mauensee, bei Dierikon, über Greppen auf Rigi, im Egelwald bei Triengen, am Enziloch bei Luthern.

728. - racemosa. 7-8. In Gärten.

729. Tilia grandifolia. 5-6. In Anlagen um Luzern häufig, zerstreut am Rigi, auf Hügeln hin und wieder, vor dem Wirthshaus auf Bramegg.

730. - parcifolia. 6. Auf Rigi, ebenso an freien steinigen Orten ob Seeburg, bei Geuensee und Dagmarsellen.

731. Helian themum vulgare. 6-8: Nicht selten aut Triften, an Waldrändern der Ebene und Berge bis hoch in die Alpen. Bei Hildisrieden, Neudorf, Muinster, Rickenbach, Wetzwil, im Hitzkircherthal, bei Weggis, auf Rigi und Pilatus, am Stricktossen auf Schratten.

,a. - vulg. tom entosum. An gleichen Orten.

„b. - vulg. hirsutum. dito.

"c. - - glabrum. dito. 
731.d. Helianthemumóv ulg. grandiflorum. Gleiche Standorte.

732. - o elandicum. 7-S. Auf unsern höhern Bergen häufig. Am Pilatus auf Rossegg, Esel, Tomlishorn, Widderfeld, ferner am Schimberg, Nesselstock, Rothhorn, Schratten n. Schafmatt.

733. N y mp ha ea alba. 7-8. In Seen, Weihern, stehenden Wassern und Sumpfgräben der Ebene utberall. In Lu-• zerner- und Rothsee, in der Rhone und im Lowerzersee.

734. - l u te u m. 7-8. An denselben Stellen. 735. - cynanea. Bisher einzig in der Schobinger'schen Gärtnerei gezogen.

\section{Digynia.}

736. Pa eonia officinalis. 4-5. In Landgärten.

737. - suffruticosa. 5-6. In Gärten.

\section{Trigynia.}

738. Delphinium ajacis. 7-8. In Gärten nnd auf Kirchhöfen häufig.

739. - elatum. 6-7. dito. 
740. A c conitum Hapellus. 7-9. In der Ebene, auf Bergen und Alpen nicht selten. Im Moos bei Büron, in den Stöcken, im Schongauerwald, im Wiholz bei Nendorf, auf Rigi, Napf, Pilatus, im Sörenberg bis Nesselstock, Tagweid, Rothhorn, Schratten.

741. A conitum commarum. 7-8. Am

Nesselstock, Rothhorn u. Schratten, auch in Gärten.

742. - intermedium. In Gärten.

743. - l y c o kto n u m. 6-7. In der Ebene und bis in die Voralpen, an schattigen Stellen niclit selten. In Rifigund Surseerwald, Egelmoos und Eiholz im Surenthal, Horbachwäldli bei Kaltbach, bei Rippertschwand, im Wald beim Rothen, auf Rigi, Pilatus, Napf, bei Bridern am Schimberg, im Emmenthal auf Schratten, im Walde beim Rotzloch.

\section{Pentagynia.}

744. A quilegia vulgaris. 5-6. Ueberall an Hecken und Gebüschen, in Wäldern. An der Krummenfluh neben der Reuss, im Schachenwald, zwischen Weggis und Vitznau. 
745. Nig ella da ma s ce na. 6-7. In Gärten. 746. - nana pleno. In Gärten.

\section{Poligynia.}

747. Liriodendron tulipifera. 6-7. In Anlagen bei Luzern.

748. $\mathrm{Cle} \mathrm{matis} \mathrm{vita} 1 \mathrm{~b}$ a. 7-8. In Hecken u. Gebüschen bis zur Buchengrenze nicht selten.

ᄁa. - vit. c o e rulea. In Gärten.

749. - viticella. 6-7. dito

750. Thalictrum aquilegifolium. 6-7. An Hecken, Wald- und Grabenrändern der Ebene und Berge bis zur Tannengränze nicht selten. Zwischen Horw, Kriens und Luzern hätfig, im Surenthal bei Sursee, bei Büron am Hexenbächli, bei Geuensee, Mauensee, St. Urban, auf Bürgen, Rigi, Pilatus, Schafmatt, Tag: weid.

751. Thalictrum min uls. 7-8. Am Pilatus, an der Holzfluh häufig, vom Birchboden bis Gemsmätteli, längs der steilen Fluh.

352. - g l a u c u m. 7. In Gärten nieht selten, besonders in Dagmarsellen. 
753. Anemone nemarosa. 3-4. An Hecken, Wiesen, Gebüschen und Wäldern iiberall, von der Ebene bis zur Tannengrenze.

754. - nareissiflora. 6-7. Von der Tannengrenze an auf grasigen Plätzen nicht selten. Am Rigitossen, am Pilatus im Nauen, auf u. am Klimsenhorn, zwischen Bründlen und Oberalp, anf Feuerstein, ob Sihlwängen an der Schratten, am Nesselstock auf Tagweid.

755. - hortensis. 5-8. In Gärten.

756. - ranunculoides. 5. Selten. Zwischen Winikon u. Staffelbach, zwischen Beckenried und Buoch.

757. - vernalis. 5-6. Auf Pilatus am Fusse des Esels, Mattgrat, Steiglishaupt und Widderfeld, am Feuerstein.

758. - alpina. 5-7. An steinigen Orten der Alpen und Voralpen. Auf Rigi und Pilatus, vom Klimsenhorn bis Esel, von Briindlen bis Widderfeld, am Schimberg, Schafmatt, Nesselstock, am Stanser- und Buochserhorn. 
759. Anemone pulsatilla. 3-4. Zwischen Adelboden und Zofingen.

760. - sine nomine. In Gärten.

761. Hepatica triloba. 3-4. An steinigen, buschigen Abhängen und in Wäldern. Bei Littau am Wege nach Dorenberg. Massenhaft am Fusse des Rigi, von Greppen bis Vitznau, im Schachenwald und Obernau ob Kriens, am Lopperberg und Bürgen. In Gärten die gefüllte Form.

762. Ficaria ranunculoides. 3-5. Ueberall bis über 4000 Fuss Höhe.

763. Ranunculus divaricatus. 7-8. In stehenden Wassern. Am Luzernersee, im Rifigweiher, bei Wauwil, in Suren- und Hitzkircherthal.

764. - fluitans. 6-8. Im fliessenden Wasser. An der Reuss bei Luzern und Inwil, an der Rhone im Hitzkircherthal, in der Sure, zwischen Mauensee und Wauwil, bei Ettiswil, Wèggis, Küssnacht und Seewen.

765. - heterophyllos. 7-8. An der Sure bei Sursee $\mathbf{u}$. im Rifigweiher, selten. 766. - aconitifolius. 4-5. An Bächen u. auf nassen Wiesen der Ebene, Berge 
und Alpen, bei Eschenbach u. Würzenbach, am Bach bei Seehiisli, bei Wetzwil. Aut nassen Wiesen des Pilatus nicht selten, bis Tagweid und Maisee am Rothhorn.

767. Rannnculus platanifolius. 5-7. In schattigen Waldungen der Voralpen. Am Pilatus im Aufsteigen nach dem Tellenpfad und Brïndlen, hinter Sörenberg im Staffelwald, im Steinebachtobel bei Horw.

768. - alpestris. 5-7. Nach dem Schmelzen des Schnees auf allen unsern Alpen. Auf Rigi, Pilatus, Schimberg, Schratten, Napf und Enzifluh bis über die Tannengrenze.

769. - lingua. 6-7. Am Ufer der See'n, in Gräben und stehenden Wassern. Am Luzerner- und Rothsee, bei Sempach, Mauensee, Wauwil, im Hifzkircher- und Surenthal.

770. - flammula. 6-9. Auf feuchten Wiesen und sumpfigen Stellen der Ebene bis zur Tannengrenze.

771. - reptans. 7-8. An sandigen, fenchten Stellen an der Halde bei Luzern und am Baldeggersee. 
76. Ranunculus arvensis. 5-7. In Getreideäckern fast überall.

773. - sceleratus. 6-9. Am Luzernersee längs der Halden und am Sempachersee.

774. - a cris. 5-7. Ueberall auf Wiesen der Ebene, Berge und Alpeu.

,a. - - angustifolius. Ueberall, wie oben.

b. - - latifolius. Ueberall, wie oben.

775. - l a nuginosus. 6-8. In Wäldern u. Gebüschen der Ebene und Vorberge häufig. Bei Luzern am Gütsch, im Halti- u-Bireggwald, Rifig, Rothenburgertobel, bei Maunensee, in der Ehrlosen, auf Rigi, Pilatus, im Aufsteigen nach Bründlen und Tellenpfad, zwischen Ennethorw n. Kriens, im Aufsteigen zum Hergottswald.

776. - I y c o c to n ifolius. 7-8. In der Bergregion. Zwischen Hitzkirch u. Lieli.

777. - a uricomus. 5-6. Im Hitzkircherthale bei Aesch, im Erlengebiisch, gegen den See, zwischen Rüdikon und Hämikon beim Würzenweg, zwischen Schongauer Brandholz u. dem Miiswangermoos, im Eichwald bei 
Triengen, im Horbachwäldli bei Kaltbach, zwischen Aesch und Fahrwangen.

777 a. Ranunculus auricomus lobatus. An den gleichen Stellen.

"b. - auricomus heterophyllus. An obigen Stellen.

778. - montanus. 6-7. Auf allen unsern Bergen, Vorbergen und Alpen. Vom Rigi u. Naz̧ iiber die Entlebucherberge bis zur Schratten, dem Rothhorn und der Pilatuskette, bisweilen im Sande der Bergbäche.

ra. - - grandiflorus. Am Buochserhorn.

779. - villarsii. Im Nauen am Pilatus, auf begraseten Stellen zwischen Klimsenhorn und Kriesiloch, bei Maisee an Rothhorn.

780. - repens. 5-9. Gemein an Wegen, in Aeckern, auf fettem Boden und an Gräben der Ebene und Berge bis zur Tannengrenze.

781. - nemorosus. 6-8. In Hecken und Gebuischen, auf trockenen Matten der Ebene und Berge bis hoch in die Alpen häufig. Um Luzern an der Halden bis Meggen und Weggis, bei Maisee am Rothhorn. 
F82. Ranunculus bulbosus. 5-8. Um Luzern häufig in Sümpfen bei Meggen etc., am Fusse des Rigi von Weggis bis Gersau.

, a. - bulb. augustifolius. Ebenso.

,b. - - latifolius. Ebenso.

783. Adon is vernalis. 4-5. In Gärten.

784. - aestivalis. 7-8. In Gärten.

785. 0 altha palustris. 4--8. Ueberall an Bächen, Gräben, Sümpfen und nassen Wiesen, von der Ebene bis hoch in die Alpen.

786. Hell eb orus niger. 12-3. In Gärten. 787. - viridis. 3-4. Selten. Im Walde ob Lieli, innert den Mauern der Musegg zu Luzern, zwischen Nöllithor und dem Gässli, am südlichen Abhange des Bürgen am Rande des Friedhöflers bei St. Antoni, am Pilatus, in der Nähe des Seelisberger Kurhauses.

788. Trollius europaeus. Häufig auf feuchten und sumpfigen Wiesen der Berge und Voralpen. Auf Rigi, vom Langwasen ob Kriens bis zur Spitze des Esels am Pilatus, auf Blasen bei Flühli bis Emmenthalfluh an der Schratten, vom Sörenberg bis Tag- 
weid am Rothhorn, ob Herrgottswald gegen Neualp bis Eigenthal.

\section{D id y in a mi a.}

\section{Gymnospermia.}

789. Salvia officinalis. 6-7. In Gärten. 790. - glutinosa. 6-7. An schattigen und steinigen Orten. Längs der Reuss und Emme, bei Weggis und Vitznau, im Schachenwalde bei Kriens, im Wiggern- und Surenthal, bei Wikon.

791. - pratensis. 5-7. Auf trockenen Wiesen. Von Gelfingen bis Aesch, an der krummen Fluh bei Luzern, von der Emmenbriicke bis Emmen, bei Kriens, Udligenschwil, Dagmarsellen, Reiden, Hochfluh, im Surenthal, am Pfenningerhubel bei Triengen.

792. - verticillata. 7-8. An steinigen u. waldigen Stellen. An der Strasse zwischen Sursee und Tann, bei Hot- 
stetten, beî Triengen im Dorf, Winikon im Flïglisried.

793. Salvia sclarea. 7. In Landgärten. 794. - indica. 7-9. In Gärten. 795. - l e onuroides. 7-9. In Gärten. 796. - splendens. 7-9. In Gärten. 797. - fulgens. 7-9. In Gärten. 798. - polphyanta. 5-7. In Gärten. 799. - Lycopus europaeus. 6-S. An feuchten Stellen, Wegen und Gräben nicht selten. Um Luzern, Meggen und Weggis, an der Emme im Galgenwald, bei Hildisrieden, auf der Udligenschwilerallmend und im Surenthal.

800. Rosmarinus officinalis. 5-7. In Landgärten.

801. Lavendula spica. 7-8. In Gärten. 802. M arrubium vulgare. 6-8. In Gärten und verwildert an Schutthaufen. 803. Lamium maculatum. 5-10. Leber- ' all an Wegen und Hecken. 804. - albu m. 5-10. Gleiche Standorte. 805. - purpureum. 3-10. Ebenso. 806. Galeobdolon luteum. 5-6. Häufig an Wegen, Hecken und schattigen: 
Orten der Ebene bis zur Buchengrenze.

807. Ballota foctida. 6-9. Hin und wieder an Hecken und Schutthaufen. Bei Oberkirch, Sursee, Geuensee, Büron, Triengen, Hochdorf und Ermensee.

808. Stachys sylvatica. 7-8. Häufig an Hecken, in Wäldern und schattigen Orten der Ebene und Berge.

809. - alpina. 7-8. In der Berg- u. Alpenregion, an offenen und waldigen Stellen hänfig. Vom Eichberg bis Gschweich, bei Schenkon, Sursee, Winikon, Rütihof, Tann, Wetzwil, zwischen Schwarzenbach u.Mosen, am Rotherbad, zwischen Wohlhausen u. Menzberg, im Gütschwald bei Luzern, zwischen Malters und Schwarzenberg, Tellenpfad am Pilatus, vom Brüdernmätteli bis Grund am Schimberg.

810. - palustris. 7-8. An feuchten Stellen nicht selten. Am Luzernersee, im Suren- und Wiggerthal.

811. - l an a ta. 6-8. In Gärten.

812. - annua. 7-8. In Stoppelfeldern häufig. 
813. Sta ehys recta. 7-8. An kiesigen Stellen in Gebuischen. Zwischen Eich und Schenkon am See, am Pilatus?

814. Gal e o p sis la da num. 7-8. In Halmfeldern häufig.

815. - ochroleuca. 7-8. In Getreideäckern. Bei Dagmarsellen, Reiden, Pfaffnau, Grossdietwil, St. Urban, Luthern, Triengeu, zwischen Seeburg und Meggerhorn.

816. - tetrahit. 6-10. Häufig an Wegen und Gräben, in Feldern und abgehauenen Wäldern.

817. L e onurus cardiaca. 6-8. Nicht häufig. Bei Schenkon, Wikon, Buchs an Hecken und steinigen Stellen.

818. Glechoma hederacea. 4-5. An

Wegen, Hecken und Gebüschen der

Ebene überall bis zur 'Tannengränze.

819. Betonica officinalis. $7-8$. An Waldrändern, in lichten Gebüschen und trockenen Stellen, nicht selten. "a. - off. alba. Bei Luzern am Gütsch. 820. Origanum vulgare. 7-8. An trocknen Hügeln, Wegen und Hecken der Ebene und Berge häufig.

821. - majorana. 7-8. In Landgärten. 
822. Nepeta eataria. 7-8. Bei uns selten. An der Burgruine bei Rothenburg, auf Lugisdorf bei Luthern.

823. Hy sopus officinalis. 7-8. In Landgärten.

824. Satureia hortensis. 7-9. In Gärten. 825. Prunella vulgaris. 6-7. Ueberall auf Wiesen und Weiden der Ebene bis zur Tannengränze.

826. - grandiflora 7-8. In der Bergund Voralpenregion häufig. Auf Rigi, Napf, Pilatus, Schratten, von Sörenberg bis Nesselstock. Auch in der Ebene, so am Lindenberg.

827. Clinopodium vulgare. 7-8. An trockenen steinigen Stellen iiberall, an Hecken, in Gebüschen der Ebene und Berge bis zur Buchengränze.

828. Scutellaria galericulata. 7-8. An

Wassergräben u. Sümpfen der Ebene nicht selten. Am Luzernersee, an der Reuss und Emme, im Surenthal bei Aesch, Ermensee und Wauwil.

829. Thymus serpillum. An trockenen, magern Hügeln und Triften der 
Ebene und Berge bis hoch über die Tannengränze.

829. a. Thymus serpillum $\mathrm{ch}$ a maedrys. An den gleichen Standorten.

"b. - angustifolia. Wie oben. 830. Ca la $\mathrm{m}$ in tha a cinos. 6-8. In Feldern und Aeckern bei Geuensee, Büron, Sursee, am Sempachersee, bei Hochdorf, Meggen und Kiissnacht.

831. - alpina. 7-8. Ueberall auf unsern Bergen und Alpen. Auf Rigi, Napf, Schafmatt, Rothhorn, Pilatus, im Geröll der Alpbäche bis in die Ebene. 832. - officinalis. 8-9. An steinigen, rauhen Stellen der Ebene und Hiigeln hin und wieder. Von Geuensee bis Triengen, bei Büron an der Burg, zwischen Sursee und Wikon, am Hafendeckel, bei Uffhusen, an der Hochfluh, zwischen Altwis und Hämikon, zwichen Weggis u. Vitznau, am Lopper.

833. M elissa officinalis. 7-9. In Gärten. 834. Melitis meliss ophyllum. 4-5. Hin und wieder. Bei Schenkon an der alten Burg, zwischen Triengen und Rütihof im Risibühl, am Kreuzhubel zu Dagmarsellen. 
835. Verbena of ficinalis. 6-9. Gemein an Hecken und Wegen, doch nicht iiber die Grenze der Wallnussbäume. 836. - hybrida. In Gärten. 837. - defiance. \begin{tabular}{l|l}
838. & - mahonettirubra \\
839. & - melindres
\end{tabular} In Gärten. 840. Browallia viscosa. In Gärten. 841. Chelone glabra. Ebenso. 842. Lephospermum scandens. Ebenso. 843. Penstemon durmondii. Ebenso. 844. II entha sylvestris. 7-8. Häufig in

Wäldern, Waldrändern, Strassen, Gräben, an trockenen wie an feuchten und sumpfigen Stellen.

„a. - sylvest. nivea. An gleich. Stellen.

nb. - nemorosa. Ebenso.

nc. - - grandifolia. Ebenso. 845. - piperita. 7-9. In Gärten. 846. - viridis. 7-9. In Gärten, auch verwildert.

847. - sativa. 7-9. In Landgärten. 848. - arvensis. 7-9. Häufig als Unkraut in Feldern u. Aeckern, besonders auf lehınigem Boden.

849. - a quatica. 7-9. Auf feuchten nassen Stellen der Ebene und Berge. "a. - - hirsuta. Ebenso. 
849. b. Mentha aquatica-rivularis. An gleichen Stellen.

850. - crispa. 7-8. In Gärten.

851. - pulegium. An sumpfigen Stellen im Gütschwalde bei Luzern, selten.

852. Ajuga reptans. 4-6. Auf feuchten Wiesen der Ebene bis in die $\mathrm{Al}$ pen häufig.

„a. - rept. alba. Am südlichen Abhange des Sonnenberges.

853. - genevensis. An frockenen, etwas sandigen Stellen. Am Sempachersee, zwischen Eich und Schenkon, bei Büron, Littau, Uffikon bis Reiden, Wauwil bis Nebikon.

854. - piramidalis. 6-7. An trockenen Stellen bei Schenkon, an den Sandhügeln von Dagmarsellen bis Wikon, in der Waldwiese iiber dep obern Stermel.

855. - chamaepitys. 5-9. Im Surenthal bei Schenkon, Büron, Genensee, Winikon, Triengen, Kulmerau, bei Uffikon, Schongau und Aesch, um Hochdorf, zwischen Ibenmoos und Günikon.

/ 856. Teucrium scorodonia. 7-8. An trockenen, steinigen Orten, Hïgeln, 
Weg- u. Waldrändern bis zur Wallnussgränze häufig. Um Luzern, bei Adligen- n. Udligenschwil, am Fusse des Rigi von Weggis bis Seewen.

857. Teucrium montanum. 6-9. Am Fusse unserer Vorberge und Alpén. Am Rigi, Pilatus, Lopper nicht selten bis an das Seegestade, an der Schafmatt und auf der Rüche im Kragen.

858. - chamaedrys. 7-9. An sonnigen, felsigen Stellen am Pilatus gegen Hergiswil zu, am Lopper, am Fusse des Rigi.

859. - botrys. In Fruchtäckern nicht selten. Am Sempachersee, von Sur- see bis Triengen, von Eschenbach bis Hitzkirch, um Dagmarsellen. 860. - scordium. 7-8. Im grossen Moos bei Triengen.

\section{Angiospermia.}

861. Catalpa syringaefolia. 7-8. In Anlagen um Luzern.

862. Utricularia vulgaris. 7-8. In Sumpfgräben nicht selten. Im Suren- und Hitzkircherthal, am Luzer- 


\section{$-130-$}

nersee im Moos und an der Halden, zwischen Staffeln w. Emmenbrïcke, zwischen Ebikon und Root, im Rifigweiher, bei Buetigen, bei Mauensee, Wauwil und den Weihern von St. Urban, auf Sumptstellen bei Goldau.

863. Utrecularia minor. 6-7. Im Surenthal in Gräben. Bei Wanwil in den Seelöchern zwischen Wauwil und Egolzwil.

864. Calce olaria. Diverse Varietäten. In Gärten.

865. Pinguicula vulgaris. 5-6. Häufig in feuchten Wiesen und an sumpfigen Stellen. Auf der Horwer-Allmend, am Luzerner-, SempacherRoth- und Baldegger-See, im Kapf bei Büron. In Bergsümpfen bis hoch in die Alpen des Rigi und Pilatus. 866. - grandiflora. Am Pilatus hin und wieder.

867. - alpina. 5-8. Auf allen unsern Bergen. Auf Rigi, Napf, auf den Entlebucherbergen, an der Pilatuskette bis zum Rothhorn, im Rothenburger Bachtobel.

868. Gratiola of ficinalis. Bei Wauwil. 
869. 0 robanche minor. Häufig als Unkraut schmarotzend auf den Wurzeln des Klee's. Um Sursee und im Hitzkircherthal.

"a. - min. procerior. Gleiche Standorte. 870. - c a ry o phyll a cea. 6-7. Am Rigi hin und wieder, beim kalten Bad. Auf Voralpen. Auf der Rengg am Pilatus.

871. - epithy mn m. 7-8. Meist auf Wurzeln von Thymus serpillum. Bei Littau, auf Menzberg.

872. - caerulea. 6-7. Auf den Wurzeln von Achillea millefol. Um Luzern, bei Littau, Rueggifingen, am Schlichtenwäldli, Sempach zu.

873. - romosa. 8-9. Auf Hanfwurzeln im Surenthal hin u. wieder, bei Buchs.

8i4. L athraea squamaria. 4-5. In trockenen Wiesen u. Wäldern, besonders unter Nussbäumen. Im Schilt- u. Galgenwald an der Reuss, häufig an den Ufern des Vierwaldstättersee's, bei Greppen, Weggis, Vitznau, von Meggen bis Küssnacht, bei Luzern an der Halden, am Wege nach Kriens, bei Stafteln, zwischen Mosen und Beinwil. 

875. Tozzia alpina. 6-8. An feuchten
felsigen Stellen der Alpen und Voralpen. Auf Rigi unter Schneealp, zwischen Dächli und Kulw, am Pilatus im Aufsteigen nach Bründlen und Tellenpfad, an Steiglisalpliicke und Oberalp, am Schimberg, am nördlichen Abhange des Nesselstockes.

876. Pedicularis sylvatic a. 6-7. In Sümpfen der Berge und Voralpen bis zur Tannengränze. Um Luzern auf dem Gütsch, bei St. Karli, Meierskappel, Riffigweiher, zwischen Dorenberg u. Sidlern, von Langwasen bis Mühlemä̈̈̈s, auf Neualp am Fusse des Napf, auf Gürmseh, von der Rüche bis Guggern am südlichen Fusse der Schafmatt, am Rigi bei Küssnacht und Goldau.

"a. - sylvat. a lba. Auf Langwasen

bei Kriens.
877. - palustris. 5-6. Häufig in Siim. pfen der Ebene u. Berge. Am Luzernersee, bei Wauwil, im Surenthal. unsern höhern Bergen, an grasreichen Stellen unter u. über der Tan- 
nengränze. Auf Rigi bis Kulm, auf Napf, Pilatus, Schimberg, Schafmatt, Feuerstein, Nesselstock, Schratten, Rothhorn.

879. Pedicularis versicolor. 6-8. Am Pilatus vom Klimsenhorn bis Esel u. Tomlishorn, Bründlen, Gemsmätteli, auf Schafmatt, Giirmsch, Feuerstein, Salzboden an der Schratten auf Nesselstock bis Rothhorn.

880. Pe dicularis foliosa. 6-8. Auf Alpen und Voralpen bis iiber die Buchengränze an steinigen n. grasigen Stellen. Auf Rigistaffel, Känzeli, Dossen, am Pilatus im Aufsteig nach Bründlen, anf Tellenpfad u. Klimsenhorn, anf Nesselstock u. Tagweid bis Maisee, Schimberg, Emmenthal an der Schratten, Bargelenweng auf Schafmatt.

881. Antirrhinum majus. 6-8. An den Mauern alter Schlösser. Bei Wikon und Hohenrein verwildert. In Gärten zur Zierde.

882. L i n a ri a v u lgaris. 6-8. Häufig an trockenen, steinigen Stellen. Am Sempachersee, zwischen Eich und Schenkon, bei Sursee, Mauensee, 
im Surenthal, an der Emme, in Gärten und auf Kirchhöfen.

883. L in a ria minor. 7-9. Auf Aeckeru häufig.

884. - alpina. Im Geröll der Alpen und Voralpen nicht selten. Am Pilatus an der Ringfluh, Eselsfluh, Kastelenalp, am Nesselstock, Napf, Stächelegg und Enzi, bei Sihlwängen und Emmenthal an der Schratten, im Emmenbett bis Schüpfheim und bis Emmenbrücke bei Luzern, im Rümlingbett im Eigenthal.

\85. - c y mbalaria. 6-10. An alten Mauern häufig. Bei Luzern, Sempach, am Fusse des Rigi, bei Küssnacht, Weggis und Gersau.

\886. - spuria. 7-9. In Fruchtäckern. Bei Geuensee, Hochdorf und Rain.

887. - el atin e. 7-9. In thonhaltigen Aeckern. Am Sonnenberg, bei Littau, von Emmen bis Gisikon, bei Hochdorf, im Surenthal, bei Sursee, Schenkon, Uffikon, Nebikon, Pfaffnall.

888. - I a tif o li a. In Gärten. 889. - trio rni. In Gärten. 890. S erophularia nodosa. 6-9. An 
Hecken und Gräben, in Wäldern u. an steinigen Abhängen häıfig.

891. S e rop hu laria aquatie a. 6-9. An Sumpf- u. Wassergräben der Ebene bis zur Buchengrenze zerstreut. An der Halden und an der Zürcherstrasse bei Luzern, zwischen Bärtischwil und Rain, im Surenthal.

\$92. D ig italis p ur pur e a. 6-7. Häufig in Gärten, verwildert in der Nähe des Hergottswaldes.

*a. - purpuria fl. a l b a. Gleiche Standorte.

893. - g r a n d if 1 o r a. 6-8. In der Bergregion bis $3000^{\prime}$ Höhe. Auf Rigi gegen den Waldbruder, Urmistock u. bei Gersau, am Bürgen u. Lopper, am Pilatus unter Bründlen und Tellenpfad, zwischen Pfyfferswald u. Rothstock,von der Brïdern bis Grund am Schimberg, auf den Höhen von Reiden und Dagmarsellen.

894. - 1 u t e a. 6-8. Gleiche Standorte. An dem Rigi häufig, von Weggis bis Felsenthor, und von Weggis über Vitznau u. Gersau bis Seewen.

895. Erinus a $l p$ in us. 6-8. An steinigen, felsigen u. grasigen Orten, auf 
allen unseren Bergen u. Alpen. Auf Rigi und Napf, an der ganzen Pilatuskette, bis Rothhorn, auf Schrattenhỏhe und Schafmatt, bei Lützelau bis an den See herab.

896. Rhinanthus crista gallii. 5-8. In feuchten Wiesen, Aeckern und gebauten Orten als Unkraut.

a. - - minor. 5-8. Häufig in Sumpfwiesen, besonders zwischen Stansstad und Rotzloch.

, b. - - - hirsutus. Mit dem gem. Hahnenkamm zerstreut.

, c. - - major. An gleichen Standorten bis zur Tannengränze, besonders auf den Sumpfwiesen des Luzernersees. So auf der Halden und auf der Horwerallmend.

897. Melampyrum pratense. 6-7. In Wäldern, an Hecken u. auf magera Wiesen häufig.

898. - sylvaticum. 7-8. In Wäldern der Vorberge bis zur Buchengränze. Am Rigi u. Pilatus, auf Blasen bei Fluihli. 899. - arvense. 6-7. In Getreideäckern häufig. Im Suren-, Wigger- u. Winenthal, bei Hochdorf u. Schongau. 
200. Melampyrum cristatum. 6-7. In Getreideäckern, doch selten. Bei . Neudorf, Münster und Hildisrieden. 901. Bartsia alpina. 6-8. Von der Buchengränze bis zı den höchsten Spizen unserer Alpen. Auf Rigi, Napf, Bäucheln, Pilatus, Feuerstein und Rothhorn.

* a. - alp. parviflora. 6-8. Gleiche Standorte.

902. Euphrasia of ficinalis. 7-8. Ueberall auf Aeckern $u$. Wiesen der Ebene bis in die Alpen.

303. - alpina. 7-8. Auf den Alpen hin und wieder. Auf Emmenthal an der Schratten, auf Trokenmatt am $\mathrm{Pi}$ latus.

104. - minima. 8-9. Häufig auf Rothhorn, Schratten, Pilatus, auf Trockenmatt, Mattalp und Tommli, Rigikulm.

a. - odontites. 6-9. In lehmigen Aekern häufig, an Hecken und Bächen bei Seewen.

,b. - - verna. Gleiche Standorte.

$\rightarrow$ c. - - scrotina. Ebenso.

905. Schizanthus retusus albus. In Gärten.

906. Cuphea eminens. In Gärten. 


\section{Tet a d y n a mia.}

\section{Siliculosae.}

907. Rapistrum rugosum. Um Sursee, irs Wiggerthal zerstreut.

908. Biscutella laevigata. 7-8. Am Pi-

latus zwischen Kriesiloch und Esel, an der Ringfluh, auf Schrattenhöhe, Risetenfluh, in Grön auf Schafunatt. 909. - alpestris. 7-8. Aw Pilatus auf Tommlisegg, Ringfluh und Holzfluh, auf Nesselstock und Schratten.

910. Is atis tinctoria. 5. Zwischen Hertenstein und Weggis, an sonnigen Abhängen längs dem See vereinzelt. In Esparsettenfeldern. Bei Sursee längs der Eisenbahn, an der Kirchhalden bei Geuensee, im Rain.

911. Lepidium campestre. 6-7. Auf Aekern häufig.

912. - sativum. 5-6. In Gärten, verwildert auf Schutthaufen.

913. I beris a mara. 7-8. In Getreideäckern. Von Sempach bis Triengen, bei 
Eschenbach, Hochdorf bis Schongau, Münster, Rickenbach, Ettiswil.

914. I ba is u mbellata. 6. In Gärten.

915. - semperflorens. Ebenso.

916. - perephiana. Ebenso.

917. Thl aspi arvense. 5-6. Auf Feldern und Aeckern der Ebene und Berge häufig. Um Luzern, Sursee, Hochdorf, im Eigenthal, am Rigi zwischen Arth und Dächli.

918. - perfoliatum. 5-6. Auf Aeckern Von Sempach bis 'Triengen, bei Sursee, Knutwil, Winikon, Eschenbach, Hochdorf und Gerlischwil.

919. - montanum. Zwischen Hergottswald u. Eigenthal. Am Pilatus?

920. Hutchinsia alpina. 4-6. Im Geröll und an Alpbächen häufig. Am Pilatus auf Kastelnalp, Klimsenhorn, Bründlen, Mittaggipfi, am Rümling bis Eigenthal, Schimberg, Scliafmatt, Emmenthalfluh an der Schratten, Nesselstock.

921. - rotundifolia. 6-8. Im Geschiebe der Berge. Am Pilatus im Nauen, auf Kastelnalp, Bründlen, Esel und Ringfluh, auf Schratten und Rothhorn. 
922. Capsella bursa pastoris. Fast das ganze Jahr uiberall in Feldern, an Wegen und Schutthaufen.

923. C o chlearia of ficinalis. 5. In Gärten. 924. - armoracia. 6-7. Ebenso.

925. saxatilis. 7-8. Auf allen Alpen uVoralpen. Auf Pilatus, Schimberg, Schratten Nesselstock, am Blattigsteg hinten im Eigenthal. Auf Felsblöcken und in Steinritzen.

926. Camelina sativa. 6-7. Hie und da an gebauten Stellen, z. B. im Surenthal.

,a. - sat. piloaa. Gleiche Standorte.

927. - dentata. 6-7. Ebenso.

828. D raba verna. 3-4. Auf Aeckern und trockenen Hïgeln bei Luzern, Meggen, Sursee, Eschenbach und Mosen.

929. - aizoides. 5-6. An felsigen Orten. Auf Rigi, Pilatus, Nesselstock, Schafmatt und Schratten.

930. - to mentosa. 7-8. In Felsritzen des Pilatus, ob Bründlen u. Staffel, am Mittaggipfi, Steiglishaupt, Esel und Kriesiloch, auf Schafmatt, Feuerstein, Stricktossen und Rothhorn. 
931. Draba incana. 6. Am Pilatus, selten, nahe dem Mondmilchloch.

932. Petrocallis pyrenaica. 5-6. Am Heftiboden auf Schratten, am Pilatus auf Ringfluh, Eselsfluh u. Oberhaupt.

933. Alyssum calycinum. 5-6. Im Hitzkircherthal bei Aesch, Dagmarsellen. 934. - montanum. 5-6. An sandigen Stellen bei Dagmarsellen und auf der Hochfluh bei Reiden.

335. - saxatile. In Gärten.

936. Lunaria biennis. 4-6. In Gärten. 937 - rediviva. 6-7. Am Pilatus an der Nordseite der Tellenpfadlücke, östl. gegen der Fluh zu; hinten im Sörenberg an der Gränze von Obwalden.

\section{Siliquosae.}

938. Raphanus sativus. 5-6. In Gemísegärten.

"a. - vulgaris. Ebenso.

„b. - radicula. Ebenso.

939. - raphanistrum. 6-7. Unkraut in Getreideäckern. 
940. Nasturtium officinale. 6-7. An Gräben, Bächen, stehenden Wassern mit Quellwassern überall.

941. - palustre. An sumpfigen Stellen. Am Luzernersee, an der Halden bis Küssnacht, bei Ebikon, Rathhausen, in Rifig, im Surenthal u. bei Wauwil. 942. - sylvestre. 6-7. Um St. Urban, auf feuchten Stellen, nicht häufig. 943. Turritis glabra. 5-7. Im unteren Theile des Hitzkircherthals, an trockenen, steinigen Stellen. Bei Aesch bis Meisterschwand, an der alten Strasse zwischen Geuensee u. Büron, bei Willisau, Dagmarsellen, gegen Luthernthal und Hochfluh, zwischen Zuswil und Grosswangen, auf dem Hubel zu Winikon.

944. Diplotaxis tenuifolia. 6-9. Beim Wikerschlosse.

945. Mathiola incan a. 6-8. In Gärten. 946. Hesperis matronalis. 5-6. In Gärten, auch verwildert.

947. - nivea. In Landgärten.

948. Dentaria digitata. 5-7. In Bergwäldern u. Töbeln. Am Gütsch und in Wiirzenbach bei Luzern, a $m$ Schattenberg bei Kriens bis zur Rengg, 
am Wege nach Brünlen und Tellenpfad am Pilatus, auf Rigi, von Art bis Klösterli, am Rotherberg, Wiirzenweg bei Hämikon, im Tobel bei Rothenburg.

949. Dentaria pinnata. 5-6. Im Walde bei Rigiklösterli, am Feuerstein?

950. Cardamine pratensis. 4-5. Auf Wiesen gemein bis in die Voralpen. "a.- prat. alba. Gleiche Standorte. 951. - hirsuta. 5-6. An gebauten und ungebauten Stellen hänfig.

952. - a mara. 4-5. In Gräben mit Quellwasser, in feuchten Wiesen der Ebenen bis zur Tannengränze.

"a. - amara hirta. Gleiche Standorte. 953. - impatiens. 5-7. An felsigen Stellen der Berge und Voralpen, u. von daher kommenden Bäehen. Am Rigi, von Weggis bis Gersau unter Wil, im Zingel bei Seewen.

954. - resedifolia. 6-8. Am Pilatus beim Schneeloch, zwisehen Oberalp und Mittaggipfi.

955. Cheiranth us cheiri. 5-6. In Gärten. 956. A rabis thaliana. 4-9. Auf Felderu und an Wegen häufig.

957. - hirsuta. 5-6. In der Ebene und 
auf den Bergen. $\mathrm{Zu}$ Büron an de: Burg, bei Fohenrain, zwischen lialdegg und Hochdorf, bei Schongau in Brandholz, am Fuss des Rigi bei Vitznau, und des Pilatus, am Biirgen und Lopper, am Kragenberg.

957. a. A rabis hirs. sagittata. Dieselben Standorte.

"b. - - incana. 5-6. Zwischen Trokenmatt und Mittaggipti.

958. - alpina. 5-8. Im Geschiebe $1 . \mathrm{Ge}^{-}$ röll unserer Berge häufig. Auf Rigi, Pilatıs, Sörenberg, Nessclstock, Rothhorn, Schafmatt, Schratten. Am Nöllithörli innert der Ringmauer von Luzern. Von Bergbächen bis in die Ebene herabgesehwemmt. An der Halden bei Luzern.

959. - pumila. 5-6. In Felsspalten unserer höhern Berge nicht selten. Auf Pilatus, Feuerstein, Rothhorn, am Stricktossen auf Schratten, am Schimberg.

960. - bellidifolia. 6-7. Auf feuchten Stellen der Alpen. Auf Heftiboden und Schratten, an der Nordseite von Rigischeidegg, am Pilatus auf Tomlisalp, auf der Spitze des Feucrsteins. 
961. Arabis turrita. 5-6. Nicht selten am Lopper, häufig bei Acheregg, am Bürgen bei Stansstad und auf dem Ried gegen das Rotzloch, zwischen Vitznau und Gersau, am Zingel bei Seewen.

962. - ciliata. Am Rigi auf Schneealp, zwischen Schafmatt und Fenersteiu an der Wasserfalle, nicht selten.

963. Barbarea fulgaris. 5-6. An Gräben und feuchten Stellen häufig.

964. Brassica oleracea. In Gemüsegärten angepflanzt.

„a. - - capitata. In Gemüsegärten ange-

"b. - - acephala. Ebenso. pflanzt.

"c. - caulerapa. ,

,d. - - botrytis.

965. - campestris. In Gemiisegärten anna. - - oleifera. Ebenso. gepflanzt. "b. - - napifera. Ebenso.

966. - rapa. In Gemüsegärten angepflanzt. "a. - - oleifera. Ebenso.

„b. - - napifera. Ebenso.

967. Erucastrum obtusangulum. 6-8. Hin und wieder im Suren- u. Hitzkircherthal, bei 'Triengen, Büron, Kleinwangen, Schongau, an der 
Strasse zwischen Dorenberg u. Malters häufig.

968. Sisymbrium officinale. 6-8. An Wegen und Schutthaufen häufig.

969. - alliaria. 5-7. An Hecken u. steinigen Orten nicht selten. Um Luzern, Adligenschwil, im Surenthal, bei Geuensee, am Fusse des Rigi bei Küssnacht, von Vitznau bis Kindlismord.

970. Sinapis arvensis. 6-7. Häufig in Getreideäckern.

"a.- - leiocarpa. Gleiche Standorte.

"b. - - orientalis. Ebenso.

971. - alba. Angebaut und verwildert.

972. Erysimum peronskyanum. In Gärten.

\section{IVI. II o II a d e I p h i a.}

\section{Decandria.}

973. Geranium sanguineum. 6-7. Von Gersau bis Brunnen am Lopper bis znm See.

974. - palustre. 7-8. An sumpfigen Stellen, Hecken u. Gräben. Um Luzern, 
Horw, Emmen, Willisau, inı Sureuthal, am Fusse des Rigi von Küssnacht iiber Goldau bis Brunnen.

975. Geranium pratense. 7-8. Bei St.

Urban.

9ii. - sylvaticum. 6-7. In der Bergund Voralpenregion häufig. Auf Rigi, Napf, Pilatus, auf den Entlebucherbergen, bei Weggis, anf Tagweid am Maisee.

977. - pyrenaicum. 6-9. In der Ebene und auf Bergen. Bei Tribschen, Weggis, Greppen bis Kaltbad auf Rigi, am Pilatus vom Mondmilchloch gegen das Widderfeld, bei Triengen.

978. - pusillum. 7-9. An den Manern bei Luzern, bei Emmen und Aesch.

979. - columbinum. 6-8. In Feldern und Aeckern an Wegen.

980. - dis sectum. 6-7. In Getreideäckern häufig.

981. - molle. 6-8. An Mauern bei Luzern, im Rank bei Horw, bei Ermensee, Willisan, Egolzwil und Wauwil. 982. - robertianum. 6-8. An fenchten Hecken und Felsen, in Wäldern härfig. 
383. Erodium mosehatum. 6-8. In Gärten, auch verwildert.

984. - cicut arium. Bliht fast das ganze Jahr, an steinigen Orten. Bei uns nicht häufig, an der Schützenmauer bei Miinster.

985. Pelargonium roseum. 4-10. In Gärten.

986. - zonale. 5-10. Ebenso.

987. - odoratisima.

\section{Polyandria.}

988. Malva sylvestris. 6-9. In Gärten, Feldern und an Wegen.

989. - mauritiana. In Gärten.

990. - rotundifolia. 7-9. In Gärten, Feldern und an Wegen.

991. - b orealis. Aehnliche Standorte, doch seltener.

992. - cris p a. 6-10. In Landgärten.

993. - alcea. 7-8. An der Sure bei Sursee, bei Geuensee, Triengen, Dagmarsellen, Reiden, St. Urban, Zuswil an der Wigger.

994. - moehata. 7-8. Im Wiggerthal, doch selten, bei Dagmarsellen, zwischen Grossdietwil und St. Urban, bei Ennethorw. 
995. Althaea officinalis. 8-10. In Gärten, selten verwildert.

996. - rosea. 8-10. In Gärten.

997. Lavatera trimestris. 7-9. In Gärtell.

998. Hibiscus trionum. In Gärten, verwildert auf Schuthaufen.

959. - syriacus. 8-9. In Gärten und Anlagen.

1000. - calesurus. In Gärten u. Anlagen. 1001. M a lapa trifida. 6-8. In Gärten. 1002. Abutilon striatum. 6-8. In Gärten.

\section{I i a d e I p h i a.}

\section{Hexandria.}

1003. Fumaria officinalis. 4 -9. Auf gebautem Boden nicht selten. Um Luzern auf dem Friedhof und au der Halden, bei Hochdorf in Aeckern, im Surenthal um Sursee, am Sempachersee, bei Aesch, am Fusse des Rigi bei Gersau, Weggis und Lowerz. 
1004. Fumaria parviflora. 5-9. An schattigen Stellen hin und wieder. Im Weihenmoos bei Triengen.

1005. Corydalis cava. 4-5. Auf Wiesen der Ebene. Bei Büron, St. Erhardt, Gelfingen, Ermensee, Hitzkirch, Mosen, Littau, Kriens, Meierskappel, Root, am Hochstutz bei Luthern, bei Dagmarsellen, Grosswangen, vou Küssnacht bis Goldau.

„a. - eava alba. Gleiche Standorte.

1006. - solida. 4-5. Auf Bergwiesen des Rigi.

1007. Diclytra spectabilis. 5-6. In Gärten.

1008. Polygala vulgaris. 6-10. Häufig an trockenen Stellen, Matten, Hecken und Wegen.

a. - - comosa. Gleiche Standorte.

1009. - a mara. 5-6. Häufig aut feuchten Wiesen und Weiden, überall bis in die Alpen.

1010. - alpestris. 7-8. Auf Rigi, Pilatus und Gürmsch.

1011. - chamaebuxus. 4-7. In der Ebene, auf Bergen und Voralpen bis zur Tannengränze. Bei Weggis, am Luzernersee, auf Branegg, Schwar- 
zenberg, Rigi, Pilatus, im 7Schachenwald ob Kriens.

\section{Decandra.}

1012. Amorpha fruticosa. 7-8. In Anlagen.

1013. - elata. Ebenso.

1014. - Spartium junceum. 5-6. In Anlagen.

1015. S a rothamnus scoparius. $5-6$. Häufig im Habsburgeramt, am Rooterberg, bei Adligenschiwil, Meierskappel, an der Schletzhalden, am Hertenstein bei Weggis, bei Altishofen, Richenthal u. Pfaffnau, zwischen Menzberg und Willisau, am Kiemen bei Immensee.

1016. Genista tinctoria. 6--7. Anf trokenen Hügeln bei Wikon, Dagmarsellen, Hochfluh, Pfaffnau und St. Urban, am Rigi von Gersau bis Seewen, am Urmiberg.

1017. C y tisus laburnum. 5-6. In Anlagen 1018. - sesselifolia. Ebenso. 1019. - capitatus. Ebenso. 1020. Ononis spinosa. 7-8. Häufig au 


\section{$-152-$}

trokenen Orten, sandigen Aeckern, Wald- und Wegrändern bis $2500^{\circ}$ Höhe.

1020. a. 0 nonis spinos a arvensis. An gleichen Standorten.

1021. Anthyllis vulneraria. 6-8. Auf / magern Weiden, Hügeln, trokenen Stellen der Ebenen $u$. Berge bis in die Alpen. Bei Emmenbrïcke, Meggen, im Eigenthal, auf Tomlishorn am Pilatus.

na. - - a lpestris. 6-8. Nur über der Tannengränze.

1022. L u p in us hirsitus. 7-8. In Gärten.

1023. - angustif o lius. 7-8. Ebenso.

1024. - l u te us. 6-8. Ebenso.

1025. - mutabilis. In Gärten.

1026. Phase olus vulgaris. 6-9. Iu

Gemüsegärten.

, a. - - elatior. Ebenso.

"b. - - humiliar. "

1027. - $\mathrm{n}$ a n u s. 6-9. In Gemuisegärten.

1028. - multifl orus. 7-9. Ebenso.

1029. Lotus corniculatus. 5-10. An

Wegen, Weiden, Waldrändern, auf

Wiesen der Ebene bis hoch in die Alpen. 
1030. Lotus uliginosus. 6-8. In Heckeu u. Gebüschen, an Gräben u. etwas feuchten Stellen auf den Allmenden häufig.

1031. - siliquosus. 5-6. Am Fusse des Pilatus an feuchtenStellen. Auf Horwerallmend, ob Hergiswil, im Eigenthal. 1032. - tetrag o n o lo bu s. 7-8. In Gärten. 1033. Trifolium fragiferum. 6-9. An feuchten Stellen hin $u$. wieder, an der Reuss bei Emmen, am See bei Ennethorw, bei Brunnen, zwischen Triengen und dem Bade Knutwil.

1034. - pratense. 6-7. Ueberall an Wegen und in Wiesen der Ebene bis in die Voralpen.

1035. - medium. 6-7. Auf allen Hügeln bis in die Voralpen.

1036. - a $1 \mathrm{p}$ in u m. 6-7. Auf Widderfeld am Pilatus, auf Bäuchlen, am östlichen Abhange des Fenersteins und an Rothhorn.

1037. - incarnatum. 6-7. Zwischen Winikon u. Reiden am Wege, an Wiesen und Ackerrändern, im Gopplismoos bei Luzern angebaut.

1038. - rubcus. Am Fusse des Rigi vou Vitznau bis Kindlismord. 
1039. Trifolium arvense. 7-9. Auf́ Feldern u. Aeckern.

1010. - repens. 5-9. Ueberall an Wegen u. auf Triften der Ebenen u. Berge

\1041. - cespitosum. Am Pilatus auf Klimsenhorn, Widderfeld, Geissriicken $и$. Tomlishorn, am Napf, Nesselstock, Tagweid und Rothhorn.

1042. - hybridum. 6-9. Am Lindenberg bei Müswangen u. Niederschongau, auf Aeckern und Wiesen.

1013. - montanum. 5-7. In der Bergregion häufig. Am Fusse des Rigi u. Pilatus, auf Gschweich, zwischen Wetzwil u Rickenbach, bei Münster.

1044. - ochroleu cum 6-7. An trokenen Stellen, nicht häufig. Bei Aesch u. am Weg nach Meisterschwanden.

1045. - agrarium. 6-8. In Aeckern, Wiesen u. Weiden bis in die Voralpen häufig. Bei Meggen, Kiissnacht, auf Herrgottswald, Bramegg und Lindenberg.

1046. - procumben s. 5-10. An Gleichen Standorten.

1047. - filiforme. 5-9. Auf feuchten Wiesen u. lehmigen Aeckern fast uiber- 
all. Bei Rain, Neuenkirch und am Sonnenberg bei Lnzern.

1017.a. Trifolium fili.f. minimum. $5-9$ Bei Gottsmännigen.

1048. - badium. 7-8. Auf allen unseren Bergen. Auf Rigi, Pilatus, Schafmatt, Emmenthal an der Schratten, vom Sörenbergli bis Nesselstock 11. Tagweid, von Gïrmschalp bis Feuer stein.

1049. Melilotus vulgaris. 7-9. An Wegen und sandigen, steinigen Orten, zwischen Sempach u. Schenkon, im Flusskies der Emme, bei Mauensee, bei Lützelmatt zu Luzern.

„a. - - gigantea. 7-9. Beim Holıhof. 1050. - officinalis. 7-9. Aut Wiesen, an Wegen, Gräben n. Ufern. Zwischen Serupach und Schenkon, am Flussbett der Emme, Hafendekel, gegen Ebikon.

1051. - arvensis. 7-9. An Wegen und Sandgruben hin u. wieder. Zwischen Kriens u. Ennethorw, in Flusskies der Emme.

1052. - caerulea. 6-7. Hie und da in Gärten. 
1053. Medicago lupulina. 5-10. Häutig an Hecken, in Wiesen u. grasigen Orten.

1054. - falcata. 6-10. Im Hitzkircherthal an sonnigen Stellen, bei Gelfingten, zwischen Aesch u. Schongau.

1055. - sativa. 6-9. Angebaut, auch verwildert.

1056. Pisum sativum. Angebaut.

„a. - - sacharatu m. In Gemüsegärten.

„b. - - arvense. Gebaut u. verwildert.

1057. Vicia hirsuta. 6-7. In Getreideäckern im Suren- u. Hitzkircherthal, bei Büron, Triengen, Hochdorf, Emmen und Rothenburg.

1058. - tetrasperma. 6-7. In Getreideäckern bei Nenenkirch, Nottwil, Sursee, im Surenthal, bei Hochdorf $u$. Rain.

1059. - silvatic a. 7-8. In Bergwäldern hie u. da. An Pilatus im Aufsteig nach Bründlen u. Tellenpfad, am Höchberg beim Eigenthal, im Sörenberg; am Fusse des Nesselstockes, über Gersau am Rigi u. bei Lowerz, bei Briidern am Fusse des Schimberg, im Lutherthal bei Dagmarsellen u. Winikon. 
1060. Vicia cracca. 6-8. Häufig an Hecken, in Wiesen u. Gebüschen der Ebene bis auf die Bramegg.

1061. - dumetorum 6-8. In Gebüschenu. Wäldern der Berge und Vorberge. Bei Krumbach, am Lindenberg, von Hohenrain bis Schongau, zwischen Aesch und Fahrwangen, bei Mosen, am Rigi über Vitznau, am Urniberg u. bei Seewen.

1062. - sepium. Ueberall an Hecken und in Wiesen.

1063. - sativa. 6-7. Häufig im Getreide. n. - obovata. Gleiche Standorte. ,b. - - angustifolia. Ebenso. 1064. - lutea. 6-7. In Kornfeldern im Wiggerthal, bei Ettiswil, Kaltbach, St. Erhardt, Wauwil, im Surenthal bei rìriengen, Ebersol, Urswil und Hohenrain.

1065. - faba. Angebaut, besonders im Entlebuch.

1066. Orobus vernus. 4-5. In Gebüschen u. Wäldern bis zur Buchengränze. Am Rigi, am Hertenstein bei Weggis, am Pilatus, Lopper u. Bürgen, bei Winkel im Steinbruch. *a. - - albus. Gleiche Standorte. 
1067. Orobus tuberosus. 4-6. Auf den Bergen des Wiggerthales, am Stempfelberg, zwischen Dagmarsellen u. Reiden, an der Hochfluh, zwischen Pfaffnau u. Langnau am Wege, zwischen Rüediken u. Aesch, im Walbert bei Triengen.

1068. - luteus. 5-7. An der Südseite der Blumalp, am Stanser- u. Buochserhorn.

1069. Lathyrus pratensis. 6-8. Auf feuchten Wiesen, in Hecken u. Gebüschen ïberall.

1070. - sylvestris. 7-8. Am Fusse des Rigi, auf den Höhen von Dagmarsellen und Reiden, zwischen Altbüron und St. Urban, Riiedikon u. Aesch, Marclistein bei Triengen.

1071. - palustris. 7-8. An Gräben im Egelmoos bei Triengen zerstreut.

1072. - latifolius. 6-10. In Gärten.

1073. - odoratus. 6-10. Ebenso.

1074. - hirsutus. 6-7. Unter dem Getreide in Hinterland, bei St. Urban, im Hitzkircherthal, bei Schongau und Miiswangen.

1075. - nissolia. 6-7. Im Getreide bei Münster, Neudorf, Sempach, Sursee, 
Kulmeran, Winikon, Hochdorf, Lrmensee, Schongau und Egolzwil.

1076. Lathyrus aphaca. 6-7. In Getreideäckern bei Hitzkirch, Schongau, Müswangen, Hochdorf und Dagmarsellen.

1077. - angalatus. 6-7. In der Gegend von Ettiswil im Getreide.

1078. Oxytropis uraliensis. 6-7. Am Pilatus, häufig auf Klimsenhorn, zwischen Esel u. Kriesiloch, Kastelnalp, iiber Brïndlen an der Fluh.

1079. - montana. 6-7. Am Pilatus häufig, auf Frakmünd, Rossegg, Mattgrat, Bründlen, Gemsmättli, auf Schratten, Schafmatt, Nesselstock, Roth- und Tannliorn.

1080. - campestris. 7-8. Häufig an der Spitze des Nesselstockes.

1081. Astragalus glyeiphyllos. $7-9$. In Gebii:chen, lichten fräldern, grasigen Stellen, zerstreut. Bei Geuensee, Rütihof, Triengen, Schenkon, Sursee, Hafendekel, Uffikon, Buchs, Rothenburg, Hitzkirch.

108:. Phace astragalina. 7-8. Am Pilatus, Nesselstock, Tagweid, Rothhorn, Heftiboden an der Schratten. 
1083. Phaca frigida. 7-8. Am Pilatus im Nauen, auf Staffelalp und Klimsenhorn; am Nesselstock iider Tagweid und Maisee bis Rothhorn, uiber Stillaub am Schimberg, auf Schafmatt, an der Engellauelenfluh.

1084. Colutea arbarescens. 5-10. In Gärten.

1085. - cruenta. 5-8. Ebenso.

' 1086. Coronilla emerus. 5-6. Massen. haft beim Steinbruch zu Winkel, am Fusse des Rigi von Hertenstein iiber Weggis bis Seewen, am Rürgen, Lopper, beim Rotzloch, am Pilatus und an der Schratten, nie iber der Buchengränze.

1087. - nemoralis. 9. Im Buchwäldli zwischen Aesch und Ruediswil, und an der Strasse zwischen Aesch und Fahrwangen.

1088. - vaginalis. 6-7. Zwischen Tomli u. Mondmilchloch am Pilatus, an der Schrattenfluh, auf Spirtossen an der Schafmatt.

1089. - varia. 6-7. Zwischen Triengen $\mathbf{u}$ Lerau.

1090. Hippocrepis comosa. 5-7. Auf trokenen Stellen der Ebene, Bergo 
und Alpen. Anf Hafendeckel, zwischen Knutwil und Uffikon, an der Kirchhalden bei Geuensee u. Wetzwil, auf Rigi und am Pilatus, auf Steiglisegg 11 . Kirchboden, am Nesselstock bis zum Fusse des Rothhorns, 6000' Höhe.

1091. Ornithopus perpusillus. 5-6. Auf sandigen Stellen zwischen Letten u. Reiden, am Waldsaume zwischen " Hinterletten u. Sixtel, auf den Sandhiigeln bei Zofingen, daselbst aut dem Heiterplatze.

1092. Hedysarum obscurum. 7-8. Auf Rigi, am nördlichen Abhange des. Pilatus, auf Klimsenhorn, Tellenpfad, im Aufsteig nach Briindlen, an der Schneeschmelze, Schimberg, Schafmatt, am Nesselstock, Rothhorn, Feuerstein, Klusmatt und Emmenthalfuh auf Schratten.

1093. Onobryehis sativa. 5-7. Angebaut.

1094. - montana. Am Pilatus auf dem Grate der Mattalp, Tomlisalp, am Nesselstock, Feuerstein und Schafinatt. 
1095. Galega officinalis. 6-8. In Gärten. 1096. Robinia pseudacacia. 6-7. In Anlagen nicht selten. Im Löwengarten bei Luzern, hie und da verwildert, so im Walde bei St. Karli. 1037. - viscosa. 6-7. In Anlagen. Auf Thorenbach $u$. im Tivoli bei Luzern. 1098. - hispida. In Anlagen. 1099. Glycinia chinensis. In Gärten. 1100. Cercis siliquastrum. 4-5. In Anlagen.

\section{IVII. Poly a d e lp ha.}

1101. Hy peri cum perforatum. 6-8. Häufig an trokenen Hügeln, Zäunen, Weg- und Waldrändern.

1102. - tetrapterum. 7-8. Auf feuchten Stellen der Ebene und Berge häuhg. 1103. - quadrangulum. 7-8. In der Berg- u. Voralpenregion. Auf Anhöhen bei Luzern, am Lintenberw, Schwarzenberg, Bramegg, Langwasen bei Kriens, im Staffel hinter Sörenberg, auf Emmenthal an der Schratten. Auch in der Ebene bei Richensee und Stäfflingeu. 
1104. Hypericem humisfusum. 5 -9. Auf Aeckern und Wiesen zerstrent. Bei Luzern, Adligen- und Ldligenschwil, Meggen, Küssnacht, Immensee, auch auf Kurzenhütten am Fusse der Schratten.

1105. - calycinum. 7. Bei der alten Seeburg verwildert, sonst in Gärten.

1106. - mon ta n um. 6-8. In der Bergregion bis zur Buchengrenze. Um Luzern auf Gütsch und Dietschiberg, Neuhabsburg bei Meggen, Hochfluh bei Reiden, Menzberg, Bramegg,Schwanegg bei Fliulli, am Fusse des Rigi u. des Pilatus.

1107. - pul chrum. 7. Meiştens neben Erica vulgaris auf lange nicht aufgefrischtem Boden. Auf Schwarzenberg zwischen Gengg u. Gibeln, von Schachen iiber Bramegg bis Finsterwald, bei Wohlhusen, Obfliih und Kriesbäumen bei Hasli, Stampf hei Romoos.

1108. - hirsutum. 6-8. An trockenen Yügeln, in Hecken u. Gebüschen. Am Dietschiberg bei Luzern, auf den Anhöhen von Dagmarsellen u. Rei. 
den, am Fusse des Rigi, bei Immensee, Gersau und Wilerbrücke.

1109. Hypericum coris. Am Fusse des Rigi, bei Gersan und Kindlismord.

\section{S y n g e ll e s i a. 1. Ligulatae.}

1110. Lapsana communis. 6-7. Häufig an Hecken, Gräben u. Schutthaufen.

1111. Cichorium intybus. An Wegen und trockenen Stellen wild, veredelt gebaut.

1112. - e n divia. 7-8. In Gemüsegärten.

1113. Lactuca sativa. 7-8. In Gemiisegärten.

1114. Sonchus arvensis. 7-8. Auf lehmbodigen, etwas feuchten Aeckern, fast uiberall.

1115. - laevis. 7-9. An gebauten und ungebauten Stellen, auf Schutthaufen nicht selten.

1116. - asper. 6-8. Wie die Vorige.

1117. - alpinus. 7-8. An grasreichen, schattigen Stellen der Alpen und Voralpen. Auf Rigi, Pilatus bei Frakniünd, am Nesselstock, zwischen 
Salwidli u. Schratten, Angstalp auf Schafmatt.

1118. Hieracium pilosella. 5-9. An sonnigen Abhängen, Waldrändern und trockenen Weiden der Ebene und Berge häufig.

1119. - alpinum. 7-8. Auf den höhern Spitzen unserer Berge, so auf Widderfeld und Mittaggipfi am Pilatus, bei Maisee, auf Rigischeidegg.

1120. - c a erulescens. 7-8. Unter Maisee am Rothhorn anf einer grasreichen Wiese neben H. alpinum.

1121. - murorum. 6-9. An trockenen 0rten, Felsen u. Mauern, in Wäldern, an Wald- u. Wegrändern der Ebene bis in die Alpen häufig.

„a. - murorum obtusifolium. Gleiche Standorte.

„b. - - a cutifolium. Ebenso.

"c. - - in e is u m. Ebenso.

„d. - - sylvaticum. Ebenso.

"e. - - pictum. Ebenso.

1122. - ca esium. 7-8. Am suidlichen Abhange der Schratten, Spirtossen auf Schafmatt, Rigistaffel.

1123. Hieracium silvatium. 6-9. In Gebuisehen, Hügeln, in Wäldern, an 
Waldrändern von der Ebene bis zur Tannengränze. Lm Luzern, am Gütsch, Biregg, auf Langwasen bei Kriens, bis Muihlemäïs, durch's Entlebuch bis an den Ursprung der Emme.

1124. Hieracium ramos. 7-9. In der Bergregion hin u. wieder. Auf Schwarzenberg, Bramegg u. den Anhöhen zwischen Entlebuch und Farnern, auf Menzberg zwischen Waldegg u. Sperbelegg, von Entlebuch bis Blasen, bei Flühli.

1125. - amplexicaule. 7-8. Auf Bergen und Voralpen. Am Rigi beim Felsenthor, in der Lützelau, im Zingel bei Seewen, am Lopper, auf Nesselwäng u. Nesselstock, seltener am Pilatus. 1126. - jaquini. 6-7. An steinigen Orten der Alpen u. Voralpen, vereinzelt. Bei Stillaub an Schimberg, auf Nesselstock, Stricktossen an der Schratten; auch in der Ebene, in der Schlucht vom Rotzloch und an Felsen bei Seewen.

1127. - villosum. 6-7. Auf Rigi, Napf, Pilatuskette bis Scheibenguitsch, auf Feuerstein bis Rothhorn. 
1127. a. Hieracium vill. valde pilosum. 6-7. Am Pilatus.

1128. - flexuosum. 6-8. Neben H. villosum auf Felsen der Oberalp, ïber Stillaub am Schimberg, aut Tagweid, Rothhorn, Salzboden, Stricktossen an der Schratten.

1129. - d e n d a tu m. 7-8. Leber Stillaub am Schimberg.

1130. - glaucum. 7-9. Auf Felsen des Rigi, am Feisenthor unter dem Kaltbade, iiber Vitznan u. Kindlismord.

1131. - auricula. 6-10. Auf Wiesen u. Weiden, an Abhängen u. Wegrändern der Ebenen bis zur Buchengrenze.

1132. - flore nt in u m. 6--7. Antrockenen Stellen zerstrent. Lm Luzern, südlich vom Weinberg u. am Gütsch. Am Sempachersec u. bei St. Erhardt, an der Landstrasse bis Dagmarsellen, an der Hochfluh bei Reiden, im Hitzkircherthal, zwischen Hochdorf, und Baldegg, bei Altwis, Hämikon u. Müswangen, am linken Emmenufer, bei Flühli an der Emme, auf dem Rigi, bei Vitznau, Gersau und Kindlismord. 
1132.a. Hieracium flor. praealtum. An vorigen Standorten.

nb. - - piloselloides. Ebenso.

1133. - fallax. 6-7. Von der Hochfluh bei Reiden über den Stermel bei Dagmarsellen nach dem Lutherthale häufig, am Lindenberge.

na. - fallax exstolonosum. Gleiche Standorte.

"b. - - decipiens. Ebenso.

1134. - aurantiacum. 7-8. Am Napf, südlich vom Hapfighubel, der Stächelegg zu. In Gärten gezogen.

,a. - aurant. bi color. 7-8. Auf Birchboden am Pilatus.

1135. - umbellatum. 8-9. Auf Triften, in Gebüschen, an Waldrändern der Hügel bis ïber die Buchengränze häufig.

, a. - - angustifoliu m. An gleichen Standorten.

,b. - - la tifoli u m. Ebenso.

„c. - uniflor um.

1136. - b or e a l e. 8-9. Gleiche Standorte, doch seltener.

1137. - rig i d u m. 7- 8. Zerstreut in Wäldern und Gebüschen. Von Gibelfluh bis Schongau, auf Sonnenberg bei 
Luzern, auf Krienser-Schattenberg,

Bramegg, bei Weggis u. Art.

1138. H i e ra ciu m s a b a nd u m. 7-9. An

Felsen bei Wikon, oberhalb Weggis gegen die Telli, bei Luthern.

1139. - pren an thoides. 7-8. Am Pilatus an der Tellenpfadliieke, zwischen Nesselstock u. Schratten, beim Salwidenbad, auf 'Tagweid am Rothhorn; nördlich von Rigiseheidegg.

1140. Crepis a urea. 7-8. Auf allen Voralpen u. Alpen. Auf Rigi u. Napf, bis 'Tomlishorn am Pilatus, u. westlich auf der ganzen Bergkette bis Feuerstein, Rothhorn und Schratten.

1141. - mo ntan a. 6-7. Am Pilatus auf Widderfeld, im Sörenberg anf Tagweid gegen Maisee, am Rothhorn, sehr vereinzelt.

1142. - a lpestris. 8. Am Pilatus von Tomlisegg bis Ringfluh, auf Rigi gegen Lowerz hin.

1143. - vi rens. 7-8. Gemein auf Wiesen, Aeckern und an Wegen.

1144. - p a l ud o s a. 6-7. In feuchten Wiesen u. sumpfigen Wäldern der Ebene u. Berge häufig, bis Rigischeidegg, u. 
am Pilatus an der Tellenpfadliicke und im Stafielwald.

1145. Crepis biennis. 5-6. Häufig auf Wiesen und Aeckern.

,a. - - in cana. 5-6. An steinigen, trokenen Orten.

1146. - praemorsa. 5-7. Auf Hügeln u. Bergen, nicht häufig. Am Geissenrain bei Altwis, Riiedikon u. Schongall.

1147. - blattaroides. 7-8. AnfRigi, Seeboden, am Pilatus zerstreut, an der Tellenpfadluicke, Steiglisegg, Ring-, fluh gegen Tomlisegg, im Sörenberg von der Schlachthiitte gegen Staffelwald, anf Nesselstock u. Tagweid häufig, iiber Stillaub am Schimberg, auf Schratten.

1148. Barkhansia taraxacifolia. 5-6. Häufig an trokenen, sonnigen Hügeln. Um Luzern, Meggen, von Rothenburg iiber Sempach bis Kulmerau.

1149. - s e tos a. 8-9. In Getreidefeldern nm Hochdorf.

1150. Will emetia apargioides. 7-8. Häufig auf sumpfigen Stellen des Rigi, besonders von Fellmis am Vitznauer- 
stock bis Scheidegg u. von da gegen den Dossen.

1151. Prenanthes purpurea. In Bergwäldern fast iiberall.

a. - - lance o la ta. Gleiche Standorte.

1152. - muralis. An felsigen u. steinigen, schattigen Orten, oft mit der Vorigeu. Zu Luzern an Mauern, am Guitsch, im Surseerwald, an Hochfluh bei Reiden u. bei Brüdern am Fusse des Schimbergs, am Fuss des Rigi bei Kiissnacht u. Vitznau.

1153. Taraxacum officinale. 5. In der Ebene auf Wiesen, auf trockenem Boden, an Wegen und Strassen.

,a. - - triviale. Gleiche Standorte.

"b. - - alpestre. 5. Bei Maisee 1. am Pilatus.

1154. - palustre. 4-5. In Sumpfwiesen der Ebene und Berge. Bei Inwil - an der Reuss und am linken Ufer des Sempachersee's.

1155. L e ontodon hastile. 5-9. Hänfig auf Wiesen, Weiden u. Triften.

„a. - - gouani. 5-9. Auf den hohen Spitzen des Pilatus.

1156. - hispidu m. Neben den Vorigen.

1157. - dubium. 7-8. Am Pilatus auf 
Bründlenalp, im Geschiebe zwischen Trockenmatt u. Mittaggipfi.

1158. Leontodon croceum. 7-8. Auf Rigischeidegg häufig u. an der Pilatuskette bis Rothhorn.

1159. - autumnale. 7-8. Auf Wiesen u. Triften der Ebene und Berge.

na. - - laciniatum. Ebenso.

1160. - a lpestre. 7-8. Am Pilatus und Rothhorn, besonders häufig auf dem Mittaggipfi.

1161. Scorzonera hispanica. 6-7. Gepflanzt.

1162. Picris hieracioides. 7-8. Gemein, an Weg- und Waldrändern bis zur Buchengränze.

1163. Tragopogon pratense. 6. AufWiesen und Triften häufig.

1164. Hip po cho eris radicata. 7-8. Hällfig in Wiesen und Aeckern bis zur Buchengränze.

1165. - helvetica. 7-8. Am Pilatus anf Oberalp über der Schneeschmelze und am rothen Tozzen gegen das Mittaggipfi. 


\section{Tubulosae.}

1166. Echinops exaltatus. 8. In Gärten.

1167. Centaurea cyanus. 6-8. In Kornfeldern häufig.

1168. - montana. 6-8 In der Berg- und Voralpenregion bis zur Tannengränze nicht selten. Längs der Emme und Fontanne bis zum Napf, am Schwarzenberg, auf den Romooserbergen, im Sörenberg, auf dem Rigi, Schimberg, im Nauen am Pilatus, oberhalb der Hergottswalderbriicke, im Rothenburger-Bachtobel.

1169. - jacea. 6-9. Ueberall an Wegen, Wiesen, trokenen $\boldsymbol{u}$. feuchten Stellen bis zur Buchengränze.

1170. - nigrescens. Auf Anhöhen bei Dagmarsellen.

1171. - nigra. 7-8. Auf trokenen Hiigeln nicht häufig. An der Strasse zwischen St. Urban und Grossdietwil, auf den Anhöhen von Dagmarsellen, an der Hochfluh bei Reiden, bei Hüswil, an den Hügeln am Hallwilersee.

1172. - s cabios a. 6-8. Auf trockenen Stellen der Ebene und Berge. 
1172.a. Centaurea seabiosa alba. 6-8. Zwischen Altwis u. Gelfingen, zwischen Nottwil und Hutprächtigen.

1173. - kotsch y a a. 7-8. Am südlichen Abhange der Schafmatt über Alp Grön, an der Fluh.

1174. - benedicta. 7-8. Angebaut.

1175. - suaveolens. In Gärten.

1176. L a p pa glabra. Vereinzelt an Wegen, Strassen und steinigen Orten bis in die Voralpen.

na. - - major. Ebenso.

„b. - - minor. Ebenso.

1177. - tomentosa. 7-8. Gleiche Standorte.

1178. Carduus crispus. 8-9. Häufig an angebauten Stellen. Von Nottwil iiber Sursee, durch's Surenthal; ron Hochdorf bis Aesch; um Luzern sel ten.

1179. - personata. 7-8. Am Nesselstock von der Emme herabge chwemmt, bis zur Emmenbrücke bei Luzern, so zwischen Hasle und Schüpheim, Blatten und Malters.

1180. - defloratus. 6-8. In der Berg-u. Alpenregion häufig. Auf Napf, Rigi und der ganzen Pilatuskette - auf 
hohen Gräten sehr klein. Im Bett der Ilfis und Emme herabgeschwemmt bis Emmen.

1181. Carduus nutans. 7-8. An Wegen und steinigen Orten. Zwischen Nottwil und Sursee, bei Sempach, Hildisrieden und Römerschwil zerstreut. 1182. - marianus. 6-8. In Landgärten; verwildert bei Immensee.

1183. Cirsium lanceolatum. 6-9. An Strassen и. abgelegenen Orten nicht selten, bis in die Voralpen. Auf Bramegg, im Grund am Schimberg.

1181. - oleraceo-lanceolatum. 7-8. An der Emme, zwischen Emmenbriicke u. dem Vonmoos'schen Eisenwerk.

1185. - eriophorum. 7-8. In Sörenberg zwischen Witemoos und Schlachthiittenalp.

1186. - arvense. In Feldern, Aeckern u. Abhängen der Ebenen und Berge.

1187. - palustre. 7-10. An sumpfigen Stellen u. in feuchten Wäldern bis zur Buchengränze häıfig.

1188. - palustre riviculare. 7-8. Häufig neben der Vorigen im Sörenberg, zwischen Kirche u. Drischlibrïcke. 


\section{$-176-$}

1189. Circium oleracea palustre. In feuchten Wiesen zerstreut. Auf Horwerallmend, im Moos bei Adligenu. Udligenschwil, zwischen Rothenburg u. Neudorf, im Chïsirainwald, bei Hitzkirch, Hellbühl, Vollenloch bei Mühlemääs, im Sörenberg u. auf Rigi.

1190. - acaule. 7-8. Auf feuchten u. troekenen Stellen der Ebene bis in die Alpen. Am Krienbach bei Luzern, an der Reuss bei Emmen, am Rigi, auf Menzberg, auf der Spitze des Schimberges, im Sörenberg, am Gürmsch bis Feuerstein.

n a. - - caules ce ns. Gleiche Standorte.

1191. - rivulare. In der Bergregion. Zwischen Sörenberg u. Drischlibrïcke, im Flïhli.

1192. - oleraceum. 7-10. Auf Wiesen der Ebene und Berge gemein. Auf Gürmsch.

1193. - - acaule. In der Berg- u. Voralpenregion. Am Krienbach, am Rigi bei Goldan, zwischen Küssnacht und Seeboden, gegen Hildisrieden, auf Blasen bei Flühli, im Sörenbergli, 


\section{$-177-$}

auf Twanegg am Fusse des Schimberges.

1194. Cirsium olerace o-rivulare. 7-8.

Im Sörenberg häufig, zwischen Kirche und Drischlibrücke.

1195. - spinosissima. 7-8. Auf Alpen und Voralpen, auf Rigi, Bründlen am Pilatus, Schimberg und Nesselstock, Tagweid u. Maisee am Rothhorn, an der Schratten.

1196. - s pinos.-acaule. 7-8. Auf Schönenboden im Sörenberg.

1197. Carlina vulgaris. 7-8. Auf trockenen Hügeln, steinigen Abhängen und Waldrändern.

1198. - a caulis. 8-9. Auf sonnigen Hiigelu. Auf Gschweich, Nenegg bei Meggen, Rigi vom Seeboden bis Kulm und Scheidegg, im Eigenthal, auf den Romooserbergen, von Briidern bis Gürmsch.

1199. Cynara scolymus. 8-9. In Gemiisegärten.

1200. Bidens tripartita. 7-9. häufig auf torfigen Stellen, an Gräben u. Mistlachen. Bei Suree, im Surenthal und an der Reuss bei Buchenrain. 1201. - cernua. 8-9. Auf Sumpf u. 'Torf 
hin u. wieder. Häufig zwischen Tam und Münster, im Muiswangermoos, bei Eschenbach, zwischen Ebikon u. Root, Mauensee und Wauwilermoos. 1202. Santolina chamoecyparissus. 7-8. In Gärten.

1203. Artemisia vulgaris. 8-9. Häufig, von St. Erhardt bis Egolzwil, zu Wikon, Reiden u. Dagmarsellen.

1204. - absynthium. 7-9. In Gärten.

1205. - pontica. 7-8. Ebenso.

1206. Tanacetum vulgare. 7-8. An Mauern u. in Gärten von Thierärzten.

, a. - vulg. crispum. 7-8. Ebenso.

1207. Gnaphalium montanum. 6-7. Bei Dieboldswil, Winikon und auf dem Letten.

"a. - mont. minimum. 6-7. An der Hochfluh bei Reiden.

. " - sylvaticum. 8-9. An Waldrändern u. trockenen Stellen der Ebene und Berge bis zur Buchengränze, z. B. auf Blasen bei Flühli.

"a. - sylv. citrinum. Gleiche Standorte.

„b. - - $\mathrm{fuseum}$. Ebenso.

„c. - - rectum. Ebenso.

1208. - uliginosum. 8-9. Aut feuchten, 
etwas maorgrindigem Botlen nicht seiten.

1209. Guaphalium sup inum. Auf Pilatus am Fusse des Esels.

"a. - - pusillum. Auf Widderfeld am Pilatus, Salzboden an der Schratten, Rothhorn, an der Spitze des Feuersteins und Rigidossen.

1210. - dioicum. Häufig auf Bergen bis hoch in die Alpen, auf Gschweich, Bürgen, Schwarzenberg, Rigi, Langwasen bei Kriens, Pilatus, am Fusse des Esels, u. unter Neualp am Weg, Blasen bei Fluihli.

1211. Guaphalium carpathicum. 7-8. Am Pilatus häufig. Auf Klimsenhorn, Esel und Laub.

1212. - leontopodium. 7-8. Am Grat des Rothhorns, zwischen 'Tagweid u. Maisee häufig, selten auf́ 'Tomli am Pilatus, auf Nesselstock.

1213. - margaritacenun. 6-8. In Gärten häufig, massenhaft auf dem Friedhof zu Vitznau.

1214. Helichrysum bracteatum. 6-9.

In Gä̈rten.

1215. - hastatum. Ebenso.

1216. - rosenm. Ebenso. 
1217. Eupatorium e an a b inum. 7-8. An feuchten und nassen Stellen und Gräben.

1218. Con yza squarrosa. 7-9. Auf trockenen Hügeln zerstreut, an Waldrändern. Beim Nöllithörlein und ar der Museggmaner bei Luzern, aut Mühlegg bei Meggen, längs der Lmme von Werthenstein bis Gerlisehwil, vom Eichberg bis Schenkon, am Ha. fendeckel, bei Baldegg, am Rigi vou Weggis bis Seewen.

1219. Adenostyles albifrons. $7-5$ Gemein auf Voralpen und Alpen. Auf Rigi, Napf, rom Pilatus bis 'Tannhorn.

12z0. - g l a bra. Ebenso.

1221. - s o n e hifolia. In Gärten.

1222. Petasites officinalis. An Grä- : ben und feuchten bewässerten Wiesen. Am Würzenbach bei Luzern, beim Seehüsli, im Surenthal, Munimatt bei Geuensee, zwischen Ettiswil und Zell, Dagmarsellen u. Reiden, St. Urban u. an der Emme.

1223. - a lb u s. 5-6. In schattigen Gebiischen u. Tobeln, häufig in Bergen u. Voralpen. Bei Adligenschwil, im 
Rifig, am Gütsch u. Rooterberg, am Fusse des Rigi und Pilatus häufig. 1224. Petasites niveus. 5-6. In der Alpenregion. Am Pilatrs zwischen Staffel und Oberalp, auf Tomlisalp.

1225. - a $1 \mathrm{p}$ in u s. 7-8. Auf allen höheren Bergen. Auf Rigi, Napf, Pilatus u. Tagweid am Rothhorn.

1226. Tussilago farfara. 2-5. Häutig in feuchtem, lehmigem Boden bis $5000^{\prime}$ Höhe.

A627. Arnica montana. 6-9. Häufig aut Alpen u. Voralpen. Auf Rigi, Napf, Pilatus bis Tannhorn. Nie unter der Buchengrenze. Auf Lauelenalp, Mühlemääs, Frakmünd, am Brüdernmätteli, Gürmsch und Sörenbergli.

1228. - scorpioides. 7-8. Auf den höheren Bergen an feuchten Abhängen. Am Pilatus, auf Brïndlen, längs der Fluh, zwischen Laueleu und Klimsenhorn, auf Kastelenalp bis zum Fusse des Esels. Auf Schimberg, Schafmatt, Rothhorn, von Maisee bis Stïffeli, am Nesselstock u. Schrattenfluh.

1229. Bellidiastrum micheli. 6-9. In der Berg- u. Voralpenregion häufig. A uf 
Rigi, Napf, in den Entlebucherbergen, an der Pilatuskette bis Tannhorn. An Bächen u. feuchten Abhängen, auch herabgeschwemmt. So am Krienbach bei Luzern, an der Renggbriicke, im Rothenburgertobel.

1230. Aster alpinus. 6-9. Auf allen Bergen bis iiber $4000^{\prime}$ Höhe. Auf Rigi, Napf, Bäucheln, an der Pilatuskette bis Rothhorn, Schafmatt u. Scluratten.

1231. - chinensis. 7-11. In Gärten.

1232. - novi belgii. 9-11. In Gärten.

1233. - novae angliae. 10-11. Ebenso. 1234. Solidago virga aureas 6-8. In Wäldern.

na. - - minuta. 6-8. Auf Rigi u. Pilatus.

1235. - canadensis. 8-9. In Gärten. An Bach- u. Flussufern verwildert. An der Reuss u. Emme, auf der Reussinsel beiLuzern, an d. Sure bei Triengen. 1236. Inula dysenterica. 7-9. Häutig an Gräben u. feuchten Stellen der Ebene und Berge.

1237. - helenium. 7-9. In Gärten von 'Thierärzten.

1238. -- s a licium. 7-8, In Hitzkircher- 
thal, bei Aesch am See, im Geissenrain und Tröletentobel bei Schongau. 1239. In ula vaillantii. 9. Am Sempachersee in Gebiischen zwischen Eich und Schenkon.

1240. Erigeron eanadense. 6-8. Ueberall auf trockenen sandigen Stellen der Ebene und Hiigel bis zur Tannengränze.

1241. - a cre. 7. Auf trockenen Hiigeln. Am obern Krienbach, an der Emme, auf Rigi.

1242. - al p in u m. 7-8. An der ganzen Pilatuskette, auf Schafmatt, Schratten und Rothhorn.

,a. - - villarsi. Gleiche Standorte.

"b. - - glabratum. Ebenso.

ne. - - glandulosum. Ebenso.

1243. - un iflorum. 7-8. Auf Esel und Tomlishorn am Pilatus, anf Heftiboboden u. Betlenalp an der Schratten, auf der Spitze des Feuersteins und auf dem Grate des Rothhorns nicht selten, aut dem Gipfel des Buochserhorns.

1244. Senecio vulgaris. 4-10. Ueberall als Unkraut.

1245. - sylvatieus. 7-8. In abgeholzten 
Wäldern hin $u$. wieder. Im Rifig-, Ebikoner- u. Surseerwald, bei Holzhof, Mühlegg bei Meggen, Roggliswil, Dagmarsellen, Hochfluh bei Reiden.

1246. Seneciojacobea. 7-8. An Waldrändern, Gräben u. sumpfigen Stellen, anf Hügeln u. trockenen Standorten häufig.

1247. - erueaefolius. 8-9. Auf Lettboboden, an Wegen und trockenen Hügeln nicht selten.

1248. - cordifolius. 7-8. Aut allen Alpen um die Sennhütten häufig. Auf Pilatus, Rigi, Napf, auf den Entlebucherbergen, am Sonnenberg, auf Emmenthal an der Schratten.

1249. - lyratifolius. 7-8. Hinter Flühli an der Emme, auf Rigi, zwischen Fellmis und Scheidegg, von Art bis Lowerz, immer vereinzelt und in Ganzen nicht häufig.

1250. - p alu dosus. 7-8. Häufig in Sümpfen, an allen unseren See'n, Gräben und Teichen.

1251. - doronicum. 6-7. Häufig vom Pilatus bis Tannhorn, 5-7000' hoch. 
Am Nesselstock, auf Tagweid und Schratten.

1252. S e necio a lpestris. 7-8. In der Bergregion an grasigen Stellen bis über die Buchengränze. Am Napf, Rigi, vom Seeboden bis Staffel, am Pilatus, Schimberg, Schafmatt, Staffelwald hinter Sörenberg.

„a. - - fuchsii. Gleiche Standorte.

,b. - - avatus. Ebenso.

1253. - hybrida. In Gärten.

1254. - e l e gans. Ebenso.

1245. - maritima.

1256. B ell is perennis. 1-12. Ueberall.

1257. Chrysan the mum leucan the mum. 5-10. Häufig auf Wiesen, Aeckeru Hügeln der Ebene und Berge.

1258. - mont a num. 5-8. Auf Rigi und Pilatus, Nesselstock, am Emmenufer bei Dorenberg.

1259. - halleri. 7-8. Auf Rigi hin und wieder, am Pilatus und der ganzen Kette bis zum Rothhorn nicht selten, auf Bründlen, Trockenmatt, gegen Mittaggipfi, am Klimsenhorn, Eselsfluh, bei Maisee u. am Nesselstock, auf Einmenthalfluh an der Schratten, auf Schafmatt. 
1260. Chrysanthemum alpinum. $7-8$. Auf dem Grat des Rothhorns, ant Eselsfluh am Pilatus.

1261. - c o r o n a ri u m. 8-9. In Gärten.

1262. - in di c u m. S--11. Ébenso.

1263. - atrosanguineum. Ĺbenso.

1261. Matricaria chamomilla. 5-10.

In Getreideïckern des Hitzkircherund Wiggerthals, in Gärten \%. auf Schutthaufen.

1265. - in od ora. 7-9. Im Surenthal häufig, bei Horw, Root, Emmen, Schongall und Miiswangen.

1266. - partheninm. 6-7. An Manern und auf Schutthaufen verwildert, in Gärten gezogen.

1267. Calendula officinalis. 6-9. In Gärten gepflanzt, auf Schutthaufen verwildert.

1268. T a getes patula. 8-10. In Gärten. 1269. - erecta. 7-10. Ebenso.

1270. - pulchra. Lebenso.

1271. Anthemis arvensis. 5-7. In Aeckern häufig. Bei Hohenrain, im Suren- u. Wiggerthal von Ettiswil bis Altishofen, bei Wikon.

1272. - nobilis. 7-9. In Gärten. 
1273. Anthemis tinctoria. 7-8. Zwischen Altwis und Hitzkirch.

1274. A chillea mill efoliu m. 6-10. Häufig an Wegen, Gräben und in Feldern.

1275. - tomentosa. 5-7. In Gärten.

1276. - ptarmica. 7-8. An nassen Stellen, nicht selten. Im Suren-, Wigger- u. Hitzkircherthal, am Luzernersee, bei Kiussnacht $u$. Weggis, auf Bramegg, im Schachenwald ob Kriens und au der Stollenegg.

1277. - atrata. 7-8. An der Pilatuskette im Felsschatten an befeuchteten Stellen ïber der Tannengränze. Auf Briindlen, auf Lanelen bis Klimsenhorn u. Esel, über Trockenmatt, bei Maisee am Rothhorn, auf Schimberg, bei Sihlwängen u. Stricktossen, an der Schratten.

1278. - macrophylla. 7-8. An grasigten Stellen der Voralpen, bei uns selten. Am nördlichen Abhange des Nesselstockes bei den groseenSchirmtanuen häufig, hinter Sörenberg im Staffelwald.

1279. Calli op is b i color. 7-9. In Gärten 1280. - nigra speciosa. Ebenso. 
1281. Calliopsis trumondi. In Gärten.

1282. Dahlia mutabilis. 7-10. In Gärten. 1283. Buphthalmum salicifolium. 6--7. In der Voralpenregion auf allen unseren Bergen. Auf Rigi am Felsenthor, zwischen Weggis u. Vitznau; auf Tellenpfad am Pilatus, am Nesselstock, in der Völli auf Schratten.

1284. Helianthus annus. 8-9 In Gärten. 1285. - tubcrosus. 9-11. Ebenso. 1286. - multiflorus. 8-10. Ebenso.

1287. Ru dbekkia la cin ia ta. 8. In Gärten. 1288. - purpurea. 8. Ebenso.

1289. - amplexifolia. Verwildert an der Halden.

1290. Zinnea elegans. 7-8. In Gärten.

\section{Gy $n$ an di ia.}

\section{Orchideae.}

1291. Orchis bifolia. 6-7. Auf Weiden, in Wäldern u. Gebüschen der Ebene u. Berge häufig.

1292. - chlorantha. 6-7. In dunkeln Wäldern. Am Gütsch und Sonnenberg, am Fusse des Rigi, bei Udligenschrvil . 
1293. Orchis pyramidalis. 5-7. Am Geissenrain zwischen Altwis u. Schongau, am Krienbach bei Kriens, am Schlosshügel bei Wikon, am Rigi.

1294. - morio. 4-5. Auf feuchten Wiesen u. lehmigen Hügeln häufig.

1295. - mascula. 4-5. IHäufig in Wiesen und trockenen Orten bis in die Voralpen.

na. - - latifolia. Gleiche Standorte.

,b. - - alba. 4-5. Am Pilatus.

1296. - globosa. 6-7. Auf Alpen u. Voralpen. Am Pilatus, im Aufsteigen nach Bründlen, auf Tellenpfad, Mattalp, Ringfluh, Klimsenhorn, auf Rigi, Schimberg, Schafmatt, Nesselstock und Schratten.

1297. - coriophora. 5-6. Auf Wiesen, selten. Bei Sehongau, zwischen Riiedikon und Tröleten.

1298. - militaris. 5-6. An lettigen, feuchten und trockenen Stellen bis zur 'Tannengränze. Bei Meierskappel, im Rothenburgertobel, am Geissenrain bei Schongau, beim Ilolzhof, zwischen Wetzwil und Diegistall, vom Napf der Fontanne entlang bis Doppleschwand, am Emmerberg 1. 
der Emme nach bis Dorenberg häıfig, bei Inwil an der Reuss, am Rigi von Goldau bis Lowerz und Rigikulm.

1298.a. Orchis milit. alba. 5-6. Zwischen Daginarsellen und Reiden.

1299. - ustulata. 5-6. Auf feuchten und trockenen Wiesen der Ebene und Berge, bis in die Alpen zerstreut. Bei Gelfingen, im Surenthal, im Kapf bei Büron, zwischen Mauensee und Surseerwald, bei Inwil an der Reuss, und am Emmerberg massenhaft; am Rigi iiber Vitznau, am Pilatus auf Tomlisalp, am Fusse der Schratteu und am Nesselstock.

1300. - fusca. 5-6. Auf Hügeln, nicht häufig. Am Dietschiberg bei Luzern, am Geissenrain bei Schongall.

1301. - pallens. 5-6. Im untern Tommli am Pilatus.

1302. - ma culata. 5-6. Auf feuchten Wiesen und in Wäldern häufig, übera 1 bis zur Buchengränze.

1303. - - latifolia. 6. Zwischen Kreuzbuch und Meggen, auf Sumpfwiesen.

1304. - latifolia. 5-6. Auf feuchten Wic- 


\section{$-191$}

sen häufig. Am Luzerner- u. Rothsee, bei Wauwil, im Suren- u. Hitzkircherthal, auf der Udligenschwiterallmend, auf Seeboden am Rigi.

1304.a. Orchis latif. alb a. Gleiche Standorte.

1305. - angustifolia. 5-6. Am Luzernersee bis Seeburg häufig, bei Meggen.

,a. - - alb a. 5-6. Gleiche Standorte. 1306. odoratissima. In der Ebene, auf den Bergen und Alpen. Auf Horwerallmend, Bramegg, Gürmschalp; am Pilatus im Aufsteig nach Briindlen, zwischen Laub und Tomlisalp, an der Ringfluh, auf Trockenmatt; am Rigi östlich vom Dossen u. bei Kindlismord.

1307. - conopsea. 6-7. Auf trockenen und feuchten Wiesen, an Waldrändern häufig. Im Schachenwald, bei Horw, an Lindenberg.

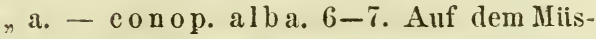
wangermoos, u. zwichen Horw und Kriens.

1308. - viridis. 6-7. Auf allen unseren Bergen $u$. Voralpen zerstrent. Im Eigenthal häufig, auf Steiglisalp am 
Pilatus, zwischen Staffel und Rigikulm; im Emmenthal u. Sihlwängen an der Schratten, am Nesselstock.

1309. Orchis albida. 6-8. Auf allen unseru Bergen und Alpen, häufiger als die Vorige. Auf Rigi u. Pilatus, massenhaft auf Rigischeidegg; auf Bösegg bei Willisau, am Napf, im Eigenthal.

1310. Nigritella angustifolia. 6-8. Auf Alpen von 5-7000 Fuss Höhe. Am Pilatus auf Klimsenhorn und Esel, Natt- und 'Tomlisalp, Gemsmätteli, Schwarzflühli, Feuerstein, Schafmatt, Schratten, Rothhorn, Nesselstock, Schimberg und Rigi.

1311. Cypripedium calceolus. 5-6. In der Berg- und Voralpenregion zerstreut. Im Rothenburgertobel, längs der Emme bei Dorenberg, im Fahrnbuihl, auf dem Letten zwischen $\mathrm{Wi}$ nikon 11. Uffikon, im Lutherthal bei Dagmarsellen, bei Altishofen und Egolzwil, Altwis, bei Hergottswald, im Horwerhochwald, an Fusse des: Pilatus und des Rigi, über Vitzuau häufig, beim Dächli und Schilttobel. 
1312. Sturmia loeselii. 7-8. Auf torfsumpfigem Boden. Bei Wauwil, Mauensee, am Roth- u. Hallwilersee. Nicht iiberall, aber dann massenhaft beisammen.

1313. Epipactis pallens. In dunkeln Wäldern hin und wieder. Im Haltiwald, Forenwaldtobel, bei Eich, am Gütsch bei Luzern, in der Ehrlosen, Fischernbachweid, im Buchwäldli bei Wetzwil, zwischen Buchs u. Kaltbach, im Sennhäuserwald bei Dagmarsellen, am Rigi über Vitznau.

1314. - ensifolia. Am Rigi, von Hertenstein bei Weggis bis Seewen, stellenweise; an der Emme bei Dorenberg, iu: Schächbühl bei Ruswil, am Reck holderhubel bei Münster, bei Altwis, im Buchwäldli bei Wetzwil, in der Fischernbachweid gegeniiber dem Fahrnbühl, am Bache beim Aufsteigen von Schwarzenberg nach dei.i Stäffeli, gegen Mühlemääs nnd Bonerli am Pilatus, am Lopper.

1315. - rubra. An Bergabhängen. Im Schachenwald ob Kriens, im Hergottswald, in Bachtallen bei Geuensec, im Rothenburgertobel, bei Doren- 
berg an der Emme, an der Hochflutr bei Reiden, auf Trümmerhalden über Vitznau im Bergli häufig.

1316. Epipactis palustris. 6-8. Annassen, sumpfigen Stellen nicht selten. An der Reuss, auf Horwerallmend, auf Langwasen bei Kriens, auf der Bramegg.

1317. - latifolia. 6-S. Häufig in Bergwäldern. Am Gütsch bei Luzern, im Schachenwald, in der Ehrlosen, am Eichberg, auf Bramegg.

ra. - latif. chlorantha. 6-8. Gleiche Standorte.

„b. - - rubiginosa. Wie oben.

1318. Spiranhtes aestivalis. 7. Ansumpfigen Stellen nicht selten. Am Roth- u. Mauensce, bei Aesch und Mosen am Hallwilersee, am Baldeggersee, zwischen Richensee u. Stäff-ligen, bei Weggis, am See bei Brunnen.

1319. - autumnalis. 8-10. An trockenen Orten, selten. Bei Emmen läng's der Reuss; zwischen Kaltbad und Rothstock auf dem Rigi, zwischen Weggis und Vitznau.

1320. Goodyera repens. In Gebüschen u. 
schattigen Wäldern der Hügelregion nicht häıfig. Im Guggiwald im Lu therthal, Forrenwald u. Krähenb ühl bei Kulmerau. Am Rigi über Vitznau, und von da bis Kindlismord hin und wieder.

321. Listera ovata. 5-7. Hänfig in Wiesen u. Weiden der Ebene u. Berge bis in die Voralpen. Am Sempachersee von Eich bis Sclienkon, an der Emme von Malters bis Emmenbriicke, auf Langwasen bei Kriens, im Sörenbergli.

1322. - cordata. 5-7. In Wäldern der Berge $u$. Voralpen bis fast zur Tannengränze, nicht häufig. Im Pfaffnauerwald. Am Pilatus auf Mühlemääss, auf dem Grat zwischen Bonerli und Lauelenalp, im Aufsteigen nach Brindlen, am Napf.

1323. $0 \mathrm{phrys}$ a pifera. 5-7. Anf Mügeh und Bergen. Bei Luzern am Gütsch. Gigeli, Stutzhof, Rooterberg, am Stermel zu Dagmarsellen, an Emmerberg, anf Rengg, am Lopper, am Sempachersee.

\#. - apifi. alba. Gleiche Standorte.

1324. - arachuites. 6-7. Bei Aesch, ira 
Schiltwald, am Giitsch bei Luzern, an Fusse des Pilatus und des Rigi bei Greppen, Vitznau, Gersau und Goldau.

1325. 0phrys myoides. 6. Auf trockenen Hügeln hin u. wieder. An der Emme bei Dorenberg bis Wohlhusen. Bei Müuster am Reckholderhubel, Wellnau, Wetzwil, Nunwil, am Geissenrain bei Altwis, am Lopper u. Buirgen, am Rigi bei Weggis, Vitznau, Gersau und Goldauerschutt.

X 1326. Chamaeorchis alpina. 7-8. Am Pilatus in der Nähe des Kriesilochs. 1327. A cer $\pi$ s anthropophora. Selten. Am Rütihubel bei 'Triengen, am Wege nach Riitihof, bei Sursee..

1328. Herminium monorchis. 5-7. Nicht selten auf Weiden und Triften der Ebene, Berge $u$. Voralpen. Am Sempachersee, längs der Emme, bei Luthern, am Napf, Rigi, im Eigenthal, auf Langwasen, am Pilatus, auf den Romooserbergen und im Sörenberg. 1329. E pip ogium gmelini. 7-8. In Wäldern selten. Bei Pfaffnau, im Buchwald über Weggis am Rigi.

1330. Neottia nidus avis. 5-6. In dun- 
keln Wäldern. Bei Geuensee, Wetzwil, Käsern, um Luzern, am Dietschiberg, Giitsch, Biregg, bei Horw, Malters und Schwarzenberg, im Rothenburgertobel, im Haltiwald, Schlosswald bei Kriens, Schiltwald an der Reuss, bei St. Urban, am Fusse des Rigi bis Seeboden, im Schächbiihıl bei Ruswil.

1331. Corallorhiza halleri. 6-7. Am

Pilatus, zwischen Staffelhuitte und der Fruth auf moosbewachsenen Waldstellen, in der Nähe des Mondmilchloches; im Wäldlein zwisehen Klösterli und Staffel am Rigi.

\section{Aristolochieae.}

1332. Aristolochia clematis. 6-8. In Gärten. "a. - sipho. Ebenso.

\section{II o n 0 e c i a. 1. Kräuter.}

1333. Najus major. 7-10. Im Grunde des Luzernersee's bei Weggis, im Roth- 
see, an der Schifflände beim Seehof . zu Küssnacht.

1334. Najus minor. 6-8. Bei St. Urban im Fischweiher gegen Roggwil.

/ 1335. Myriophyllum verticillatum. 7. In stehenden Wassern und Sumpfgräben. Im Suren- u. Hitzkircherthal, am Luzernersee häufig.

/ 1336. - spicatum. 7-8. Im stehenden Wasser. In Weihern des Obergrund zu Luzern, am Luzerner- und Rothsee, im Weiher bei Gurgenmühle, bei Goldau, bei Art im See, häufig.

1337. Ceratophyllum demersum. 7-8. Im langsam fliessenden Wasser. Au der Sure, an der Rhone bei Dierikon.

1338. Euphorbia helioscopia. 5-7. An gebauten sonnigen Orten. Im Hitzkircher-, Winon u. Surenthal, bei Tann, Neudorf, auf der Horwerallmend, am Weg nach den drei Liuden, längs der Hecke

1339. - platyphyllos. 7-9. Häufig an Wegen und Strassen u. im Getreide uiberall.

1310. - stricta. Zwischen Rotheuburg u. Emmen. 


\section{$-199$}

1341. E ii $p h$ orbia $d u l c$ is. 4-5. In Hecken 11. Gebüschen nicht selten. Bei Staffeln, im Rothenburgertobel, von Waldibricke bis Inwil, ron Tann bis Schenkon, dem Bachufer entlang bis an den See.

1342. - gerardiana. 6-7. An der Hochfluh bei Reiden.

1343. - cyparissius. An sandigen Stellen härfig. Am Sempachersee zwischen Eich und Schenkon in Masse, um Sursce, bis hoch in die Alpen. Aut Schratten 1 . Widderfeldfluh, anf Tomlisalp.

1344. - Peplus. 7-8. Gemein als Unkraut. 1345. - exigua. 6-9. Häufig in Aeckern. 1346. - falcata. Unbestimmter Standort.

1347. - a m y g d a loides. 4-5. Im Kuhwald bei St. Urban.

1348. - lathy ris. 6-7. Gartenpflanze.

1349. Cucurbita pepo. 6-8. In Landgärten.

,a. - - maxima. Ebenso.

„b. - - verrucosa. Ebenso.

,c. - - aurantia. Ebenso.

nd. - - melopepo. Ebenso. 1350. Cucumis sativa. 5-8. In Gärten, 1351. Arum maculatum. 4-5. In Hecken. 
Gebüschen $u$. Wäldern. Im Surenund Wiggerthal, bei Buchenrain $u$. Gisikon, im Schiltwald an der Reuss, im Rotzloch.

1352. Calla palustris. 7-8. In Sumpfu. Abzugsgräben des Chüsirainwaldes bei Sempach, bei Nasssteg im Meggerwald.

1353. Richardia a ethiopica. 2-6. In . Gärten.

1354. Urtic a dioica. 7-10. Ueberall an Hecken u. Wegen, an ungebauten Orten der Ebene u. Berge bis hoch in die Alpen.

1355. - urens. Seltener als die Vorige, übrigens gleiche Standorte. Bei Meggen, Gisikon, um die Chorherrenhäuser bei Münster.

1356. Poterium sanguisorba. 6-9. An trockenen Hügeln häufig bis in die Voralpen. Im Gütschwalde.

\section{Holzgewächse.}

1357. P in u s a bies. 5. In allen Waldunbis 5000 Fuss Höhe.

1358. - picea. 5. Ebenso, doch nur bis 4000 Fuss Höhe. 
1359. $\mathrm{P}$ in us a l ba. In Anlagen.

1360. - larix. 4-5. Am Giitsch u. Dietschiberg bei Luzern. Um Uffikon und Wikon.

1361. - sylvestris. 5. Von der Ebene bis in die Voralpen, bei uns nicht häufig.

1362. - mo n t a na.

,a. - - uliginosa. Auf Sumpt- und Moorboden der Berge u. Voralpen. Im Torfmoos am Bürgen; im Vollenloch, Lauelenwald u. Eigenthal am Pilatus; bei Guggern an der Schafmatt.

๓b. - mont. uncinata. Auf Gürmschalp am Fusse des Fenersteins und Alp Grön an der Schafmatt.

„c. - mont. pu milio. Am Pilatus und am Fusse der höchsten Spitze des Feuersteins.

1363. - a u s tri a c a. 5-6. Im Guitschwald bei Luzern.

1364. - strobus. 5-6. In Anlagen und auf dem Guitsch u. Sonnenberg angepflanzt.

1365. Thuja oc cidentalis. 4-5. In Anlagen. So im Tivoli.

1366. - orientalis. Ebenso. 
1357. Juniperus eommunis. 5. Auf trockenen Hügeln, in Wäldern u. Gebüschen.

13b8. - n a na. Häıfig auf Alpen und Voralpen.

1369. - s a bi n a. 4-5. In Anlagen.

1370. - virginiana. Im Tivoli.

1371. Taxus ba c cata. In Bergwäldern vereinzelt. Am Fusse des Rigi, über Art, an der Postunen u. Hertenstein bei Weggis, von Weggis gegen den Rigi, zwischen Lützelau und Vitzuau; auf Biregg, in Haltiwald bei Ennethorw, in Entlebuch hin und wieder, bei Flïhli in der Lamm, auf Schwändealpfluh u. Kra. genberg, zu Romoos in Hintergadenstadt, bei Entlebuch im Rossfarren, am Napf bei Herrlisberg in der Ehrlosen, zwischen Hämikon u. Schongau am Lindenberg. In Gartenanlagen, z. B. im Tivoli.

1372. 1iuxus s e m p e rviren s. In Gärten zu Hecken und Einfassungen. Am obern Krienbach grosse Bäume in Freien.

1373. Ju g la n s regi a. 4-5. In der Ebene überall. 
1374. Alnu s glutinosa. An sumpfigen Stellen häufig, von der Ebene bis Bramegg.

1375. - in cana. An trockenen Stellen häıfig, besonders an Bachufern der Bergregion bis zur Buchengränze. 1376. - viridis. 5-6. Von der Hügelregion bis hoch in die Alpen. Häufig am Rooterberg, Dietschi- u. Sonnenberg, zwischen Malters und Schwarzenberg, auf Napf u. Rigi, auf den Romooserbergen, am Pilatus auf Klimsenhorn und der ganzen Alpenkette bis Rothhorn und Schratten.

1377. Betula alba. 4-5. Stellenweise auf sumpfigem n. trockenem Boden, an Bergabhängen von der Ebene bis zur Tannengränze.

a. - alba pendula. Gleiche Standorte.

b. - - verrucosa. Ebenso.

c. - - pubescens. 4-5. Am Sempacher- n. Wauwilersee, auf Seeboden am Rigi.

1378. Carpinus betulus. 4-5. In Wäldern, Hecken n. Gebiischen. Bei Uffil:on, Rothenburg, im Surenthal, in der Hasenwart bei Sursee, an der 
Hochfluh bei Reiden, im Letten, am Inwilerberg.

1379. Platanus occidentalis. 4-5. In Anlagen. Obergrund in Luzern.

1380. - orientalis. 4-5. In Anlagen.

1381. Morus alba. 5-6. Angebaut.

1382. - nigra. 4-5. Ebenso.

1383. Quercus pedunculata. 5. In der Ebene häufig bis zur Gränze des Nussbaumes zerstreut, selten als grössere Waldungen angepflanzt.

1384. - sessiflora. 6. Bis 3000' Höhe. Am Fusee des Rigi und mit der andern vermischt fast überall.

1385. Corylus avellana. 2-3. Ueberall in Hecken und Gebuischen bis zur Buchengränze.

1386. - tubulosa. 2-3. In Gärten.

1387. Castanea vesca. Häufig am Fusse des Rigi, von Greppen bis Vitznau, bei Meggen, Horw auf Kastanienbaum.

1388. Fagus sylvatica. 5. Ueberall bis 4000' Höhe.

1389. Ficus carica. Zu Lützelau bei Weggis in Freien, sonst in Gärten. 


\section{D i o e c i a.}

\section{Holzartige Gewächse.}

1390. Empetrum nigrum. In Torfsümpfen der Alpen. Am Fusse des Rothhorns, auf Torfboden am Feuerstein.

1391. Vis cum a lbu m. 3-4. Auf 0bstbäumen schmarotzend.

1392. Salix alba. 4-5. Am Ufer von Seen, Flüssen und Bächen häufig.

1393. - vitellina. Gleiche Standorte.

1394. - fragilis. 4-5. An Hecken u. Bächen. Am Bächlein gegen Littau, bei Meggen, Neuenkirch, im Surenthal, bei Buttisholz.

1395. - babylouica. In Anlagen.

1396. - riparia. 4. Gemein, an Bach- u. Flussufern bis in die Voralpen. Am Luzerner- und Sempachersee, an der Reuss u. Emme, bis hinter Flühli.

1397. - retusa. 6-7. Am Pilatus, von Bründlenalp bis Tomlishorn, Esel u. Mittaggipfi, auf Rigi, Rothhorn, Nesselstock, Schimberg u. Schratten. ra. - - kitaibiliana. 5-6. Am Pila- 


\section{$-206$}

tus, auf Briindlenalp, an feuchten, felsigen Stellen, zwischen Klimsenhorn und Heidentannli, in Emmenthal an der Schratten.

1397.b. Salix retusa denticulata. 5-6. Auf Bründlen.

, c. - - serpyllifolia. 5-7. Am Fusse des, Esels, auf Mattgrat, Mittaggipfi und Klimsenhorn am Pilatus.

1398. - herbacea. 7-8. Am Rothhorn, zwischen Maisee und dem Gipfel.

1393. - hastata. 7. Am Nesselstock häufig, auf 'Tagweid, am Rothhorn, Schrattenfluh.

1400. - pilosa. Am Pilatus auf felsigen Stellen, im Aufsteigen rom Mühlemääs gegen das Engelfeld am Klimnsenhorn, zwischen Bründlen und Gemsmätteli.

1401. - triandra. 4-5. Nicht selten in Hecken und Gebiischen, an Bächen und Flussufern bei Luzern, Malters, Littau, Hochdorf, fast uiberall.

na. - - a m y g dalina. Gleiche Standorte.

.b. - - stipularis. Ebenso.

1402. - pentandra. 5-6. Häufig in Anlagen, sonst zerstreut in der Alpenund Voralpenregion. 
1403. Salix nigricans. 4-5. An Hecken, in Wäldern u. Gebiischen.

1404. - purpurea. 4-5. Gemein in Hecken und Gebüschen, Abhängen, Bachufern bis zur Buchengrenze.

1405. - capraea. 3-4. Häufig in Hecken, Gebüschen, Tobeln, Abhängen, meist mit trockenem Boden.

1406. - cinerea. 3-4. Häufig an Gräben, Hecken und Gebiischen, meistens auf feuchtem Boden.

1407. - grandifolia. 4-5. In Bachtobeln der Bergregion bis zur Buchengränze. An der Renggbrücke, im Rothenburgertobel, gegen Hergottswald, im Blattigbachtobel, am Weg nach Brïndlen, beim Kloster Werthenstein, von Sörenbergli bis Sörenberg.

1408. - a urita. 4-6. An feuchten, sumpfigen Stellen der Ebene u. Berge bis zur Buchengränze. Im Eigenthal, auf Nühlemääs, Branegg, Emmen thal an der Scluratten.

1409. - repens. 4-5. Auf Torfmöösern bei Manensee $u$. Wauwil, am Rothsee, bei Muinster, im Schongauermoos und Zellmoos bei Sursee.

1410. - reticulata. 6-7. Auf allen unse- 
ren Alpen iiber der Tannengränze, zerstreut. Am Pilatus im Nauen, auf Schratten, Tagweid am Rothhorn und Nesselstock.

1411. Populus tremula. 3-4. In Wäldern, Hecken und Gehiischen bis in die Voralpen.

1412. - alba. 4. In Anlagen.

„a. - ea nes e ens. Ebenso.

1413. - nigra. 4. An Bächen u. Flüssen häufig. An der Emme und Reџss.

1414. - pyramidalis. 4. In Alleen.

\section{Kräuter.}

1415. Tamus communis. 5-6. An Hecken, Gebüschen und Wäldern. Um Luzern gegen Littau, Adligenschwil 11. Ebikon, im Schilt- und Galgenwald an der Reuss, am Emmerberg von Langnau bis Malters, bei Weggis, in der Ehrlosen, am Lindenberg. 1416. Humulus lupulus. 7-9. Wild an Hecken u. Zäunen der Ebene häufig, längs der Emme bis Werthenstein, auf der Horwerallmend längs der Strasse. Angebaut bei Vitznau. 1417. Cannabis sativa. 7-8. Angebaut. 
1418. Rhodiola rosea. Auf dem Pilatus?

1419. Mercurialis perennis. 4-5. In Gebüschen $u$. Wäldern häufig, fast iiberall bis zur Buchengränze. *)

1420. - annua. 6-9. Zwischen Sursee und St. Erhardt auf Aeckern.

\section{G I a m ace a e.}

\section{Gramina.}

1421. Anthoxanthum odoratum. 4-5. Ueberall von der Ebene bis in die Alpen.

1422. A lopecurus agrestis. Auf Aeckern im Hitzkircher- u. Surenthale, häufig bei Sursee, Tann u. Bïron.

1423. - pretensis. 6. Auf Spissen bei Heggen, an den Strassenrändern u. der Eisenbahn bei Emmenbriicke.

1424. - geniculatus. In Sumpfgräben. 1425. - fulcus. Am Luzernersee, in der Rhone bei Dierikon.

*) Durch Abkochen und Verdunsten gewinnt man daraus eine schöne braune Malerfarbe, ähnlich der Terra siena. Ich habe sie probirt zum Koloriren von Pflanzent abbildungen und sie gut befunden. 
1426. Phleum pratense. Ueberall in Aeckern, Feldern und Wiesen.

, a. - - nodo sum. Ebenso.

1427. - a lpinum. 7-8. Auf allen unseren Bergen und Alpen.

1428. - commatatum. 7-8. Auf Rigi, Napff, Pilatus und allen höhern trockenen Alpen.

1429. - michelii. 7-8. Am nördl. Fusse des Nesselstocks, häufig in Geröll, u. von da iiber Tagweid bis Maisec, auf Rigi, Pilatus an der Holzflub, auf Emmenthalfluh an der Schratten.

1430. Phalaris arundinacea. 6-7. An Gräben, See'n und Teichen häufig. Am Luzermer- u. Rothsee, längs der Reuss, am Sempachersee, an den See'n des Hitzkircherthals, im Wiggrerthal.

1431. - picta. In Gürten u. auf Kirchhöfen. 1432. Leersia oryzoides. 7-9. In Gräben bei Emmen, Rothenburg, Klöpfen, Eschenbach, Ebikon, Buchenrain, Root, Meierskappel, Kiissnacht.

1433. Panicum gl a ucum. 6-8. In Stoppelfeldern, an trockenen Hügeln überall. 
1431. Panicum viride. 7-9. In Getreideäckern häufig.

1435. - it a licum. Angebant.

1436. - crus galli. 7-8. In Dörfern unit an Misthaufen nicht selten, an Wegen und Strassen iberall.

1437. - mileaceum. 6-7. Angebant.

1438. - sanguinale. 7-8. An den Hauem von Luzern, neben der Reuss. An Wegen, Strassen u. Feldern zerstreut. 1439. - glabrum. 6-7. Auf trockenen, sandigen Stellen. Bei Luzern, Buchenrain, zwischen Seesatz u. Sempach, auf den Anhöhen bei Reiden.

1440. - nigricans. In Gärten.

1441. Milium effusum. 6-8. In Wäldern häufig.

1412. Agrostis vulgaris. 6-7. Fast uiberall an Hügeln und Waldrändern.

na. - - stolonifera. Gleiche Standorte.

"b. - - hispida. Ebense.

1443. - stolonifera. 6-7. Wie lie Vorige häufig.

"a. - - alba. Ebenso.

"b. - - gigantea. Ebenso.

144t. - spica venti. 6-7. Häníg in (retreideäckeriı. Bei Sursee, Ettiswil, Miunster, Nendori, im Hitzkircher-n. 


\section{- $212-$}

Wiggerthal, bei Schongan, Roggliswil.

1445. Agrostis tenella. 7-8. Aut Alpwiesen im Entlebuch u. am Pilatus. 1446. - alpina. 7-8. Auf felsigen Stellen der Alpen. Auf 'Tomlisalp, Rigikulm u. Scheidegg, Rothhorn, Feuerstein u. Schafmatt.

1447. - rupestris. 7-8. Auf Rigischeidegg, an Felsen des Filatus, am Esel, auf Tomlisalp, Mittaggipfi, Gemsmätteli und Feuerstein.

1448. - canina. 6-7. Auf feuchten Wiesen u. Torfboden. Bei Mauensee, im Wauwilersumpf.

1449. Calamagrostis pseudophragmites. 7-8. Häufig an Reuss u. Emme.

1450. - argentea. 7-8. An felsigen Stellen. Am Fusse des Rigi bei Liitzelau, Vitznau u. Gersau, am Urmiberg u. Lopper.

1451. - lanceolata. 7-8. Am Luzernersee.

1452. - montana. Auf Hügeln u. Bergen. Am Gütsch bei Luzern, an der Emme bei Dorenberg, Werthenstein, an der Ringfluh am Pilatus.

1453. - grostis acutiflora. 7-8. Bei Phi- 
lipp Neri im Renssthal, an der Schletzhalden bei Luzern, am obern Krienbach u. an der Emme.

1454. Ca la ma stricta. 7-8. Am Maunsee. 1455. Molinia caerulea. 8-9. In Waldungen, auf feuchten Wiesen, auf Riedboden der Ebene und Berge häufig.

1456. Ielica nutans. 5-6. In schattigen Wäldern u. Gebüschen nicht selten. ,a. - ciliata. 6-7. Am Wege von Weggis nach Vitznau bis Kindlismord.

1457. Triodia decumbens. 6-7. Hänfig in Berggegenden bis in die Voralalpen. In Rifig, bei Rothenburg, Eschenbach, am Lindenberg, Hundsrücken, bei Miihlegg, auf Rigi, Seeboden, Urmiberg, von Kriens bis Mühlemääs, ain Lopper, Bürgen, vom Schwarzenberg bis Napf.

1458. Phragmites communis. 8-9. An See'n, Teichen, Fliissen und Siimpfen häufig.

1459. B riza media. 6-7. In Wiesen und Weiden der Ebene u. Berge, gemein, bis in die Alpen.

1460. Brizopyrum seculum. In Gärten. 
1461. Po a annua. 3-10. Ueberall sehr gemein, in Wiesen, um die Häuser, an Wegen der Ebene bis in die Alpenregion.

1462. - al pina. 6-7. Auf allen unseren Alpen häufig.

"a. - - vivipara. 6-7. Ebenso.

"b. - - brevifolia. Ebenso.

1463. - laxa. 6-7. Am Pilatus hin und wieder, bei Frakmünd, Brindlen; häufig am nördilichen Abhang und Geröll des Nesselstocks, zwischen Maisee und Staffelalp am Rothhorn. 1464. - mino r. 7-8. Am Fusse des Rothhorns.

1465. - trivialis. 6-7. Auf fenchten Wiesen und nassen Stellen, gemein.

1466. - pratensis. 5-7. Auf allen Wiesen sehr häufig.

"a.- - latifolia. Gleiche Standorte.

„b. - - angustifolia. Ebenso.

1467. - nemoralis. 6-7. In Hecken, Wäldern und auf Felsen.

.. a. - - vulgaris. Gleiche Standorte.

"b. - - firmula. Ebenso.

"c. - - gla u ca. Ebenso.

468. - scrotina. 7-8. Häufig in Strencriedern an luzernersee, von der 
Halden bis Wuilzenbach und am Rothsee.

1469. Poa caesia. 6-7. Auf Aeckern bei

Hämikon.

1470. - eompressa. 7-9. An trockenen magern Orten nicht selten. Bei Buchenrain, zwichen Hochdorf und Baldegg, bei Roggliswil, zwischen Kaltbach 11. Egolzwil, Hafendeckel, bei Nenegg zu Meggen.

1471. - distichophylla. 7-9. Im Geschiebe des Pilatus, im Nanen, zwischen Esel und Ringluh, über Staffelhuitte; anf Rigischeidegg, zwichen Maisee und Staffelalp am Rothhorn. 1472. Glyceria fluitans. 6-7. In stehenden 11. fliessenden Wassern, an Gräben häufig.

1473. - spectabilis. 7-8. In stehenden u. langsam fliessenden Wassern. Im untern Theile des Wiggerthals, bei Dagmarsellen im Dortbach und Schmïrzgraben häufig, n. hinab lois Reiden und Langnau.

1474. - aquatica. 6-7. In Gräben hin u. wieder. Bei Sursee und Mauensee. 1475. Cynosurus cristatus. 6. Auf allen Wiesen bis in die Alpen. 
1476. Dactyli s g lomerat a. 6-9. Ueberall von der Ebene bis in die Alpen.

1477. Koeleria cristata. An trockenen Stellen häufig. Bei Wetzwil, Krumbach, Hafendeckel, am Rooterberg. 1478. Sesleria caerulea. 4-6. Anf Bergen u. Alpen. Auf Pilatus, Rigi, Schimberg, Napf und in den Entlebucherbergen.

1479. Aira cespitosa. 6-9. Häufig an feuchten sandigen Stellen der Ebene und Berge.

1480. - flexu osa. 6-8. Auf Bergen bis in die Alpen. Auf Rigi, Pilatus u. den Entlebucherbergen.

1481. - cary o p hyll ea. 6. Zwischen Langnau und Pfaffnau.

1482. A vena sativa. 7-8. Angebaut.

1483. - orientalis. 7-8. Ebenso.

1484 - elatior. 6-8. Ueberall in Wiesen und Aeckern.

1485. - bulbosa. 6-8. In Aeckern als Unkraut.

1486. - pubescens. 6. In Wiesen nicht selten. Um Iuzern, im Hitzkircherund Surenthal.

1487. - pratensis. 6-7. Am Fusse des Pilatus hin u. wieder, bei Alpnacht. 
1488. Avena flavescens. 7-9. In Wiesen häufig.

1489. - distichophylla. 7-9. Zwischen Esel und Ringfluh am Pilatus in Geschiebe.

1490. - versicolor. Am Felsengrat zwischen Gugel und Feuerstein, unter Naisee am Rothhorn, am Pilatus auf Klimsenhorn, 'Tomlihorn u. Widderfeld.

1491. Holcus lanatus. 5-8. Ueberall in Wiesen.

1492. - mollis. 6-8. Nicht so häufig. An Hecken, Strassen u. Waldrändern. Bei Adligenschwil, Littau, Sempach, im Surenthal, bei Kulmerau, Malters und Miiswangen.

1493. Festuca ovina. Auf trockenen Wiesen, in der Nähe von Torfmöösern. Zwischeu Münster u. Tann, bei Udligenschwil u. an Hochfluh bei Reiden.

1494. - halleri. Auf Rigikulm, Eselsgrat, Tomlisalp u. Klimsenhorn am Pilatus, auf Feuerstein und Rothhorn.

1495. - alpina. Auf Tomlisalp, Eselsfluh u. Gemsmätteli am Pilatus, auf Rigi, Schratten, Feuerstein u. Schafmatt. 
1496. Festuca duriuscula. 5-6. Auf trokenen Hügeln u. Wiesen der Lbene Berge und Alpen.

,a. - dur. hirsuta. 5-6. Gleiche Standorte, doch seltener.

1497. - gl a u ca. 5-6. Auf den Sandhiigeln im Wiggerthal, von Dagmarsellen bis Wikon, diesseits des obern Stermels häufig, auf Hochıluh.

1498. - violacea. 7. Am Pilatus häıfig. Im Nauen, am Klimsenhorn u. Eselsfluh; auf Tagweid am Fusse des Rothhorns.

1499. - varia. 7-8. Am Pilatus auf Klimsenhorn, Riugfluh und Tomlisalp nicht selten.

1500. - pumila. An der Rigi hin u. wieder; häufig am Pilatus, auf Klimsenhorn, Tomlisalp, Gemsmättli, Ringfluh; auf Tagweid an Rothhorn, am Schimberg, auf Schafmatt, aufschrat ten.

1501. - heterophylla. 5- 7. An lichten Stellen am Luzernarsee, auf Hiigeln bis in die Alpen.

1502. - rubra. 5-7. In Gebiischen u. Wiesen, au Waldrändern u. grasreichen Stellen hä ufig. 
1502.a. Festuca rubra megastachys. An vorigen Standorten.

„b. - - longiseta. Ebenso.

"c- - nigrescens. Ebenso.

1503. - arundinacea. 6-7. An Flussufern und sandigen feuchten Orten. An der Reuss u. Emme von Wohlhusen bis Gisikon, an der Wigger u. am Sempachersee.

1504. - pratensis. 5-6. Ueberall an Wegen u. auf Wiesen bis in die Voralpen. na. - - loliacea. 5-6. Am Lindenberg u. an Waldrändern bei Müswangen. 1505. - sylvatica. 6-9. In Berg- u. Alpwäldern. Am Rigi bis Seeboden und Dächli; im Aufsteigen nach Bründlen und Tellenpfad am Pilatus, am Bürgen und Nesselstock.

1506. - scheuchzeri. 6-8. Auf Pilatus, an Esels- u. Ringfluh, vom Heidentannli bis Klimsenhorn, auf Staffelalp, am Nesselstock u. Rigidossen. 1507. - gigantea. 6-8. An schattigen Orten, in Hecken u. Gebüschen.

1508. - aspera. 6-7. In Hecken, Gebiischen und Waldungen.

1509. - erecta. 6-9. Ueberall in Wiesen der Ebene und Berge. 
1510. Bromus sterilis. 7-8. An Wegen und ungebanten Stellen. Um Luzern an der Halden, bei Rothenburg, am Fusse des Rigi bei Weggis, Vitznau und Gersau.

1511. - mollis. 6-8. Ueberall in Wiesen.

1512. - arvensis. 6-7. In Getreideäckern. hin u. wieder. Am Sempachersee, zwischen Bahnstation und Seehiisli, und im Hitzkircherthal.

1513. - scealinus. 6-7. Unter dem Getreide häufig, fast überall.

1514. - velutinus. 6-7. Unter dem Getreide hin und wieder.

1515. Brachy podium sylvaticum. 6-8. In Hecken, Gebüschen u. Wäldern iiberall.

1516. - pinnatum. 6-8. An Wegen, Gebiischen $u$. Waldrändern. Zwischen Rothenburg u. Neudorf, Baldegg u. Gelfingen. Am Fusse des Rigi bei Vitznan und Weggis.

1517. Nardus stricta. 5-7. Auf trockenen Bergweiden bis hoch in die Alpen. Auf der Spitze des Feuersteins. 1518. Lolium temulentum. 6-7. Als Lnkraut unter allem Getreide.

1519. - arvense. 6-7. Hie $u$, da, doch 
selten, im Getreide und auf Wiesen. Auf der Musegg bei Luzern, u. gegen die Hochfluh bei Reiden.

1520. Lolium perenne. 6-7. Fast iberall an Wegen; in Wiesen oft angebaut.

ra. - - tenue. 6-7. Gleiche Standorte.

"b. - - ramosum. Ebenso.

„c. - - compositum. Ebenso.

1521. - multifl or u m. 6--8. Um Luzern häufig, an der Halden, bei Weggis und Buchenrain.

„a. - - muticum. 6-8. Gleiche Standorte.

„b. - - ramosum. 6-8. Bei Meggen.

1522. Triticum vulgare. Angebaut.

1523. - turgidum. Selten gebaut.

1524. - spelta. Angebaut.

1525. - di c o c e m. In Berggegenden gebaut.

1526. - monососеит. Auch so, doch seltener.

1527. - repens. 6-8. In Aeckern u. Wiesen häufig.

1528. - caninum. 6-8. In Hecken und Gebüschen nicht selten. Um Luzern u. Ebikon, im Hitzkircher-, Wiggeru. Surenthal, am Fusse des Rigi bei Vitznau, Gersau und Kindlismord. 
1529. Triticum intermedium.6-8. Beim Einfluss des Würzenbachs in den Luzernersee.

1530. Secale cereal e. 6-7. Angebaut.

a. - cornatum. Verdorbener Auswuchs des Vorigen.

1531. Hordeum murinum. 6-9. An Wegen, Mautern und Schutthaufen nicht selten. Bei Luzern, am Fusse des Rigi zwischen Weggis und Gersau.

1532. - sylvaticum. 6-7. In Bergwäldern zerstreut. Im Schachenwald

- beim Hergottswald, im Rifig, am Lindenberg, bei Hämikon u. Schongau, auf Bramegg und Schwarzenberg, in Aufsteigen nach Brïndlen und Tellenpfad, am Biirgen, bei Brürderu am Schimberg, Kurzenliutten bei Fliihli, am Napf, Rigi iiber Vitznau, unter Seeborlen, beim Dächli.

1533 - vulgare. Angebaut.

"a. - - coeleste. Ebenso.

"b. - - hexastichon. Ebenso.

, c. - - distichon. Ebenso.

1534. Andropogon is chaemum. 7-8. An trockenen Hügeln. Bei Ermensee, Hitzkirch, von Weggis bis Kindlis- 
mord, zwischen St. Erhardt und Dagmarsellen, am Berge von Büron bis Kulmerau.

1535. Zea mais. 6-7. Angebaut.

1536. Sorghum c n orum. In Gärten.

\section{Cyperaceae.}

1537. Cyperus flavescens. 7-9. Auf feuchten, sumpfigen Wiesen nicht selten. Im Suren- u. Hitzkircherthal, bei Baldegg, Hiltislehn bei Waldibrücke, am Sempachersee, bei der Miihle zu Buchs, Meierkappel und Küssnacht, von Brunnen bis Goldau.

1538. - fuscus. 7-9. Nit dem Vorigen. Am Sempachersee, im Surenthal bei Büron, Baldegg, Mauensee, Wauwil, St. Lrban, Miihle bei Buchs.

1539. - longus. 8-9. Am Luzernersee beim Wiirzenoach, und bei Meggen unter Käppelihof, bei Küssnacht.

1540. - flavabellatum. In Gärten, doch selten.

1541. Schoenus nigricans. Am Sempacher-, Wauwiler-, Baldegger-, Rothund Manensee, Mosen, Weggis und auf Horwerallmend. 
1512. Schoenus ferrugineus. 5-6. An vorigen Standorten, häufig.

1543. - mariscus. 7-8. An unsern kleinen See'n. Am Rothsee u. Manensee.

1544. - albus. 7-8. An Siimpten. Am Roth-, Wauwiler-, Mauen- u. Hallwilersee, am Nasssteg bei Meggen, im Forrenmoos bei Meierskappel, Holzgut bei Schüpfheim, auf Rigiseeboden.

1545. - fuscus. 6. Bei Wauwil.

1546. Scirpus palustris. In Sümpfen"u. auf Torfboden überall. Ain Luzernersee, im Suren-, Hitzkircher- und Wiggerthal.

1547. - ba e othryon. 7-8. In Siimpfen. Bei Schenkon am See, bei Aesch, Mauensee und Wauwil.

1548. - a c i cularis. 6-8. In Sümpfen bei Wauwil, am Sempachersee, bei St. Urban am Fischweiher, Langenthal zu, bei Schongan, Goldau.

1549. - cespitosus. Auf Bergsiimpfen, fast überall. Auf Rigischeidegg, im Eigenthal, auf Brïndlen und Oberalp, von Langwasen bis Mühlemääs, 
auf Gürmsch, Wisenegg, Sörenberg und Salwidli im Entlebuch.

1550. Scirpus ovatus. 7-8. Bei Meggen am See, am Hallwilersee.

1551. - la custris. Ueberall an See'n u. Teichen und grossen Gräben.

1552. - triqueter. 7-8. Im Surenthal. 1553. - s ylva ti cu s. 6-7. Häufig an Gräben $u$. in nassen Wäldern.

1554. - m a ritimus. In Torfsiimpfen bei Wauwil, südwestl. der Bahnstation. 1555. - s e t u c e u s. 7-8. An feuchten Wegen zwischen Rathhausen u. Buchenrain, bei Dierikon, im Fahrnbühl.

1556. - c o mpressus. 6-8. Auf feuchten, sumpfigen Stellen der Ebene u. Berge.

1557. Eriophor um latifolium. 5-6. Auf Siimpfen der Ebene 1. Berge häufig.

1558. - angustifolium. In Berg- u. Alpensümpfen häufig. Auf Rigischeidegg und Seeboden, Langwasen, Gürmsch. Auch in der Ebene. Im Wauwilersumpf.

1559. -- triquetrum. 5-7. Im Sumpfe bei Wauwil, Manensee, auf Rigiseeboden. 
1560. Erio $p$ h orum al $p$ in un. Auf Torfboden der Ebene u. Alpen, nicht selten. Am Rothsee, bei Wauwil, auf Langwasen ob Kriens, im kntlebuch, Sörenberg, Wisenegg und Salwidenbad, auf Giirmsch bis F'euerstein, in den Pilatussümpfen, $\boldsymbol{a u f}$ Rigiseeboden.

1561. - vagi n t u m. 6-8. In Sümpfen und auf Torfboden der Ebene und Berge häufig. Bei Wauwil, am Rothsee, auf Rigiseeboden, im Pilatussumpfe zwischen Kastelen u. Klimsenhorn, Oberalp, bei Salwiden und Guirmsch.

1562. - c h e u ch z e r i. 6-8. An Sumpfstellen der Schratten, auf Rigischeidegg.

1563. Sparganium ramosum. 6-7. In Sumpfgräben u. an Teichen häufig. 1564. - s i m plex. 7-8. Gleiche Standorte, duch seltener. Am Luzernersee, im Wanwiler-Sumpf. In Sumpfgräben zwischen Römerschwil u. Hildisrieden, zwisehen Ebikon 1. Dicrikon.

1565. - n a t a n s. 6-7. Bei Wauwil.

1566. 'T y p ha latifolia. In stehenden Wassern, Teichen u. Siimpfen. Am Lnzerner-, Sempacher- und Rothsee, 
bei Oberhocken und im Surenthal, häufig am Mamensee und im Wauwilersumpf, massenhaft an der Luthernbriicke bei Nebikon.

1567. Ty p ha angustifolia. 6-7. An der Reuss, von der Emmenbriicke bis Gisikon, an feuchten, sandigen Stellen häufig.

1568. Carex davalliana. 4-6. Auf Sïmpfen u. sauern Wiesen der Ebene, Berge u. Alpen häufig.

1569. - dioica. 5. Auf Torfsümpfen bei Wauwil, am Manen- 11. Rothsee, im Mohrenthal bei Luzern, auf RigiSeeboden.

1570. - pulicaris. 5. Auf Sumpfboden nicht selten. Am Roth- u. Mauensee, bei Wauwil, bei Horw hinter Leim, im Müiswangermoos bei Oberschongau, am Fusse des Schimberg, bei Geugelhusen, im Eigenthal am Pilatus bis zur Buchengrenze, auf Rigi-Seeboden.

1571. - pauciflora. 5-6. Auf 'Torfsimpfen der Ebene bis in die Alpen. Im Rothenburgerwald, auf Schneeälplein u. Seeboden am Rigi, Oberalp am Pilatus, Vollenloch, im Ei- 


\section{$-228$}

genthal, Sörenberg, Gürmsch, Salwidli, zwischen Rothhorn u. Schrattenfluh, u. andern Stellen im Entlebuch.

1572. Carex paniculata. 5-6. In Sümpfen der Ebene u. Berge. Am Rothu. Baldeggersee, auf Rigi-Seeboden, gegen die Kulm, im Eigenthal, auf Bründlen u. Oberalp am Pilatus, vom Grund am Schimberg bis Gürmsch.

1573. - teretiuscula. 5-6. Auf Moorboden häufig. Am Rothsee, auf Horwerallmend, bei Wauwil, an allen unseren See'n.

1574. - paradoxa. 5-6. Auf Sumpfboden, an unsern See'n hin u. wieder. Am Roth- u. Luzernersee.

1575. - vulpina. 5-6. An sumpfigen Stellen, Gräben u. See'n. Im Surenthal, bei Ebikon und Emmen.

1576. - nemorosa. 5-6. An trockenen Stellen. Auf dem Hundsriicken bei Buchenrain.

1577. - muricata. 5-6. An trockenen u. feuchten Stellen, Wegen, Wald- u. Strassenrändern, in Gebuischen, Wiesen u. Wäldern der Ebene u. Berge. „a. - - virens. 5-6. Gleiche Standorte. 
1578. Carex stellulata. 5-6. An feuchten, sumpifigen Stellen, an allen unsern See'n. Auf Gütsch, im Eigenthal, auf Rigi, vom Langwasen bis Nauen u. Klimsenhorn am Pilatus.

1579. - leporina. 5-6. Auf feuchten Wiesen, an Wegen $u$. Waldrändern der Ebene und Berge. An der Reuss, am Luzernersee, bei Wauwil, im Rifig, Muiswangermoos, am Rotherberg, im Eigenthal, auf Bramegg, Gürmsch, Rigi, bis Scheidegg.

1580. - brizoides. 5-6. In Hecken, Gebuischen $u$. Waldungen häufig. An der Halden, in Eich- u. Giitschwald bei Luzern, bei Udligenschwil, Root, Eschenbach u. Hochdorf.

1581. - canescens. 5-6. Auf Sumpf- u. Torfboden in Wäldern. Am Gütsch, bei Rothenburg, bis in die Sümpfe von Oberalp und Klimsenhorn am Pilatus, von Rigi Klösterli bis Scheidegg.

1582. - elongata. 5-6. Auf feuchten u. sumpfigen Stellen. Am Roth- und Baldeggersee, im Rifig, an Gräben des Liliewaldes, zwischen Buchenrain u. Rathhausen. 
1583. Carex remota. 5-6. In feuchten, schattigen Wäldern. Am Gütsch, Biregg, Riffig und Surseerwald, im Chüsirain, Haltikon, Küssnacht, Rigi, beim Dächli.

1584. - atrata. 7-8. An der Pilatuskette an trockenen Stellen. Am Fusse des Esels, auf Klimsenhorn, Laub- u.'Tomlisalp, auf Widderfeld am Pilatus, auf Haglern, Maisee, am Rothhorn.

na. - atrata nigra. Gleiche Standorte.

"b. - - aterima. Ebenso.

1585. - praecox. 3-5. Häufig an Wegen, Weiden $u$. Waldrändern der Ebene und Berge bis in die Alpen.

1586. - longifolia. 4-6. In Gebüschen u. Hecken. Nicht selten bei Luzern, Rothenburg, Baldegg $u$. Schongau.

1587. - montana. 4-5. In der Hügel- $u$. Bergregion bis zur Tannengränze, an Rainen, Wäldern u. Gebüschen nicht selten. Häufig am Lindenberg, von Schongau bis Hohenrain, Kirchhalden bei Geuensee, am Rigi, Napf und Pilatus.

1588. - tomentos a. 5-6. Auf feuchten Wiesen und in schattigen Wäldern. Am Rooterberg, im Miiswangermoos, 
bei Emmen, Rothenburg, zwischen Nenalp u. Schwarzenberg, auf Sumpfstellen bei Goldau.

1589. Carex pululifera. 5-6. In Wäldern n. Gebiischen, an grasreichen Stellen hin u. wieder. Bei Rothenburg, am Lindenberg, zwi chen Miiswangen u. Kilchholz, Guggibad, in Wäldlein am Rothsee, am suidlichen Abhange des Feuersteins, auf Muihlemääs und Rigischeidegg.

1590. - humilis. 3-5. An trockenen Stellen, selten, weil schwer zu finden. Bei Dagmarsellen, gerade iiber dem Waisenhanse am Berge, an der Hochfluh bei Reiden, am Lopper, zwischen Riitli u. Seelisberg, Vitznau u. Gersau.

1591. - digitata. 4-5. Ueberall in Wäldern und Gebüschen der Ebene und Berge bis zur Tannengrenze.

1592. - ornithopoda. 4-5. Häufig auf etwas feuchten Stelleu, Wiesen, Gebiischen $u$. Waldungen, oft neben digitata, von der Ebene bis in die Alpen und selbst iiber die Tannengränze.

1593. - sempervirens. 7-8. Häufig auf trockenen Weiden. Auf Rigi und 


\section{- $232-$}

Napf und der ganzen Pilatuskette bis Roth- $u$. Tannhorn, an der Schratten u. Schrattenhöhe. Unter Rigistaffel häufig mit C. tenui u. C. ferruginea.

1594. Carix ferruginea. Häufig auf unseren Bergen. Auf Rigi, Napf, Enzifluh, an der Pilatuskette bis Rothhorn u. Schratten.

1595. - fuliginosa. Auf Gürmsch, Feuerstein, Napf u. Enzifluh, u. andern Stellen des Entlebuchs.

1596. - firma. Am. Pilatus häufig an felsigen Stellen, massenhaft zwischen Trockenmatt u. Mittaggipfi, im Aufsteigen nach Bründlen, am Mattgrat und am Fusse des Esels, am Stricktossen, auf Schratten, Schimberg, Rothhorn, Rigi, Napf und Enzifluh.

1597. - tenuis. 6-7. An fenchten Stellen der Alpen. Auf Rigikulm gegen das Klösterli, auf Rigistaffel am Wege nach Küssnacht, an felsigen Stellen bei Seewen, auf Pilatus an der Ringfluh u. Schwendialp, Schratten.

1598. - c a pillaris. 6-7. Am Feuerstein, Pilatus auf Mattgrat, am Fusse des Esels. 
1599. Carex al ba. 4-5. An Wegen, Gebüschen und Wäldern der Ebene bis zur Buchengränze. Bei Littau, an der Reuss in Schilt- u. Galgenwald, bei Schongau am Geissenrain. Lopper, vou Vitznau bis Seewen.

1600. - nitida. 5. Auf trockenen Stellen. Am Sempaehersee, zwischen Zellmoos und Oberkirch.

1601. - p a n i c e a. 5-6. Auf feuchten, sauern Wiesen iiberall, von der Ebene bis in die Alpen.

1602. - distans. 5-6. Auf feuchten Wiesen nicht selten. Am Luzernersee, Horwerallmend, im Hitzkircher- und Surenthal, auf Miiswangermoos.

1603. - hornschukkiana. 5-6. Auf feuchten Wiesen und in Sümpfen nicht selten, von der Ebene bis in die Voralpon. Am Luzernersee, bei Wauwil, Hauensee, Horwerallmend, im Hitzkircherthal, Eigenthal hinter Rothstock häufig, auf́ Rigi-Seeboden.

1604. - fulva. 5-6. An Gräben bei Wauwil, am Mauensee, auf Rigi-Seeboden.

1605. - sylvatic a. 5-6. Häufig in Wäldern. 
1606. C a rex maxima. 6. In feuchten Waldtobeln, hin- u. wieder. Am Giitsch, im Schachen-, Ebikoner- und Haltiwald, am Stämpfelberg, Hafendeckel, zwischen Fahrnbiihl u. Rothenfluh, in Meggerwald, Meierskappel, auf Rigi beim Dächli, unter Seeboden.

1607. - pseudocyperus. 6-7. An unsern kleinen See'n nicht selten. Am Sempacher- 11. Rothsee, an Gräben zwischen Wauwil und Mauensee, St. Urban u. Roggwil, beim Ettiswiler-Weiherhaus.

1608. - pallescens. An feuchten u. trockenen Orten der Ebene und Berge häufig. Von Langwasen bis Eigenthal, von Weggis bis Rigikulm und Scheidegg; auf Giirmsch.

1609. - flava. 5-6. An feuchten u. sumpfigen Orten. Am Luzerner- 11. Rothsee, im Suren-, Wigger- u. Hitzkircherthal. Nicht selten, bis in die Berge. Auf Giirmsch.

1610. - o ederi. 5-9. Zwischen Eich und Sempach im Sande am See, längs der Reuss, am Mauensee bis in die Voralpen. 
1611. Carex limosa. 5-6. In Sümpfen der Ebene u. Berge hin u. wieder. Bei Wanwil, Egolzwil, Manensee, zwischen Sörenberg u. Salwiden, am Bürgen, aut Dossen u. Seeboden am Rigi.

1612. - irrigua. 6-7. Anf Oberalp u. am Pilatussee, auf Gürmsch.

1613. - cespitosa. 6-S. Aut Sumpf- u. Moorboden der Ebene 11. Berge hin u. wieder.

1614. - vulgaris. 6-8. Hänfig an gleichen Standorten. Auf Rigi vom Klösterli gegen die Kulm und Scheidegg häufig; am Pilatus auf Langwasen, im Eigenthal, Mühlemääs, auf Brïndlen, Oberalp, im Nauen u. an Fusse des Esels; im Sörenberg, Salwidli und Giirmsch.

1615. - stricta. 5-6. Gemein, an Sümpfen, Torfmoosen u. Gräben.

1616. - acuta. 5-6. Im Hitzkircherthal, in Gräben zwischen Ballwil i. Hochdorf, bei Nunwil am See, zwischen Kleindietwil u. Sulzberg, am Rothsee, Luzernersee am Badeplatz an der Halden, am Lowerzersee.

^a. - a cuta filipendula. 5-6. Häufig 
am Luzernersee an der Halden, südlich vom Badplatz.

1617. Carex glauca. 5-6. Auf Lettboden häufig, von der Ebene bis in die Alpen.

1618. - hirta. 5-7. An sandigen, feuchten Stellen der Ebene und Berge nicht selten. Am Luzernersee u. bei Sempach bis in die Voralpen. Auf Blasen bei Flihli und im Eigenthal.

1619. - fil i f o r m is. 4-6. Häufig in stehenden Wassern und tiefen Sümpfen. Am Roth-, Sempacher- und Mauensee, bei Mosen und Wauwil.

1620. - paludosa. 5--6. Häufig an Gräben und Sümpfen, an allen unsern See'n. 1621. - vesicaria. 5-6. An Gräben, in Sumpf- und Moorboden der Ebene und Vorberge, an allen unsern See'n. Zwischen Ebikon u. Root, im Surenthal, bei Wauwil, auf Rigi-Seeboden.

1622. - ambullacea. 5-6. An den gleichen Standorten bis in die Voralpen. Auf Rigi-Seeboden, beim Scewersee, am Feuerstein.

1623. Elyna spicata. Auf Oberhaupt und Tomli am Pilatus, selten. 


\section{Juncaceae \& Juncagineae.}

1624. Juncus glaucus. 6-8. An feuchten, sonnigen Orten häufig.

1625. - effu su s. 6-7. An feuchten, sumpfigen Stellen bis in die Alpen.

1626. - diffusus. 6-7. An feuchten, der Sonne ausgesetzten Stellen u. Grïben. An der Halde bei Luzern, zwischen Rathhausen u. Seehof, im Surseerwald.

1627. - conglomeratus. 6-7. Auf Torfboden, an schattigen feuchten Stellen der Ebene bis in die Alpen.

1628. - filiformis. 6-7. In Alpsümpfen, auf Rigischeidegg, zwischen Brïndlen und Oberalp, am Pilatussec, im Salwidli.

1629. - a cutiflorus. 7-8. An fenchten Riedstellen. Am Luzerner- und Mauensee, im Surenthal.

1630. - obtusiflorus. 7-8. Am Sempachersee, bei Aesch, Manensee. Au Gräben.

1631. - lamprocarpus. 7-8. An fouchten Stellen und Gräben.

1632. - alpinus. 7-8. An sumpfigen Stel- 


\section{$-238$}

len der Alpen und Voralpen. Auf Briindlen am Pilatus.

1633. J uncus bulbosus. 7-8. In Riedern und feuchten Wiesen häufig.

1634. - buf o n i us. 7-9. Häufig auf teuchtem thonhaltigem Boden u. an Wegen. 1635. - fasciculatus. 7-9. Bei der Sprengi zwischen Rothenburg u. Gerlischwil. 1636. - triglumis. Auf Rigikulm; auf Sumpfstellen zwischen Brïndlen 11. Oberalp am Pilatus häufig.

1637. Luzula pilosa. 4-5. In Wäldern

hin und wieder. Bei Udligenschwil. 1638. - forsteri. 6-7. Gleiche Standorte. 1639. - flavescens. 6-7. In Wäldern u. in der Voralpenregion. Auf Rigi unter Scheidegg, aut Höchberg, Lauelenalp und Miihlemääs, in feuchtem Torfboden nicht selten.

1640. - campestris. Auf Torfboden am Pilatus.

a. - - vulgaris. Gleiche Standorte.

"b. - - nemorosa. Ebenso.

"b- - nigricans. Ebenso.

16t1. - maxima. 5-6. In Wäldern nicht selten. An der Schletzhalden und Giitsch bei Luzern. 
1642. Luzula spadicea. 6-7. Häufig auf Mittaggipfi am Pilatus.

1643. - al bid a. In Bergwäldern nicht selten. Bei Geuensee, Büron, zwischen Sursee u. Knutwil, bei Sempach, Meggen u. Neuenkirch; bis an den Fuss des Napf, im Hitzkircher- u. Wiggerthal.

1644. - nivea. Am Rigi über Vitznan, Urmiberg bis Seewen, vom Rütli und Treib aufwärts bis zum Seelisbergersee; am Fusse des Nesselstocks. 1645. Acorus calamus. 6-7. In stehenden Wassern und Teichen. Am Luzernersee an der Halden, massenhaft zwischen Winkel u. Ennethorw u. am Alpnachterstad; gepflanzt in Weihern bei Rothenburg, Buetigen, Hilperingen u. Triengen an der Sure. 1646. Tofieldia calyeulata. 7-8. In feuchten Bergweiden bis in die Alpen.

na. - calyc. glatialis. 7-8. Auf Pilatus am Fusse des Esels.

1647. Triglochin palustre. $6-7$. In Siimpfen der Ebene und Voralpen. Am Luzerner- und Mauensee, am F'usse des Schimberg, im Sörenbergli, am. 
Fusse des Rigi, von Brumen bis Goldau.

1648. Scheuchzeria palustris. 6-7. Massenhaft am Mauen- $u$. Wauwilersee. am Pilatussumpf zwischen Briindlen und Oberalp. 


\section{Gattungs - Rogister.}

- Die vordere Zahl becleutet die Seite in Steiger'schen Handbuch, die hintere diejenige diesés Taschenbuches.

\begin{tabular}{lr|llr}
380 Abutilon & 149 & 209 & Alisma & 73 \\
219 & Acer & 77 & 196 Allium & 67 \\
589 Acerus & 196 & 505 Alnus & 203 \\
463 Achillea & 187 & 378 Althaea & 149 \\
295 Aconitum & 113 & 359 Alyssum & 141 \\
589 Acorus & 239 & 179 Amaranthus & 60 \\
293 Actaea & 110 & 272 Amclanchier & 103 \\
449 Adenostyles & 180 & 386 Amorpha & 151 \\
312 Adonis & 120 & - & Amygdalus & 102 \\
226 Adoxa & 81 & 111 Annagallis & 30 \\
171 Aegopodium & 58 & 109 Anchusa & 29 \\
210 Aesculus & 73 & 230 Andromeda & 83 \\
172 Aethula & 58 & 558 Andropogon & 222 \\
257 Agrimonia & 100 & 115 Androsacea & 32 \\
249 Agrostemma & 96 & 303 Anemone & 115 \\
534 Agrostis & 211 & 162 Angelica & 55 \\
544 Aira & 216 & 462 Anthemis & 186 \\
334 Ajuga & 128 & 203 Anthericum & 70 \\
97 Alchemilla & 23 & 343 Antirrhinum & 133 \\
530 Alopecurus & 209 & 166 Anthriscus & 55
\end{tabular}


530 Anthoxanthum 209|326 Betonica

124

389 Anthyllis

152506 Betula

203

- Apaganthus

65444 Bidens

177

169 Apium

57353 Biscutella

138

299 Aquilegia

113180 Blitum

60.

366 Arabis

230 Arbutus

246 Arenaria

143108 Borrago

29

83553 Brachypodium 220

94368 Brassica

145

485 Aristolochia

197539 Briza

213

204 Asperagus

452 Arnica

71 - Bryzopyrum

213

1815001 Bromus

199 - Browallia

220

493 Arum

445 Artemisia

- Armeria

255 Asarum

110 Asperugo

404 Astragalus

178465 Buphthal

127

62167 Bupleurum

$9950 \pm$ Buxus

188

30

159536 Calamagrostis 212

155 Astrantia

453 Aster

90 Asperula

159 Athamantha

51330 Calamintha

57

182493 Calla

19461 Calenduliv

202

178 Atriplex

128 Atropa

545 Avena

123 Azalea

322 Ballota

368 Barbarea

53338 Calceolaria

60.465 Calliopsis

40 62 Callitriche

126

216) 289 Calycanthus 110

38):312 Caltha

133 Campanula

200

186

130

187

429 Barkshausia

123357 Camelina

145523 Cannabis

170 356 Capsella

120

348 Bartsia

$1 3 7 \longdiv { 3 6 4 }$

Cardamine

181 137 Carduns

42

452 Bellidiastrum

185) 143 Carlina

63507 Carpinus

140

459 Bellis

189 Berberis

173 Berula

177 Beta

59.512 Castanea

208

140)

143

174

175

203

$60) 567^{\text {th }}$ Carex 237 
169 Carum

336 Catalpa

158 Cancalis

434 Celosia

434 Centaurea

96 Centunculus

75 Centranthus

249 Cerastium

489 Ceratophyllum

410 Cersis

482 Cerinthe

462 Chamaeorehis

366 Cheiranthus

291 Chelidonium

Chelone

242 Cherleria

176 Chenopodium

165 Cherophyllum

214 Chlora

459 Chry santhem.

233 Chrysosplenium

418 Cichorium

173 Cicuta

64 Circaea

438 Cirsium

301 Clematis

329 Clinopodium

356 Cochlearia

204 Colchium

405 Colntea

174 Conium

194 Convallaria

125 Convolvulus

288 Commarum

449 Conyza
57 484 Corallorhiza 197

129406 Coronilla $\quad 160$

53166 Coriandrum 56

51270 Cotoneaster 102

17385 Cornus 17

2380 Crocus $16 ;$

14384 Corydalis $\quad 150$

96510 Corylus 204

198268 Crataegis 102

162127 Crepis 169

27492 Cucurbita 199

196492 Cucumis 199

14399 Cuscutir 24

110 - Cuphea 137

127 117 Cyclamen 3:3

91272 Cyclonia 103

59133 Cynanehum 42

56109 Cynoglossum 29

75443 Cynara

18.) 388 Cytisus

175

151

215

223

192

58 - Cypripedium

10

17543 Dactylis

114465 Dahlia

125221 Daphne

140128 Datura

71157 Daucus

160297 Delphinium

58364 Dentaria

65247 Dentzia

39239 Dianthus

109385 Dycliytra

180233 Dictamnus
216

188

78

40

52

112

142

95

90

150

85 
345 Digitalis

362 Diplotaxis

93 Dipsacus

358 Draba

186 Drosera

283 Dryas

434 Echinops

104 Echium

584 Elyna

515 Empetrum

477 Epipactis

215 Epilobium

483 Epipogium

214 Erica

455 Erigeron

346 Erinus

565 Eriophorum

376 Erodium

157 Eryngium

- Erysimum

118 Erythraea

370 Erucastrum

448 Eupatorium

489 Euphorbia

349 Euphrasia

291. Eschscholzia

142 Evonymus

512 Fagus

77 Fedia

547 Festuca

306 Ficaria

513 Ficus

168 Foeniculum
135 - Forstitia

142286 Fragaria

2173 Fraxinus

141203 Fritillaria

62 - Fuchsia

107383 Fumaria

193 Funchia

173

27191 Calanthus

236322 Galeobdolon

205409 Galega

193324 Galeopsis

7586 Galium

196387 Genista

74118 Gentiana

183373 Geranium

135287 Geum

22581 Gladiolus

148 325 Glechoma

52 93 Globularia

146542 Glyceria

34 - Glycinia

145446 Gnaphalium 178

180 - Godetia

198480 Goodyera

137338 Gratiola

110 238 Gypsophila

47

204146 Hedera $\quad 49$

15409 Hedysarum 161

217295 Helianthemum 111

116466 Helianthus 188

204448 Helichrysum 179

57| 106 Heliotropium 28 


\section{- $245-$}

313 Helleborus

$120 \mid 585$ Juncus

237

175 Helosciadium

59502 Juniperus

237

193 Hemerocallis

305 Hepatica

160 Heracleum

483 Herminium

363 Hesperis

379 Hibiseus

429 Hieracium

65

116

54

276 Inerria

105

196544 Koeleria

216

196 215 Koelreutera 75

142

149

165419 更actuca

164

172)321 Lamium

122

433 Hippochoeris

160 437 Lappa

9418 Lapsana

174

61 Hippuris

547 Holcus

557 Hordeum

116 Hottonia

423 Humulus

355 Hutchinsia

196 Hyacinthus

- Hydrangia

157 Hydrocotyle

127 Hyosciamus

411 Hypericum

327 Hysopus

139 asione

7.2 Jasminum

100 Jlex

151 Impatiens

162 Imperatoria

454 Inula

- Ipomaea

79 Iris

353 Isatis

99 Isnardia

504 Juglans

217 I63 Laserpitium

222340 Lathraea

33401 Lathyrus

208379 Lavatera

139320 Lavendula

67532 Leersia

7973 Lemna

52430 Leontodon

164

40325 Leonurus

162354 Lepidium

125190 Lencojum

71 Ligustrum

55

131

158

149

122

210

14

171

124

138

64

69

46202 Lilium

13343 Linaria

19

25186 Linum

133

51300 Liriodendron 114

54480 Listera

195

182|105 Lithospermum 27

$40 \mid 261$ Lloydia

16554 Lolium

138140 Lonicera

69

24391 Lotus

221

46

202|359 Litnaria

152

141 
389 Lupinus

587 Luzula

248 Lychnis

131 Lycium

$116 \mathrm{I}$ ycopsis

319 Lycopus

111 Lysimachia

256 Lythrum

- Nragnolia

98 Majanthemum

- Malapa

373 Malva

320 Marrubium

461 Natricaria

362 Nathiola

397 Medicago

537 Melica

396 Melilotus

347 Melampyrum

331 Melissa

331 Melitis

332 Mentha

117 Menyanthes

524 Mercurialis

268 Mespilus

171 Mewm

$53 \pm$ Milium

228 Monotropa

508 Morus

78 Montia

245 Moehringia

19.) Muscari

Inf Mysotis

488 Myriophyllım
152/261 Myrthus

239538 Molinia

95

41488 Najus

30 - Nalana

12. 191 Narcissus

$3(55: 3$ Nardus

100:361 Nasturtium

Nemophylla

110184 Neottia

28 327 Nepeta

149132 Nerium

14: 129 Nicandra

122136 Nicotiana

181 :300 Nigella

142476 Nigritella

15. 295 Nymphaea

21 :

155.218 Denothera

136 167 Oenanthe

126 108 Omphalodes

12(389 Ononis

127481 Ophrys

$3 \hat{i} 470$ Orchis

20! 326 Origanum

102 :339 Orobanche

58401 Orobus

21120 O Orinthogalum

82408 Onobrychis

204107 Ornithopus

16.252 Oxalis

93211 Oxycoccos

61403 Oxytropis

2i

$19 \%$
101

213

197

31

64

220

142

31

196

125

41

40

- 40

114

192

112

77

57

29

151

195

188

124

131

157

69

161

161

97

74

159 
296 aeonia

533 Panicum

292 Papaver

226 Paris

185 Parnassia

160 Pastinaca

341 Pédicularis

376 Pelargonium

222 Passarina

- Penstemon

190 Peplis

266 Persica

450 Petasites

385 Petroeallis

168 Petroselinum

Petunia

161 Peucedanum

405 Phaca

532 Phalaris

390 Phaseolus

261 Philadelphus

531 Phleum

'125 Phlox

539 Phragmites

129 Physalis

138 Phytellma

422 Picris

170 Pimpinella

:338 Pinguieula

497 Pinus

397 Pisum

95 Plantago

508 Platanus

539 Poa

125 Polemonium
112531 Populus

210 256 Portulacea

110101 Potamogeton

81495 Poterium

62284 Potentilla

54222 Polygonum

132385 Poligala

14881 Polyknemum

79430 Prenanthus

127 113 Primula

64138 Primatocarpus

$1 0 2 \longdiv { 3 2 8 }$ Prunella

180263 Prunus

141 86 Ptelea

57105 Pulmonaria

40262 Punica

54231 Pyrola

159270 Pyrus

210

2153509 mercus

101306 Eanunculus 116

210 360 Raphanus 141

39 353 Rapistrum 138

213257 Reseda 101

40143 Rhamnus 48

45347 Rhinanthus 136

172524 Rhodiola 209

57229 Rhododendron 82

130181 Rhus 61

200144 Ribes

$156 j 494$ Richardia

48

22409 Robinia

200

204277 Rosa

162

214)320 Rosmarinus 122

391281 Rubus 
466 Ruebkkja

206 Rumex

232 liuta

100 agina

515 Salix

317 Salvia

184 Sambueus

495 Sanguisorba

156 Sanicula

- Santolina

238 Saponaria

387 Sarothamnus

328 Satureia

234 Saxifraga

91 Scabiosa

166 Scandix

199 Scilla

234 Seleranthus

345 Seorphularia

329 Scntellaria

- Schizanthus

532 Scorzonere

460 Schoenus

562 Scirpus

591 Scheuchzeria

557 Secale

252 Sedum

258 Sempervivum

544 Sesleria

91 Sherardia

187 Sibbaldia

168 Silaus

242 Silene

371 Sinapis
188|371 Sisymbrium

71257 Senecio

85116 Soldanella

130 Solanum

25 - Sollya

205419 Sonchus

121272 Sorbus

61454 Solidago

24 - Sorghum

5 ? 566 Sparganium

178180 Spinacia

89251 Spergula

151274 Spiraea

12. 387 Spartium

86479 Spiranthes

20 i95 Streptopus

56181 Staphylea

68185 Statice

86214 Stellaria

134322 Stachys

125477 Sturmia

137 157 Swertia

17271 Syringa

223108 Symphytum

22142 Symphoria

240

222462 Tagetes

97182 Tamarix

100,522 'Tamus

216446 'Tanacetum

20430 'Taraxacum

63503 'Taxus

57335 Teucrium

91302 'Thalictrum

1.66 355 'Thlaspi
146

183

33

41

31

164

103

182

223

226

60

96

104

151

194

66

60

62

92

123

193

34

13

29

47

186

61

208

178

171

202

128

114

139 


\section{$-\quad 259$}

502 Thuja

330 'Thymus

294 Tilia

590 'Tofieldia

151 Thesium

284 Tormentilla

341 Tozzia

190 'Tradescantia

433 Tragopogon

392 Trifolium

590 Triglochin

538 'Triodia

555 Triticum

220 Tropaeolum

313 Trollius

201 Tulipa

367 'Turritis

451 Tussilago

567 'Typha

84 Trapa
201/175 Ulmus

125337 Utricularia

111 494 Urtica

239

51210 accinium

10776 Valeriana

132205 Veratrum

(i4) 125 Verbaseum

172331 Verbena

15365 Veronica

23) 182 Viburnum

213398 Vicia

221132 Vinca

78147 Viola

120515 Viscum

69146 Vitis

142

181429 villemetia

226

17459 zea

467 Zinnea
59

129

200

74

14

71

39

127

10

61

156

41

49

205

48

170

223

188 


\title{
Bemen linngene.
}

\begin{abstract}
Die meisten der in diesem Taschenbuche aufgeführten Gartenpflanzen des Kantons Luzern sind in der unterzeichneten Handelsgärtnerei in schönen Exemplaren und zu billigen Preisen zu haben.

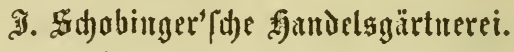

Der Herausgeber dieses Werkleins gibt zu billigem Honorar praktischen Unterricht in der Botanik, sowohl Kindern von zehn Jahren an, als auch erwachsenen Personen.

Ferner sind daselbst zu Kauf oder Tausch schön getrocknete Pflanzen zu haben. 


\section{A VIS.}

Man littet folgende Drukfehler gefälligst berichtigen zu wollen.

Seite. Zeile.

2421 Anstatt Cusenta lese: Cuscuta.

3211 - $"$ chixensis, chinensis.

3414 " centaurum , centaureum.

$37 \quad 1$ त cruticata $\%$ crutiata.

$46 \quad 17$ und

471 u. 10 anstatt Loniecra lese: Lonicera.

515 ॠ Impatien " Impatiens.

$527 \%$ Astraulia " Astrantia.

761 " parniflora " parviflora.

8323 " uvae " uva.

10414 und

1053 \% Spicaea, Spiraea.

1131 Acconitum $\leadsto$ Aconitum.

n 8 aconitum soll ausgelassen werden.

1209 anstatt Oaltha lese: Caltha.

13427 und

1353 anstatt Serophularia lese: Scrophularia.

$1352 \pi$ purpuria lese: purpurea. 1393 " Ibais Iberis.

1406 soll vor dem Eigenschaftsnamen ein

14510 anstatt fulgaris lese: vulgaris. $149 \quad 16$ und

3501 anstatt Tumaria lese: Fumaria. 1666 n ramos, ramosum. 
Seite. Zeile.

19111 Soll vor dem Eigensehaftsnamen ein - gesetzt werden.

20915 anstatt pretensis lese: pratensis. 21216 "Calama grostis lese: Calamagrostis.

$2134 n$ Calama lese:Calamagrostis. $22616 \pi$ cheuchzeri lese: Scheuchzeri. Ferner, wo augustifolia vorkommt, soll es heissen : angustifolia. " $\quad$ silvestris und silvatica vorkommt, soll in der ersten Silbe ein y gesetzt werden.

Andere minder wichtige Fehler kann der Leser selbst berichtigen. 


New York Botanical Garden Library

\section{QK 315.S27}

Schobinger-Pfister,/Taschenbuch fur reis

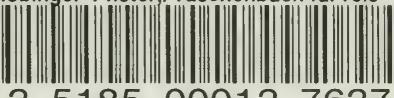

35185000127637 


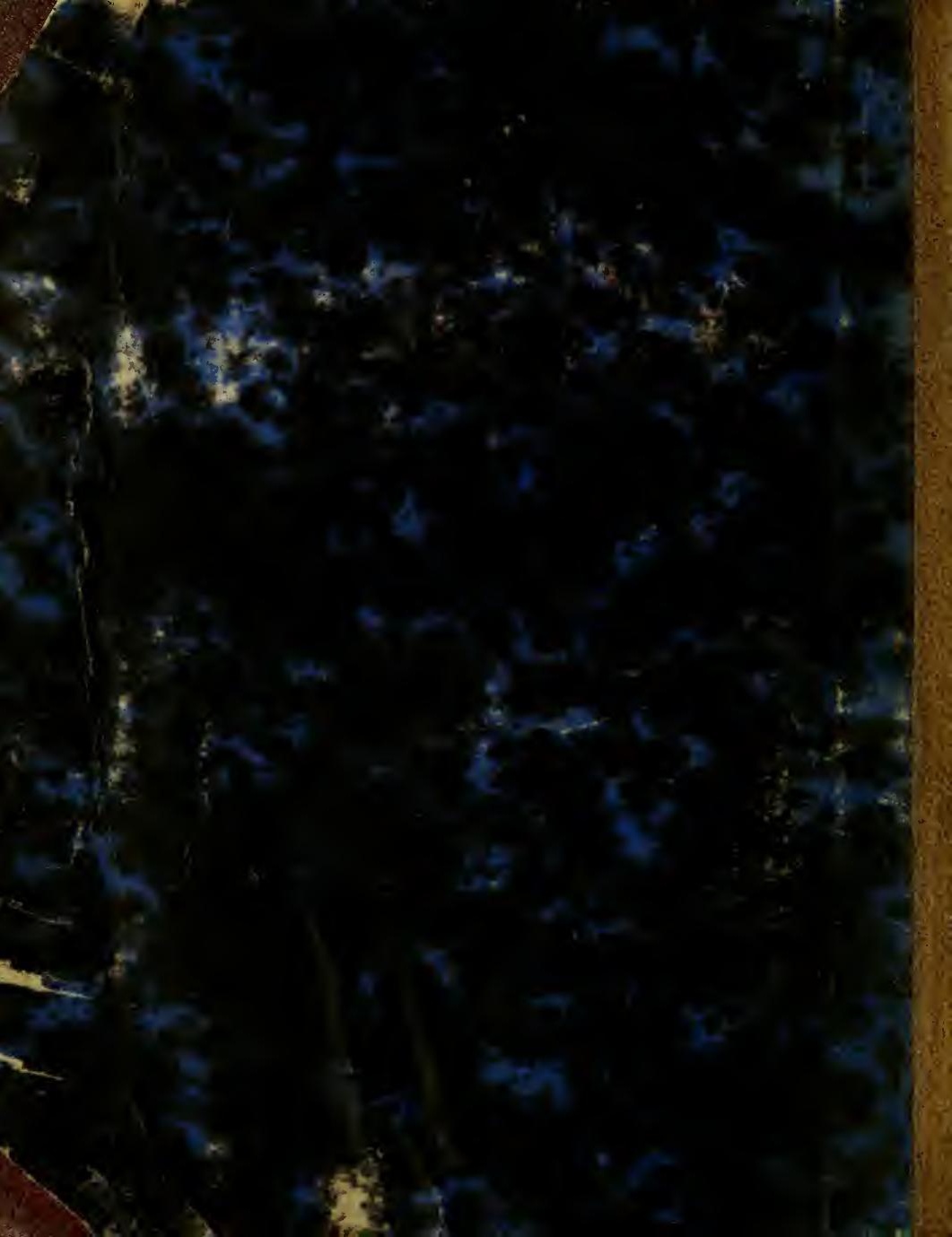

